\title{
LOOKING TO THE MOUSE: THE PLAUSIBLE IMPOSSIBLE IN ARCHITECTURE AND ANIMATION
}

\author{
BY \\ JIMMY CAPORICCI \\ A thesis submitted to the Faculty of Graduate and Postdoctoral Affairs in \\ partial fulfillment of the requirements of the degree of
}

\section{Master of Architecture}

Azrieli School of Architecture and Urbanism

Carleton University

Ottawa, Ontario, Canada

\author{
(C) 2021 \\ Jimmy Caporicci
}




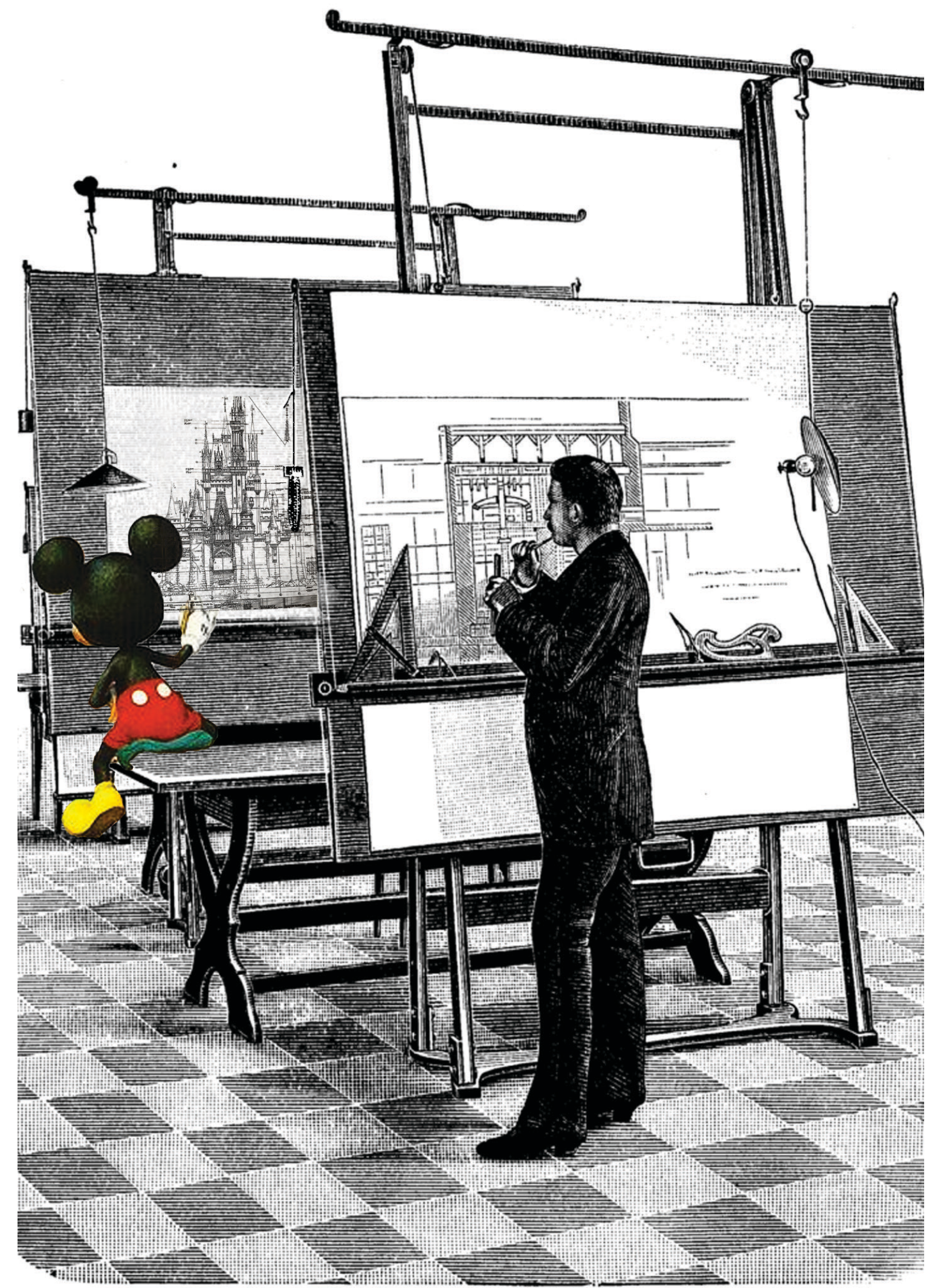

Fig. 01

It All Started with a Mouse. 
ABSTRACT

This thesis explores architecture through the lens of character driven animated film. It will critically analyze select films from the Disney and Pixar catalogue. The research focuses on four films as case studies and undertakes a visual and textual analysis of critical spaces to understand how animation responds to two contemporary themes: environmental stewardship and social sustainability. To link animation to architecture, the thesis considers the plausible impossible, a principle of Walt Disney's animation concerning making the impossible appear rational. The plausible impossible is the method to explore both animation and visionary architecture. Visionary architecture and its associated theories have an extant tradition of exploring the plausible impossible through unbuilt projects that serve to initiate vital discourse within the architectural profession. In conclusion, the thesis exploits the inherent commonality between he plausible impossible and visionary architecture to consider animation as a novel approach to explore pressing architectural issues. 
TABLE OF CONTENTS

\author{
ABSTRACT \| \\ TABLE OF CONTENTS III \\ LIST OF ILLUSTRATIONS IV \\ ACKNOWLEDGMENTS VII \\ PREAMBLE $\quad 1$
}

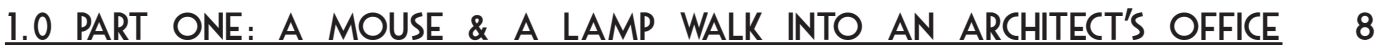

1.1 AN ANIMATED HISTORY 9

1.2 THE PLAUSIBLE IMPOSSIBLE 31

1.3 VISIONARY ARCHITECTURE 36

1.4 NARRATIVE THEMES \& ARCHITECTURAL DILEMMAS 43

1.5 A TALE OF TWO CITIES 57

2.0 PART TWO: LET'S GO TO THE MOVIES! 65

2.1 EVERYTHING'S A REBOOT THESE DAYS 66

2.2 NOW PLAYING: THE LION KING, WALL-E, UP, \& ZOOTOPIA 70

3.0 PART THREE: TO INFINITY \& BEYOND 104

3.1 SOME CONCLUSIONS 105

APPENDIX A: GULL STORY 115

APPENDIX B: ADDITIONAL INFORMATION ON DISNEY \& PIXAR FILMS 117

BIBLIOGRAPHY 129

ILLUSTRATION SOURCES 135 


\section{LIST OF ILLUSTRATIONS}

Fig. $01 \quad$ It all started with a mouse

Fig. 02 The Caporicci family at Walt Disney World $\quad$ p. 02

$\begin{array}{lll}\text { Fig. } 03 & \text { 'Gull Story' promotional poster } 05\end{array}$

Fig. 04 Late 1800s political cartoon by Winsor McCay p. 09

Fig. 05 Stills from 'Humorous Phases of Funny Faces,' by J. Stuart Blackton p. 10

$\begin{array}{ll}\text { Fig. } 06 \text { Walt Disney } 11 & \text { p. }\end{array}$

$\begin{array}{llr}\text { Fig. } 07 \text { Ub lwerks } & \text { p. } 11\end{array}$

Fig. 08 Early 1920s advertisement for Walt Disney, Cartoonist p. 12

Fig. 09 Promotional advertisement for Walt Disney's Alice Comedies, $1926 \quad$ p. 12

Fig. 10 Before Mickey, there was Oswald, the Lucky Rabbit p.13

Fig. $11 \quad$ Mickey Mouse makes his debut, starring as Steamboat Willie in $1928 \quad$ p.13

Fig. 12 Walt confers with an animator; the multiplane camera towers in the background p. 15

Fig. 13 Theatrical poster for 'Snow White and the Seven Dwarfs,' 1937 p. 15

Fig. 14 Disneyland, California. Opening Day, 1955 p. 15

$\begin{array}{llr}\text { Fig. } 15 \text { Ed Catmull } & \text { p. } 17\end{array}$

$\begin{array}{llr}\text { Fig. } 16 & \text { Alvy Ray Smith } & \text { p. } 17\end{array}$

$\begin{array}{lr}\text { Fig. } 17 & \text { John Lasseter } 17\end{array}$

Fig. 18 Ed Catmull's 'A Computer Animated Hand,' $1972 \quad$ p.17

Fig. 19-20 'The Adventures of Andre and Wally B.' concept sketch \& final poster $\quad$ p. 23

$\begin{array}{lll}\text { Fig. } 21 & \text { The Pixar Imaging Computer II } & \text { p. } 24\end{array}$

$\begin{array}{ll}\text { Fig. 22-23 Concept art and still frame of 'Luxo Jr.' } & \text { p. } 24\end{array}$

$\begin{array}{ll}\text { Fig. } 24 \text { Luxo jr. and Pixar's iconic logo } & \text { p. } 24\end{array}$

Fig. 25 'Tin Toy, 'directed by John Lasseter p. 25 
Fig. 26 the Little Mermaid's use of CAPS (1989)

p. 26

Fig. 27 The Rescuers Down Under' was the first Disney film to be coloured entirely by Pixar's CAPS

Fig. 28 Promotional poster for 'Toy Story.'

Fig. 29 The Plausible Impossible on display.

p. 32

Fig. 30 The Plausible Impossible on display.

Fig. 31-33 'Exodus: or the voluntary prisoners of architecture,' Rem Koolhaas

Fig. 34-35 'Cenotaph for Issac Newton,' 1784; Étienne-Louis Boullée

Fig. 36 'Broadacre City,' 1935; Frank Lloyd Wright

p. 39

Fig. 37 Walt Disney's original concept for E.P.C.O.T. 1966

p. 39

Fig. 38 'Earthrise,' 1968

p. 45

Fig. 39 'The Blue Marble,' 1972

p. 45

Fig. $40 \quad$ Maslow's updated 'Hierarchy of Needs' p. 51

Fig. 41-42 Cover \& Page 1 from 'Amazing Archigram 4: the Zoom Issue,' $1964 \quad$ p. 58

Fig. 43 'Plug-in City' is introduced in 'Amazing Archigram 4: the Zoom Issue,' 1964

Fig. 44 Archigram's 'Plug-in City: Maximum Pressure Area,' Project Section, 1963-1966

Fig. 45 Still from the short film, 'Planet City' (2020). Liam Young

Fig. 46-47 Still from the short film, 'Planet City' (2020). Liam Young

Fig. 48 Meet Ollie, the Bonaparte's Gull, star of 'Gull Story'

Fig. 49 The migratory journey of Bonaparte's Gulls

Fig. 50 'The Lion King' poster, 1994

Fig. 51-53 Ollie learns about the 'Festival of No Lights'

p. 79

Fig. $54 \quad$ Illustrative analysis of Disney's 'The Lion King'

p. 80

Fig. 55 'WALL-E' poster, 2008

p. 81 
Fig. 56-57 Ollie finds the Niagara River Gull Cruise

p. 83

Fig. 58 Frank shows Ollie his cabin

p. 86

$\begin{array}{ll}\text { Fig. } 59 \text { Ollie begins decorating his cabin } & \text { p. } 86\end{array}$

$\begin{array}{lll}\text { Fig. } 60 & \text { Illustrative analysis of Pixar's 'WALL-E' } & \text { p. } 87\end{array}$

$\begin{array}{lll}\text { Fig. } 61 & \text { 'Up' poster, } 2009 & \text { p. } 88\end{array}$

Fig. $62 \quad$ Illustrative analysis of 'Up' p. 95

Fig. 63 'Zootopia,' $2016 \quad$ p. 96

Fig. 64 Gulls may choose to sleep in a cabin, or a nest in the onboard trees p.100

Fig. 65 Frank shows Ollie the onboard all-you-can-eat fishing pool p. 100

Fig. 66 Honey-water steam attracts flying insects for the gulls to feed on p. 100

$\begin{array}{ll}\text { Fig. } 67 & \text { Illustrative analysis of Disney's 'Zootopia' } 101\end{array}$

$\begin{array}{lr}\text { Fig. } 68 & \text { 'Shrek,' } 2001 \text { poster } 112\end{array}$

Fig. 69 'Spider-Man: Into the Spider-verse,' 2018 poster p. 113

Fig. $70 \quad$ 'Howl's Moving Castle,' 2004 poster p. 113

Fig. $71 \quad$ 'Wolfwalkers,' 2020 poster 113

$\begin{array}{ll}\text { Fig. } 72 \text { Donald at the drawing board } & \text { p. } 132\end{array}$ 


\section{ACKNOWLEDGMENTS}

I would like to express my sincere thanks to my thesis advisor Johan Voordouw for his unwavering support of this off-beat thesis. I could not have completed it without his guidance and encouragement at every step of the way.

Thank you also to my family for getting me this far, for providing advice, feedback, and spellchecks and for the childhood introduction to those well-worn VHS copies of the Disney and Pixar films that inspired this thesis.

Finally, thank you to Tina, for being my sounding board, creative consultant, editor, and inspiration. Thank you esspecially for believing in my thesis even when I did not and making a plausible impossibility become a reality. We did it! 
spoiler alert | \'spöi-ler ə-'lərt \

(in a discussion or review of a film, book, television drama, etc.) a warning that an important detail of the plot development is about to be revealed. 
"Architecture is where imagination meets life. . It imbues our daily lives with a sense of wonder and excitement." - Thomas J. Pritzker, introduction to the 2010 Pritzker Architectural Prize recipients, Kazuyo Sejima and Ryue Nishizawa

"You might as well look at society as a place where you can really make a difference and make your dreams and other dreams possible. And you create a beautiful vision for yourself and the people around you. And the more you believe in it and the more power you give to it, the more you can get it into the world. Because there is nothing more powerful than intention. When you have a very powerful intention, the universe shifts a bit because it creates a possibility that your vision can occur." - Douglas Cardinal, personal conversation, 2020 


\section{PREAMBLE}

Architecture has been described as an act of optimism. ' It is a profession which demands its practitioners believe in the possibility of a better building, a better city, a better future. It is predicated on the idea that the built environment is more than a set-piece on the stage of the world, but rather an active participant in the human experience. Driven by that conviction, the architectural profession is ever pursuant of new and innovative ideas. The practitioners of architecture regularly look beyond their own profession to the worlds of art, technology, science, and history for inspiration. It is curious then, that architects have seemingly left character-driven animated film untapped.

Animation, too, is an optimistic act. As exemplified in the films of Walt Disney Animation Studios and Pixar Studios, animation seeks to promote the simple virtues of love, forgiveness, empathy, kindness, selflessness, and 
sharing, believing that they can instill in their audience a sense hope and optimism for the future. ${ }^{2}$ In recent decades, Disney and Pixar films have begun to address more challenging themes, such as the environmental crisis, racial inequality, and disability. The mature messages in the narratives of these films are supported and occasionally driven by the built (drawn) environment which is developed through the animation principle, the "plausible impossible."

Disney and Pixar Studios use the plausible impossible in their animated films to translate those deeper messages in a way which the audience can absorb and understand without feeling like they are being lectured. It is in this way that Zootopia, a film ostensibly about a utopian metropolis of traditionally predator and prey animals living in perfect harmony, becomes a springboard for conversations about race relations, equality and accessibility. The purpose of

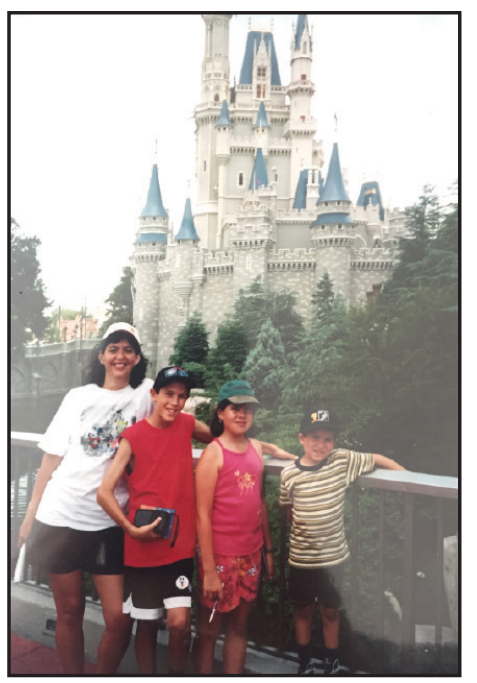

Fig. 02 The Caporicci family at Walt Disney World, 2003 (I am the furthest to the right) Photo taken by my father. this thesis is to take steps towards opening up a productive discourse between the fields of architecture and animation, not as a tool of architecture, but as an autonomous form of storytelling and world-building.

Growing up as a child of the Canadian middleclass, I was surrounded by Disney culture. My parents had a vast collection of Disney and Pixar VHS's, Disney toys and collectibles filled my room, and when I was six we went to Walt Disney World. Like so many other children around the world, Disney and Pixar films were a part of my young life. 
By my teenage years I had seen all the classics, from Snow White to The Jungle Book, and could sing all the songs. I loved these films: the animation, the music, the storytelling, and the trademark nostalgia that defines the Disney oeuvre. In some ways, this thesis was conceived as a passion project; an attempt to elevate these films which I love to a level of academic discourse in architecture. This endeavour was complicated however, by an ongoing reassessment of what the Disney brand means to other various audiences.

As I entered adulthood, my relationship to these films and the Disney legacy overall began to change. I still looked forward to the next animated feature with excitement, but my personal lens had become more critical both towards new films and the old classics. Coincident with a rising call for historical reevaluation, I was forced to reconcile my admiration for Walt Disney - the man and the organization - and their history of racism, cultural colonization and appropriation, sexism, and bigotry both within and around the production of their films. ${ }^{3}$ This complicated history is important to acknowledge when undertaking a study of Disney and Pixar films.

This thesis acknowledges the deep rooted issues that are present in Disney and Pixar's film catalogue, but its focus is to study the specific, isolated worlds created within certain films and to understand them for use of space as a narrative and communicative device. What is important to note of the 
selected movies is where they make specific commentary on one social issue, while seemingly blind to others. My analysis does not absolve the films from their pressing critiques these critiques exist - rather, it is to use Disney and Pixar Studios, as producers of popular and familiar animated films, to introduce character-driven animated storytelling as novel inspiration for architects to reassess their role in addressing urgent issues through thoughtful, informed design. Disney and Pixar Studios is the starting point. It is my hope that from this thesis, others may be inspired to investigate the potentialities offered by the films of other animation studios such as Japan's Studio Ghibli and Ireland's Cartoon Saloon which present unique cultural perspectives and storytelling styles.

The films chosen for this thesis are ones which I believe are reflective of a shifting consciousness in the world at large as well as within the fields of both architecture and animated storytelling regarding issues of environmental stewardship and social sustainability, as well as their relationship to each other. The four films are: The Lion King (Disney, 1994), Wall-E (Pixar, 2008), Up (Pixar, 2009), and Zootopia (Disney, 2016). Though it was not the original intent of the animators, I will be considering these as both animated films and works of visionary architecture. Framed as such, the concepts of environmental stewardship and social sustainability will be explored as they relate to both 
principles of architecture and character-driven animation through my perspective as one unique experience of these films. I engage in a visual analysis and critical interpretation of each, highlighting those moments in the film which offer an opportunity for further architectural discussion, and reinforce these concepts through illustrative images. Concurrent to the writing analysis of these four films, I developed my own series of vignettes - a kind of storyboard — through which I further explore Disney and Pixar's use of the plausible impossible to convey serious social and environmental commentary under the guise of whimsical children's films. Of particular concern is discovering the ways in which these types of films use their animated, 'built,' environments to support narrative themes, thereby identifying the ways in which animation may implicate architecture and encourage architects to pursue unique perspectives and find new insights.

The thesis is separated into three sections. Part

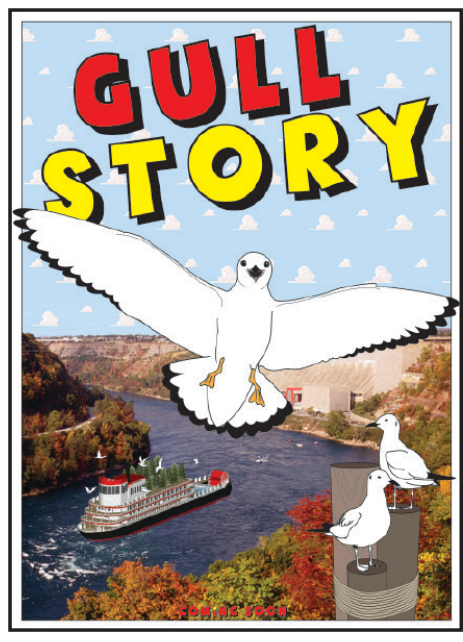

Fig. 03

Gull Story Promotional Poster 
approaches to the art of film making and storytelling. Articles by Steven Watts ${ }^{6}$, Robert Neuman ${ }^{7}$ and David I. Berland $^{8}$ are used to establish the critical role of the Walt Disney organization in American and global culture. Herbert Muchamps $^{9}$ and Arthur Drexler ${ }^{10}$ are used to frame an understanding of visionary architecture, and the Brundtland Commission"1, Gaston Bachelard ${ }^{12}$, the Hawke Research Institute ${ }^{13}$, and John Morelli14 are used to frame definitions of social sustainability and environmental stewardship. In Part Two the rationale for the selection of films is outlined followed by a visual and critical analysis of the individual films through the lens of the plausible impossible and the implications therein related to the concepts of environmental stewardship and social sustainability. These written analyses are accompanied by detailed, analytical illustrations which facilitate a deeper understanding of the relationships between narrative and space enthuse films. I will also explore these implications through a series of vignettes, following the development of my own short character-driven narrative. Part Three will synthesize and reflect on the opportunities these films present, highlighting how we may use the unique storytelling techniques of Disney and Pixar animated films to address critical issues facing the profession today. 
Preface Endnotes

$1 \quad$ Nicolai Ououssof, "Towers' Symbolic Image," Los Angeles Times, September 13, 2001.

2 David I. Berland, "Disney and Freud: Walt Meets the Id," The Journal of Popular Culture XV, no. 4 (1982): pp. 93-104, https://doi.org/10.1111/j.0022-3840.1982.1504-93.x, 95-96.

Critical texts on the subject of Walt Disney - and his company - abound. For a more comprehensive look at this complicated history see Richard Schickel's 1968, The Disney Version: The Life, Times, Art, and Commerce of Walt Disney, the first Disney biography to take a critical view of Walt Disney's life and the company's first half-century. In 2007, Michael Barrier wrote an updated biography titled The Animated Man: The Life of Walt Disney, For a deeper look at the Disney organization on the whole, see Janet Wasko's Understanding Disney: The Manufacture of Fantasy. Barrier, Michael. The Animated Man: The Life of Walt Disney. Berkeley, CA: University of California Press, 2008. Schickel, Richard. The Disney Version. New York: Simon and Schuster, 1968.

Wasko, Janet. Understanding Disney: The Manufacture of Fantasy. Cambridge: Polity Press, 2020.

Thomas, Bob. Walt Disney: an American Original. Glendale, CA: Disney Editions, 2012.

Price, David A. The Pixar Touch: The Making of a Company. New York: Vintage Books, 2009.

Watts, Steven. "Walt Disney: Art and Politics in the American Century." The Journal of American History, 82, no. 1 (1995): 84-110. Accessed May 22, 2021. doi:10.2307/2081916.

Neuman, Robert. "'Now Mickey Mouse Enters Art's Temple': Walt Disney at the Intersection of Art and Entertainment." Visual Resources 14, no. 3 (1999): 249-61. https://doi.org/10.1080/01973762.1999.9658455.

Berland, David I. "Disney and Freud: Walt Meets the Id." The Journal of Popular Culture XV, no. 4 (1982): 93-104. https://doi.org/10.1111/j.0022-3840.1982.1504-93.x.

Muschamp, Herbert. "Ideals Made of Paper and the Impact of the Unbuilt." The New York Times, March 11, 2001, sec. Art/Architecture.

"Visionary Architecture." New York, NY: MOMA, 1960. The Museum of Modern Art. World Commission on environement and Development. Our Common Future. Delhi: Oxford, Univ. Press, 1987. Bachelard, Gaston. The Poetics of Space. Penguin Books, 2014.

McKenzie, Stephen. Social Sustainability: Towards Some Definitions. 27. Vol. 27. Hawke Research Institute Working Paper. Magill: University of South Australia, 2004.

Morelli, John. "Environmental Sustainability: A Definition for Environmental Professionals," Journal of Environmental Sustainability: Vol. 1 : Iss. 1 , Article 2. (2011) Accessed May 22, 2021. doi: 10.14448/jes.01.0002 
PART ONE

A MOUSE \& A LAMP WALK INTO AN ARCHITECT'S OFFICE 
"I hope we never lose sight of one thing - that it was all started by a mouse."

Walt Disney

\subsection{ANIMATION \& A TALE OF TWO STUDIOS}

From the cave paintings of prehistory to the frescoes of ancient Rome, people have shared their stories through graphic imagery. And for nearly as long as we have been making drawings, we have been trying to make drawings move. "As early as $70 \mathrm{BC}$ there is evidence of a mechanism

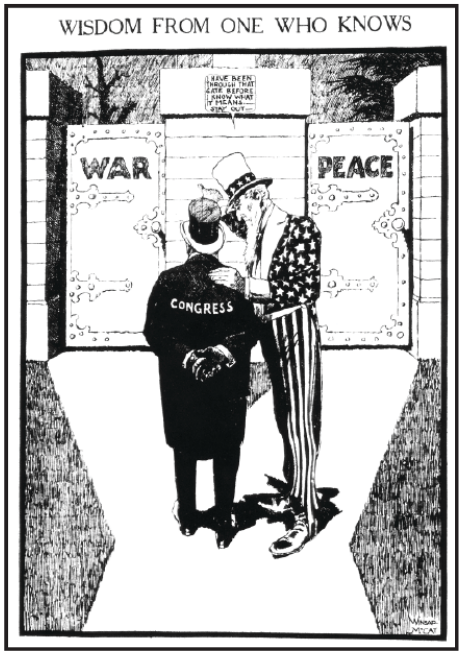

Fig. 04 Late 1800s political cartoon by Winsor McCay, one of the pioneers of animation that projected hand-drawn moving images onto a screen."1

The art form of animation as we understand it today was

born only little over a century ago with the advent of

photography. The initial vocabulary of early animated films,

however, stem from the American tradition of the newspaper

cartoon. With the growth of the newspaper industry in

the United States between 1870 and 1900, cartoonists

gained popularity illustrating political and cultural satire

in the weekly publications. ${ }^{2}$ [Fig. 04] These newspapers

provided fruitful ground for future animators to hone their 


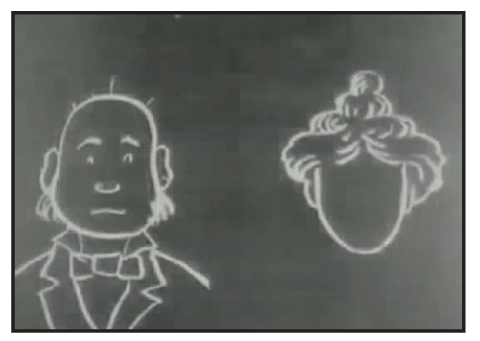

communicative drawing skills, expressively sharing their opinions through tongue-in-cheek caricature. By the early 1900s, several former newspaper cartoonists emerged as pioneers of early animation, each developing the methods and technologies that would become standards of animation.

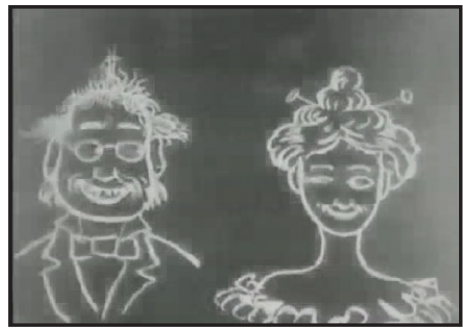

Early innovations based on the Praxinoscope dazzled audiences in the 1870s and 'lightning cartoonists' dabbled in proto-animation in the $1890 \mathrm{~s}^{3}{ }^{3}$ These works paved the way for what is generally accepted as the first animated film that is, the first film to be drawn and photographed frame-by-

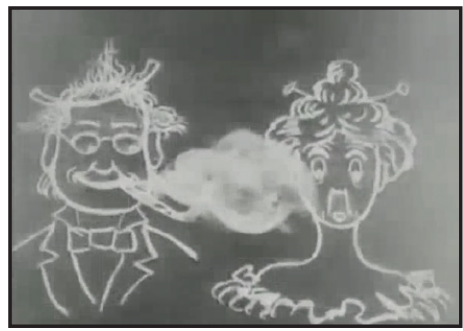

frame. ${ }^{4}$ Completed in 1906 by Stuart J. Blackton, Humorous Phases of Funny Faces was a succession of simple line drawings, each one slightly different from the last to depict a character's movement. [Fig. 05] Each drawing was captured on film chronologically and played back at a rate of 20

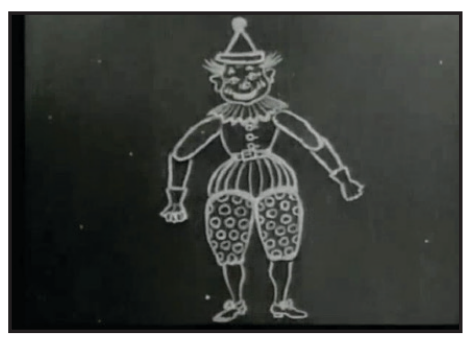
frames per second ${ }^{5}$, giving the illusion of movement. In short order, line drawings became full-bodied characters shaded in black and white. Within a few years characters were fully fleshed out in colour. Translucent paper allowed for more

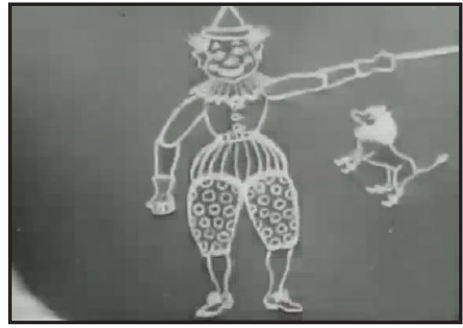
accurate reproduction of the characters on each successive image, and mounting pegs ensured that they would be captured on film in the exact same location as the last. ${ }^{6}$ In 1924, rudimentary attempts at synchronizing sound to film brought in a whole new dimension. In 1928, Walt Disney

Fig. 05 Stills from 'Humorous Phases of Funny Faces,' by J. Stuart Blackton

would perfect the merger with Steamboat Willie, Mickey Mouse's debut appearance. In 1937 Walt Disney Animation 
would revolutionize the medium with the invention of the multiplane camera, literally adding a new dimension to animated films by allowing for precise control over the depth of field in every frame. ${ }^{7}$ In the same year the company would release the first-ever full-length animated feature film, Snow White and the Seven Dwarves.

\section{WALT DISNEY ANIMATION STUDIOS}

Walt Disney ${ }^{8}$ was born in Chicago at the turn of

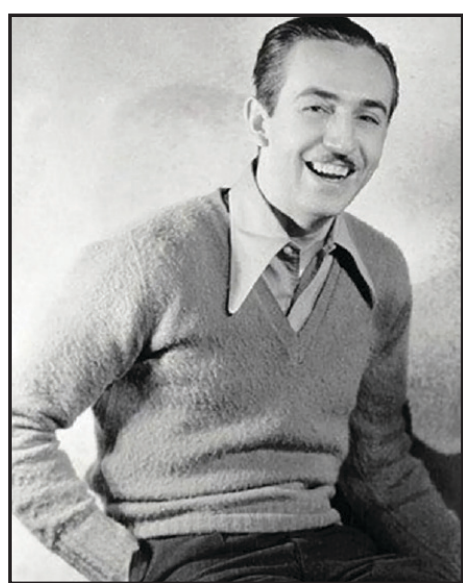

Fig. 06 Walt Disney

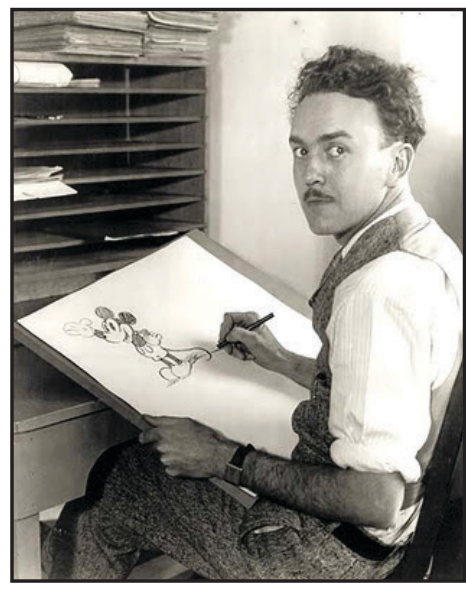

Fig. 07 Ub lwerks the century, but spent his youth on a farm in Marceline, Missouri, and later in Kansas City. Walt's early years in the pastoral mid-west imbued him with rural sensibilities and a sentimental realism carried over from the nineteenth century. From his socialist father he inherited an empathy for the 'common man', an enduring quality which would largely define his creative output. ${ }^{9}$ Walt knew from a young age that he wanted to be an artist. He had a middling talent for draughtsmanship, but more than made up for it in creativity, enthusiasm, and charm. After spending some time in France as an (underage) Red Cross volunteer during the Second World War, Walt returned to Kansas City and secured a job with a local advertisement agency. There, his work consisted of drawing advertisements and letterheads for farm equipment and supplies companies. The following year, Walt Disney and his new friend and coworker, Ub Iwerks, were hired as artists for the Kansas City Slide Company. It was 
here that Walt was first introduced to the art of animation.10

Walt quickly learned the basics of animation and studied the techniques used by the industry's best. He encouraged his employer to invest more in new technologies, making the advertisements more fluid and impressive. In the evenings Walt would experiment in his garage with a camera he borrowed from work. From that garage he began making his own animated shorts to distribute to Kansas City movie theaters. ${ }^{11} \mathrm{He}$ and Ub eventually quit their jobs and dedicated their full time to their new enterprise, Laugh-O-Gram Films, incorporated in 1922.12 They enjoyed moderate success for some time, building a workforce of several young animators and producing some popular films. However, by 1923 Walt had been forced to lay off his animators, Ub returned to the

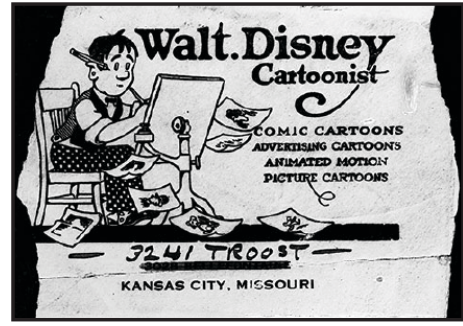

Fig. 08 Early 1920s advertisement for Walt Disney, Cartoonist

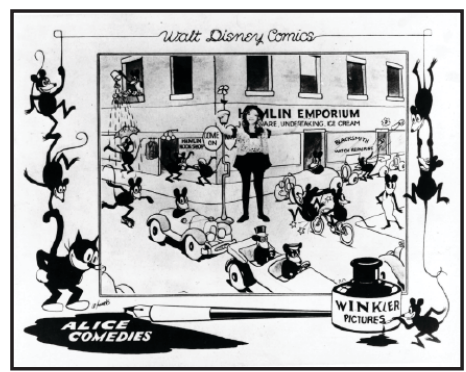

Fig. 09

Promotional advertisement for Walt Disney's Alice Comedies, 1926
Kansas City Slide Company (now the Kansas City Film Ad

Company), and Walt had resigned himself to bankruptcy.

Despite these devastations, Walt kept his optimism intact and managed to secure a film deal with a major New York distributor. With the promise of something new, Walt Disney headed to Hollywood.

In Hollywood, Walt began a series of shorts based on Lewis Carroll's Alice's Adventures in Wonderland. The Alice Comedies were unlike anything the public had seen before: a live-action Alice inhabiting a fantasy world of animated sequences. ${ }^{14}$ [Fig. 09] Walt was able to persuade Ub to join him in Hollywood and from 1924 to 1926 the series was a 
significant success. Walt's follow-up to the success of the Alice Comedies was a new animated character named Oswald the Lucky Rabbit. [Fig. 10] The Oswald films proved even more successful giving Walt and his animators a chance to further develop their narrative and technical skills. His good fortune would soon run dry, as shortly thereafter he lost the rights Oswald and more than half his animators to his former distributor.15

Forced once again to start virtually from scratch, Walt and Ub poured their collective efforts into a new character, Mickey Mouse. As the animators fulfilled the final two films

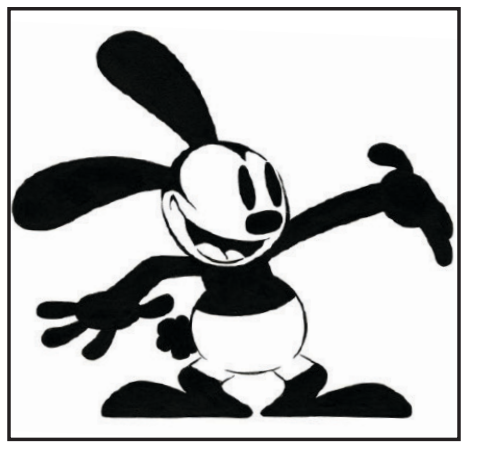

Fig. 10 Before Mickey, there was Oswald, the Lucky Rabbit

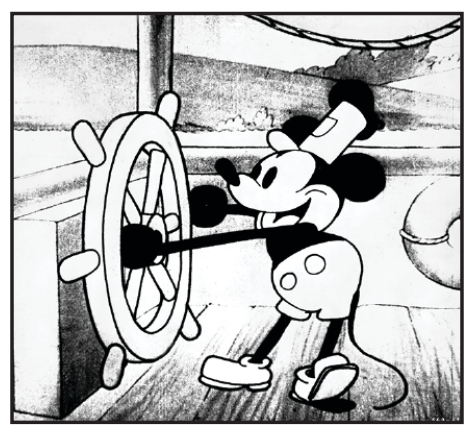

Fig. 11

Mickey Mouse makes his debut, starring as Steamboat Willie in 1928 of their Oswald contract, they worked in secret on the first

Mickey cartoon. Once it was completed, Walt was sure

Mickey would become the most famous cartoon in the world.

While Walt canvassed for distributors for Mickey, Ub and

the animation team continued to work the second Mickey

film. In 1927 Warner Bros, released the Alan Crosland film

The Jazz Singer, forever changing the film industry. The Jazz

Singer was the first feature film to have fully lip-synchronized sound and music. ${ }^{16}$ Walt was quick to realize the potential of this innovation for his own work. With the third Mickey film, Steamboat Willie, Walt and his team had mastered the art of synchronized sound and vision. [Fig. 11] After failing to find a distributor for the first two Mickey films, Steamboat Willie could not be ignored. It premiered at the Colony Theatre in New York City on November 18, 1928, and was described as 
"the sensation that Walt had dreamed it would be."17 Mickey Mouse was an instant star and made a celebrity of Walt Disney.

By 1934, after enjoying unprecedented success with the Mickey films and his Silly Symphonies series, which saw the addition of technicolour to his musical films, Walt felt that animation was narratively constricted by the 'short' format. ${ }^{18} \mathrm{He}$ resolved to make a full feature-length animated film. Dubbed 'Disney's Folly' by critics, work began on Walt Disney Productions' Snow White and the Seven Dwarfs. For the next three years Walt Disney and his team of animators worked tirelessly on the Snow White project, while continuing to produce short films like The Three Little Pigs, and The Wise Little Hen - which introduced Mickey's pal Donald Duck. During this time Walt became frustrated with the limitations of the technology he was using to film his animations, particularly the "essential flatness of the animated film."19 He was worried that, while "audiences would except the cavortings [sic] of two-dimensional pigs and wolves against painted backgrounds for an eight minute span - eighty minutes would emphasize the artifice of the animation process." ${ }^{\prime 20}$ Walt sought a way to attain more depth in his pictures; he felt that the success of Snow White depended on it.

"The answer was the multiplane camera. It developed into a towering device with a camera pointed downwards 


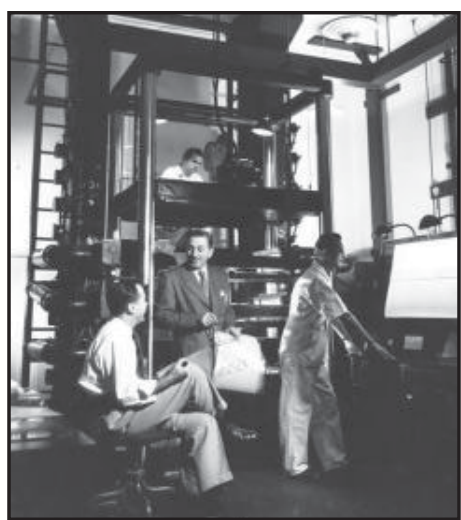

Fig. 12 Walt confers with an animator. The Multiplane camera towers in the background

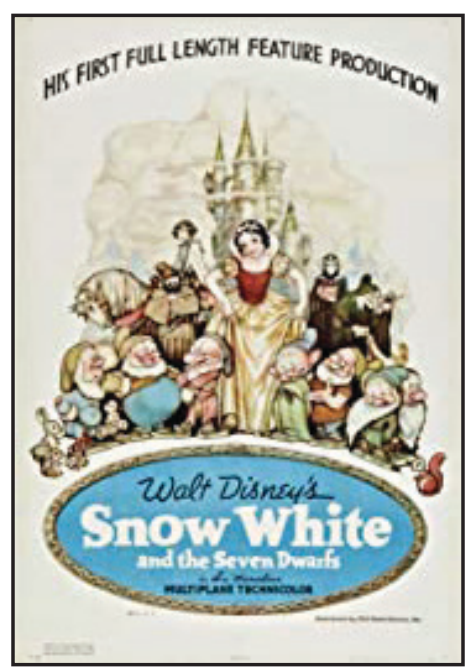

Fig. 13

Theatrical poster for 'Snow White and the Seven Dwarfs,' 1937

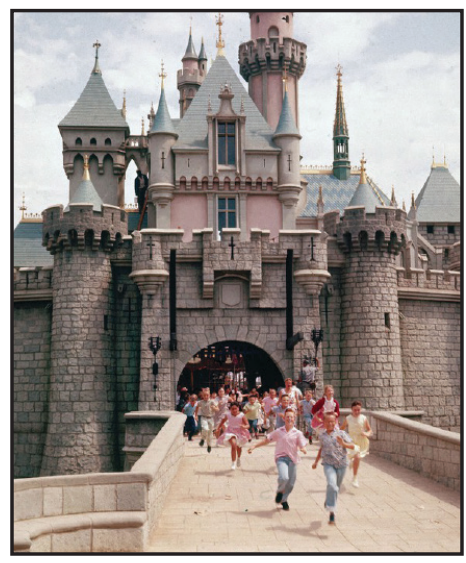

Fig. 14

Disneyland, California.

Opening Day, 1955 through four or five layers of paintings. The various levels depicted planes of vision, and the lens focus could be moved through the planes, creating the same effect of a moving camera in live action."21 [Fig. 12] Walt tested this new technology in the Silly Symphony, The Old Mill, which won an Academy Award, but more importantly, "showed Disney artists what could be accomplished in terms of mood and visual imagery."22 The multiplane camera would be utilized to great effect in Snow White and the Seven Dwarfs, adding a realistic sense of experience to the film. [Fig. 13] Far from folly, Walt's gamble on Snow White proved to be his most commercially and critically successful venture yet. At the Academy Awards that year, the young Shirley Temple presented Walt with an honorary OSCAR, and a custom statue which featured one regular sized figure, and seven miniature statuettes. Walt Disney had cemented his place in American popular culture.

It is difficult to separate the global entertainment giant that is the Walt Disney Corporation today from the beginnings of its eponymous founder and his team of animators. After his pioneering efforts in animated film he turned his attention to live-action cinema and television. Finally, in 1955 he revolutionized family entertainment with the opening of Disneyland in California. [Fig. 14] After his death in 1966 his legacy only grew. For nearly a century, "Disney has played a formative role in American Culture. 
Generations have grown up with the studio's creations."23 Since the release of the groundbreaking Snow White and the Seven Dwarfs, Walt Disney Animation Studios has remained the most commercially successful animation studio worldwide, influencing "popular views of family, gender, race, and the environment over the past century, ${ }^{\prime \prime 2}$ and it continues to exert a powerful hold over audiences to this day.

\section{PIXAR ANIMATION STUDIOS}

Unlike the myth of the Disney empire which is built on the hard work of one man's genius, the Pixar story is much more involved, intersecting with such luminaries as George Lucas and Steve Jobs. Both origin stories, however, center on individuals with a passion for animated storytelling, experimenting with new technologies and techniques to propel the medium forward. By the 1970s, animation was a well-established medium in America and had become a staple of children's entertainment. While there were some significant contributions to the art form from Japanese animation pioneers like Osamu Tezuka, Hayao Miyazaki, and Isao Takahata, ${ }^{25}$ very little had changed within the industry's technological process since Snow White - everything was still hand drawings and celluloid. The individuals that would eventually come together to form Pixar Animation Studios hoped to change that with a new piece of technology: the computer. 


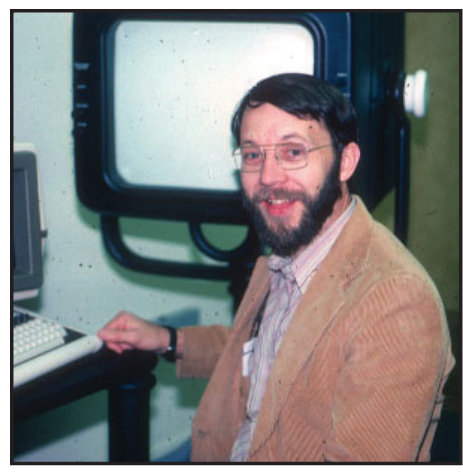

Fig. 15

Ed Catmull

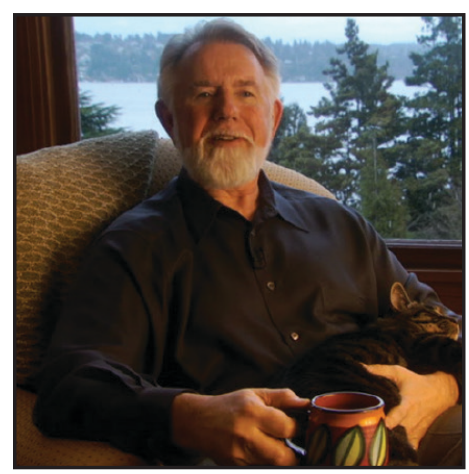

Fig. 16

Alvy Ray Smith

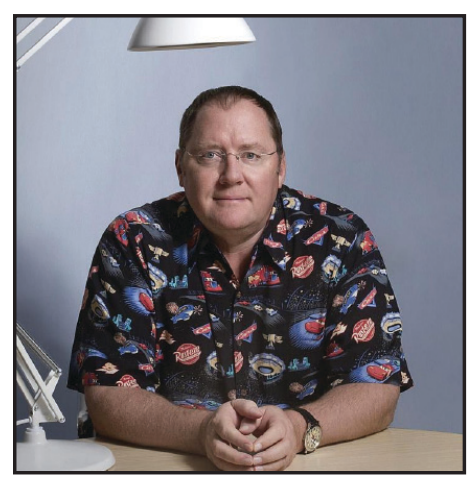

Fig. 17

John Lasseter

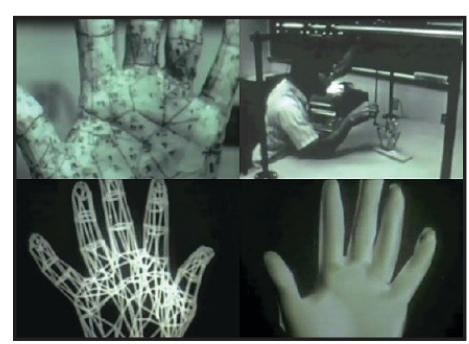

Fig. 18

Ed Catmull's 'A Computer

Animated Hand,' 1972
There are three principle characters who may be

credited with the formation and success of Pixar: Ed Catmull, Alvy Ray Smith, and John Lasseter. [Fig's, 15-17] Catmull's road to Pixar began at the University of Utah where he earned a degree in computer science in 1969 and would later earn a PhD. In his youth Catmull had aspired to be a Disney animator but had concluded that he did not have the talent to draw. Now, he thought, perhaps the computer can do the drawing for him. Thus, he began his foray into computer animation. In 1972 he completed one of the first examples of computer animation captured on film: a one minute video of his left hand, produced with a 3D animation program of his own writing. The result was jaw-dropping. With a copy of the film in hand, Catmull's professor arranged a meeting with executives from Walt Disney Animation to see if they would be interested in this revolutionary program but they declined. ${ }^{26}$

In 1974 Catmull received a call from the New York Institute of Technology. The founder and president of the university, Alexandre Shure, had recently established an animation studio at the school and was looking for equipment to operate it when he was handed a promotional film for a computer hardware company which featured Catmull's hand film. [Fig. 18] By the end of the year Catmull had become the Director of the NYIT Computer Graphics Laboratory tasked with building a team to experiment with 
3D computer animation. ${ }^{27}$

Alvy Ray Smith came from a similar educational background, studying computer programming at New Mexico State University. He earned a PhD from Stanford before becoming a teacher at New York University. An epiphany in 1973 inspired him to quit NYU and return to California, believing "something good was going to happen."28 His premonition proved true when a friend working at Xerox's Palo Alto Research Centre (PARC) invited him for a tour of the laboratory. There, Smith was introduced to a new painting software machine called 'SuperPaint.' Using a tablet and a stylus, it offered many of the most basic functions of a modern painting software. ${ }^{29}$ The machine stunned Smith, who described it as "a colour TV 'paintbrush' hooked up to a computer." ${ }^{\prime 30}$ Smith started working at PARC in August of 1974 with the assignment of creating a promotional film for SuperPaint. He and a coworker, David DiFrancesco, spent the next year experimenting with SuperPaint until Xerox pulled the plug on their program, laying off Smith and DiFrancesco. ${ }^{31}$

The pair were determined track down another piece of machinery with the technology of the SuperPaint. Their search led them first to the University of Utah and Catmull's old professor who informed them that while he did not have the equipment at the university, he knew where they would be able to find one: the New York Institute of Technology. 
Smith and DiFrancesco were welcomed at NYIT by Catmull who was happy to have two new research partners. Together with a few other hires, their job was to do whatever they thought was important, as long as it contributed to the ultimate goal of putting together a feature-length computer animated film. Sometime in that first year at NYIT Catmull and Smith reached out to the Disney organization to gauge their interest in their work. Once again they were turned away. $^{32}$

The Computer Graphics Lab became like a "fraternity of geeks,",33 as every member worked to solve some hardware problem or programming issue. The group also spent their first year at NYIT learning the principles of cel animation from a group of traditional animators Shure had developing a feature film. While the Computer Graphics set gleaned much from their analogue counterparts, the true revelation came after the completed film premiered in $1975 .{ }^{34}$ The film was called Tubby the Tuba and boasted the voice talents of Dick van Dyke. Still, the film was a complete disaster, with one animator exclaiming "I've just wasted two years of my life!" ${ }^{\prime \prime 3}$ after the credits rolled. Catmull and Smith had to face a disappointing truth: "For them to make worthwhile films someday - not just R\&D exercises to show at SIGGRAPH meetings - there also had to be people on board who understood film storytelling. Shure. . . could not be their Walt Disney." 
Catmull and Smith remained at NYIT for the next several years, developing their technologies and amassing a very impressive team of engineers and computer programmers. In 1979 they received a call from LucasFilm. Star Wars had come out a couple years prior and contrary to popular belief, all but one scene in the film was made using practical effects and traditional animation. Industrial Light and Magic (ILM), LucasFilm's special effects outfit, did not even have a computer. George Lucas was looking to put together a team of people with knowledge of computers to modernize the tools of filmmaking. Ed Catmull, seizing on the opportunity to work for a real filmmaker, became the head of LucasFilm's newly formed Computer Graphics Division later that year. Over the next year and a half six of his colleagues from NYIT quietly followed him. ${ }^{37}$ They had a new patron now - "one who was, at the moment, perhaps the most famous filmmaker on the planet." 38 In Lucas they had found a new hope.

Lucas had high demands for his new division in all areas of film post-production - "digital film compositing, digital audio mixing and editing, and digital film editing."39 However, "as Catmull and Smith saw it, there were the goals Lucas had set down, and then there was the one he ought to have, but didn't-namely, computer animation."40 Despite employing "perhaps the world's top technical talent in 3D animation," ${ }^{41}$ Lucas was not asking the group to do 
any. They finally got their chance in 1981 when Paramount Pictures contract ILM to work on Star Trek II: The Wrath of Khan. Catmull and Smith's group were able to impress the ILM people enough to be invited to work on a key sequence in the film. They were finally in the movie business. Within LucasFilm however, little changed for the aspiring computer animators. They continued to work on Lucas' computer projects while Catmull and Smith sought out other production opportunities. ${ }^{42}$

Around 1983 Catmull and Smith were approached by a young Disney animator interested in 3D computer animation, a rarity for professional animators. He was making a short film and wanted to integrate the Computer Division's 3D animation. Catmull and Smith spent some time discussing the project with the young man at Disney Animation in Burbank after which they did not hear from him again for several months until Catmull crossed his path at an industry conference. When Catmull relayed to Smith that the project had been canceled and the young man fired, they hired him on the spot. John Lasseter joined LucasFilm's Computer Division in December of 1983, completing the triumvirate of Catmull, Smith, and Lasseter which would lead the computer animation revolution. ${ }^{43}$

Like Ed Catmull, John Lasseter aspired to be a Disney animator. Unlike Catmull, Lasseter had a talent for hand drawing. In 1975 he received an invitation from the California 
Institute of the Arts (CalArts) to apply to its new character animation program. By the time he graduated from CalArts he had won back-to-back Student Academy Awards for animation in 1979 and 1980. He then joined the studio as a junior animator where he quickly became restless. ${ }^{44}$ The animation studio had become somewhat dormant in the decade and a half since its founder had died. Without Walt there to make the big decisions and take the big risks, those in charge had to fill that inimitable role, and the animation suffered for it. "Many of the younger artists were deeply frustrated with what they saw as the studio's cheapness and artistic timidity," always dreamed Disney was,"46 he later recalled.

After a brief time away from Disney working for a London-based animation studio, Lasseter returned just as production on Tron had begun in the live-action studio. The film would take place within a video game and so would require some substantially advanced special effects. Disney hired four different computer graphics production teams to work on it. Upon seeing the first computer generated scene to be made, Lasseter thought, "Walt Disney, all his career, all his life, was striving to get more dimension in his animation. . This is what Walt was waiting for." ${ }^{\prime 7}$ Lasseter made an impassioned plea to the animation executives to take an interest in this technology but Lasseter received the same response Catmull and Smith had gotten used to hearing. 
Undeterred, Lasseter used his personal networking skills to secure funding from Disney's head of live-action production to make a thirty-second promotional film. After completing this film Lasseter wanted to make a second, this time putting together a proposal to pitch to the animation executives. The idea was quickly rejected, and Lasseter was subsequently fired. ${ }^{48}$ Several months later he bumped into Ed Catmull at a conference and was invited to join the Computer Graphics Division at LucasFilm.

Lasseter's first job at LucasFilm was to work on
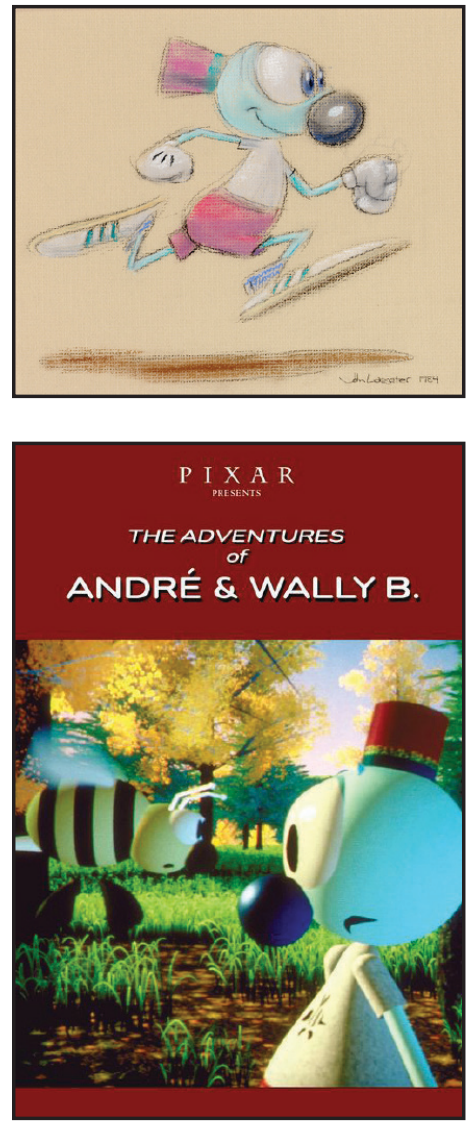

Fig. 19-20

From concept sketch to final product. 'The Adventures of André and Wally B.' earned Pixar their first OSCAR nomination in 1984 the film Catmull and Smith hoped to show at the next

SIGGRAPH ${ }^{49}$. The completed film, titled The Adventures of

André and Wally B, premiered at the 1984 conference to

resounding applause and tremendous industry acclaim.

[Fig's, 19-20] Though the work was rudimentary and crude,

the technological innovations the team had developed had

worked to great effect, and more significantly the film's story

had the character which their previous work had lacked.

Trained at CalArts by some of Walt's 'Nine Old Men,'50

Lasseter brought an accumulated knowledge from the

Disney organization and the classic animation principles that had evolved over decades there. Lasseter was a storyteller who understood how to develop character and had a restless drive to one-up himself with every new project. Catmull and Smith had found their metaphorical 'Walt Disney.'51

By 1985 George Lucas was ready to part with the 
Computer Graphics Division. Catmull and Smith were

worried he might break up this world-class team he had no vision for. Instead, LucasFilm executives instructed Catmull to find a buyer. The Graphics Division was going to be repackaged as a hardware company. ${ }^{52}$ [Fig. 21] Catmull and Smith went along with the rebranding of their team, as long as it meant they could stay together. They still had plans to make a feature film with computer animation and they knew

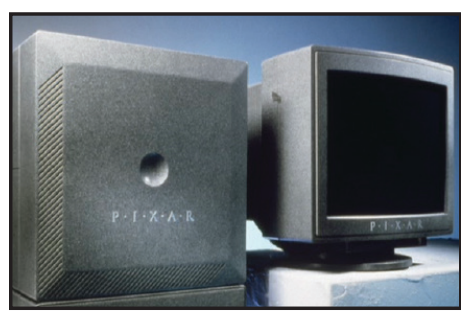

Fig. 21

The Pixar Imaging Computer II. Before they became full-time animators, Pixar made and sold computer hardeware they would need their team to advance the technology to

make it happen. After struggling to find a buyer, Smith was

put in touch with the multimillionaire computer magnate,

Steve Jobs. In the summer of 1985, Catmull and Smith met with Jobs, just months after his bitter ousting from Apple. In January of the following year, Catmull and Smith signed the
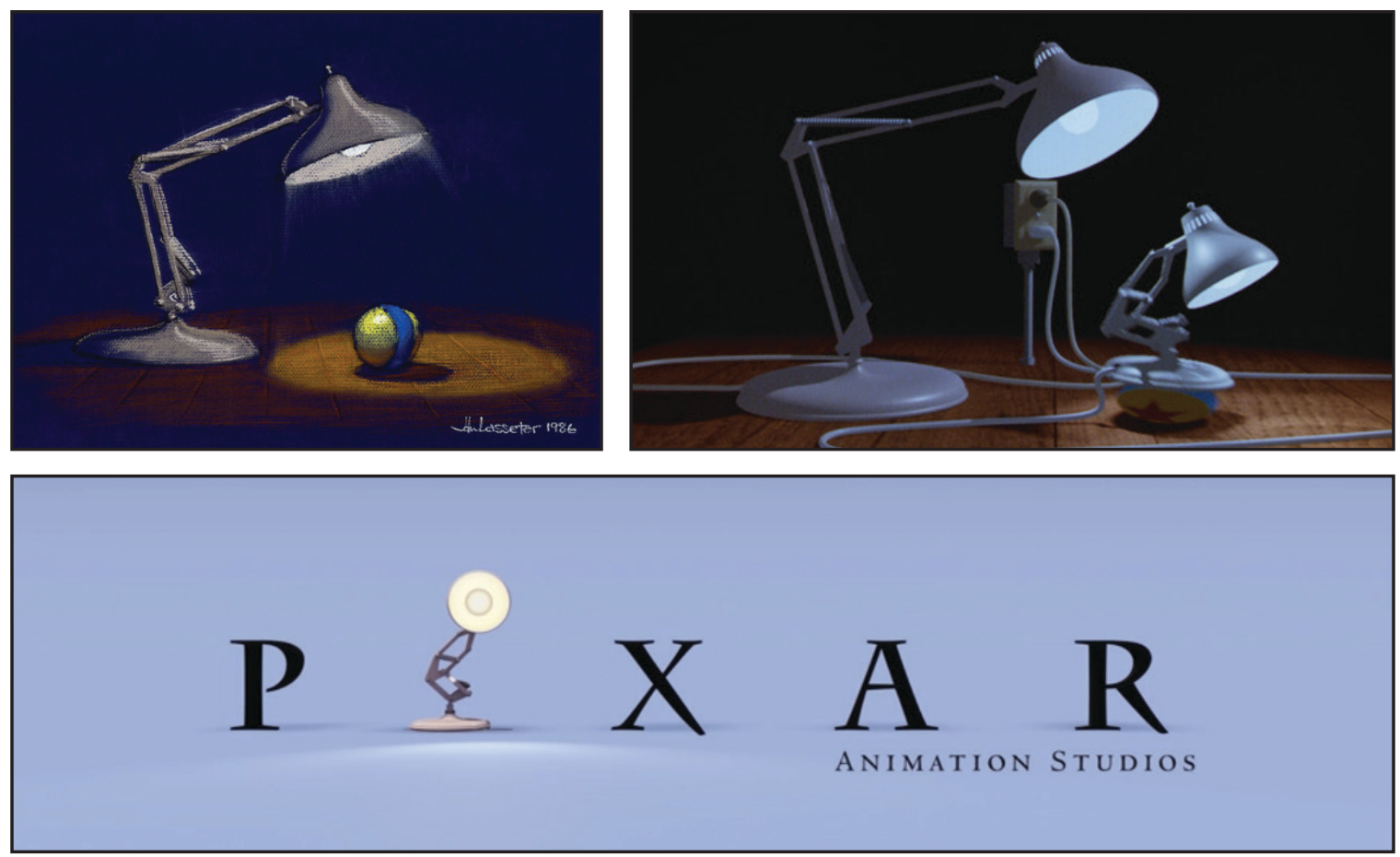

Fig. 22-24

Concept art and still frame of 'Luxo Jr.' This short film based on John Lasseter's lamp, inspired Pixar's iconic logo 
papers creating the new company, Pixar, Inc. ${ }^{53}$

Lasseter and the small animating team continued to produce short films to promote the company's computers at events like SIGGRAPH. For their first film under the Pixar name, Lasseter revisited a project he began back at LucasFilm inspired by his desk lamp. ${ }^{54}$ The resulting film, titled Luxo Jr, was an immediate success at SIGRAPH, achieving a level of photorealism unprecedented in computer animation, but more importantly capturing an emotional realism that computer animation had always struggled to reach. [Fig's. 22-24] Lasseter painstakingly animated the two lamp characters to be incredibly expressive despite having no discernible face or voice. He had "succeeded in applying the Disney touch of thought and emotion to his characters." ${ }^{\prime 55}$ A couple years later, in 1988, Lasseter produced Tin Toy, testing the new PhotoRealistic RenderMan software

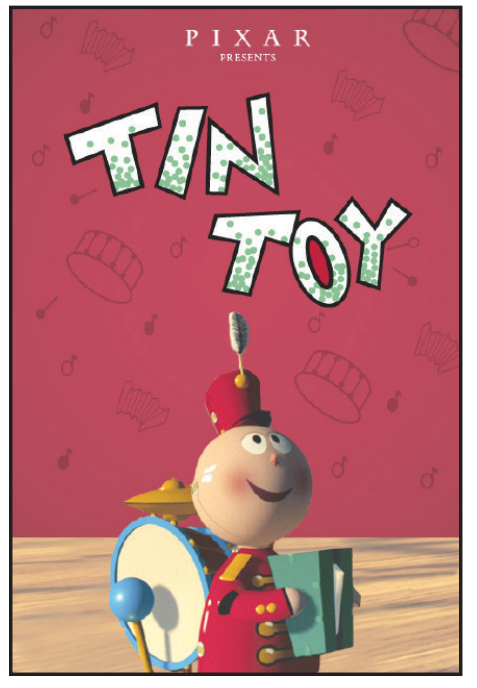

Fig. 25

'Tin Toy,' directed by John Lasseter, won Pixar their first OSCAR, in 1988
Catmull's group had designed. Tin Toy won Pixar their first Oscar in 1988, for Best Animated Short Film. [Fig. 25] The recognition "established computer animation as a legitimate artistic medium ${ }^{156}$ within the wider art form. It also prompted Disney to try to re-acquire the young animator they had let go several years earlier. Lasseter was unswayed, saying, "I can go to Disney and be a director, or I can stay here and make history. ${ }^{1157}$ History was just a few short years away. Around that same time Ed Catmull and Alvy Ray Smith finally struck a deal with the Walt Disney Company. 
Disney had begun to seriously consider replacing their traditional ink-and-paint process of colouring their films with computers. Pixar won the contract thanks in large part to the knowledge of traditional animation processes they picked up during their days at NYIT. ${ }^{58}$ The first test of the Computer Animation Production System (CAPS), in the final scene of 1989's The Little Mermaid, was such a success that Disney immediately switched all of their feature animation to use CAPS. [Fig. 26] 1990's The Rescuers Down Under would be the first film to be coloured entirely using Pixar's technology. ${ }^{59}$ [Fig. 27]

In the summer of 1990 Pixar received the news that they had been waiting two decades for: Disney was interested in making a feature film with computer animation. Though there were other organizations doing computer animation, Pixar had made themselves the obvious choice with their successful rollout of CAPS and Lasseter's

Fig. 26

The final scene of the Little Mermaid (1989) was the test-run of Pixar's colouring computer program, CAPS

unprecedented string of critically acclaimed short films. ${ }^{60}$ Negotiations continued for the next year until June 1991 when a contract was signed. During that time Alvy Ray Smith left

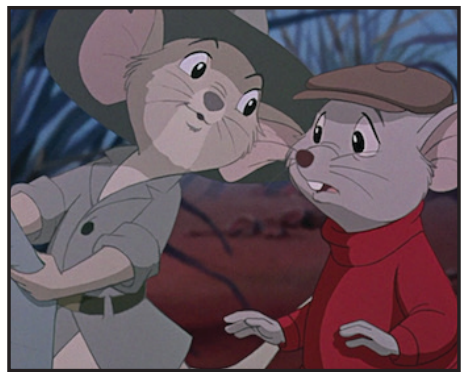

Pixar to start his own company. The deal heavily favoured Disney, giving them ownership of the film, its characters, full rights to produce sequels without Pixar, sole discretion to abandon the project at any time, etc. None of this mattered Fig. 27 1990's 'The Rescuers Down Under' was the first Disney film to be coloured entirely by Pixar's CAPS

to Catmull and Lasseter; they were finally going to make a feature film. In 1991 Lasseter presented his first treatment for 
a film called Toy Story. ${ }^{61}$

Toy Story premiered in November of 1995 after four years of hard work. [Fig. 28] Catmull, Lasseter and the Pixar team had much to learn about the production of a featurelength film. They combined the animation principles of Disney's 'Nine Old Men' with their own techniques unique to computer animation to produce a film that deliberately promoted the capabilities of the craft while remaining a thoroughly entertaining film. "Although the film had Disney's child-friendly imprimatur on it, the critics intuited

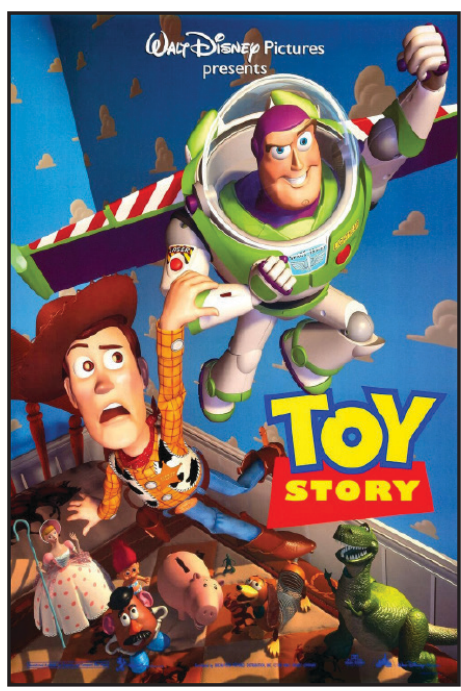

Fig. 28

Promotional poster for 'Toy Story.' Note, "Walt Disney Pictures Presents." After the success of 'Toy Story' in 1994, Pixar would renegotiate the studio's topbilling that Toy Story was meant to connect with adults as much as children."62 Toy Story became the most successful Thanksgiving debut ever, as well as the first animated film be nominated for the Academy Award for Best Screenplay, in 1996. John Lasseter received a special achievement Academy Award for "for his inspired leadership of the Pixar 'Toy Story' team."63 For Lasseter, Toy Story's success was validation "that an animated feature could eschew fairy-tale plots and instead focus on adult like characters with adult like problems, while providing entertainment to children." ${ }^{\prime 64}$ It is this same approach which has come to define the oeuvre of Pixar's work over the last two and a half decades. 


\section{AS TIME WENT BY}

With the release of Snow White and the Seven

Dwarfs in 1937, Walt Disney revolutionized animation as an art form and established it as a dominant form of children's entertainment for the next century. From the outset there has been a faction of academia dedicated to analyzing animated films for their implications on things such as childhood cognitive development, perception of race, gender, age, and self, and for their messaging about issues of equality, death, and love. ${ }^{65}$ When Pixar emerged in the 1990 s with its own brand of storytelling, it invited this same kind of critical discourse by deliberately approaching more mature themes in their films. John Lasseter held a strong conviction that storytelling is important and that animation in particular had applications beyond mere entertainment. Certainly, he hoped to entertain with his films, but he also sought to reach deeper into the audience's mind and soul and draw out more meaningful conclusions, elevating the medium's potential for meaningful storytelling. The result is that nearly every academic field concerned with human behaviour and the human condition has extensively dissected Disney and Pixar films - except architecture. Animation offers extremely fertile ground for architectural discourse, not only in terms of representation but more significantly in its unique ability to present provocative imagery and scenario in a way that is not only believable, but that garners an emotional response. 
1.1 An Animated History Endnotes

$1 \quad$ Wells, Paul. Understanding Animation. London: Routledge, 2016. p. 11

2 Smith, Conrad. "The Early History of Animation: Saturday Morning TV Discovers 1915." Journal of the University Film Association 29, no. 3 (1977): 23-30. https://www.jstor.org/stable/20687377. 
Price. The Pixar Touch. p. 94-101

Price. The Pixar Touch. p. 102-103

Price. The Pixar Touch. p. 104

Price. The Pixar Touch, p. 106

Price. The Pixar Touch. p. 107-108

The Special Interest Group on Computer Graphics and Interactive Techniques (SIGGRAPH) is an annual conference of computer graphics and animators at which companies share their recent developments with the industry. SIGGRAPH became an important pilgramage for Pixar as they developed their computer animation technology. Walt Disney's 'Nine Old Men' refers to the group of nine animators that worked with Walt since before Snow White.. They are Frank Thomas, Ollie Johnston, John Lounsbery, Marc Davis, Ward Kimball, Woolie Reitherman, Les Clark, Eric Larson, Milt Kahl. (D23. The Official Disney Fan Club. https://d23.com/a-to-z/nine-old-men/)

Price. The Pixar Touch. p. 117

Catmull and his hardware team had been building a set of devices "that could scan movie film, combine specialeffects images with live-action footage in a computer, and record the results back onto film," and a specialized computer to sit at the centre of the process. The team called their new computer the "Pixar Image Computer" Pixar being derived from 'Picture Maker' and laser, owing to the computer's use of lasers to scan film. (Price. The Pixar Touch. p. 125)

Price. The Pixar Touch. p. 149-150

Though he was a talented animator and director, Lasseter was unable to use the 3D modelling software himself, instead relying on others to execute his vision. In an effort to remedy this he set out to learn the modelling program. Looking around for inspiration he decided to model his desk lamp, a Luxo model. For the 1986 SIGGRAPH film, Lasseter built a story around the lamp. (Price. The Pixar Touch. p. 137-138)

Price. The Pixar Touch. p. 186

Price. The Pixar Touch. p. 209

Price. The Pixar Touch. p. 211

Catmull's team spent about a year developing the Computer Animation Production System (CAPS) for Disney. The system "used Pixar Image Computers (PICs) to scan pencil drawings of characters, colour them, composite them onto scanned backgrounds and other image layers, and record the frames onto film." It also replaced the multiplane camera as a means of achieving depth which had been in use since Walt Disney developed it in 1937. The system would eventually earn Disney and Pixar a technical Academy Award in 1991.

Price. The Pixar Touch. p. 182-187

Price. The Pixar Touch. p. 233

Price. The Pixar Touch. p. 249

Price. The Pixar Touch. p. 309

Price. The Pixar Touch. p. 312-316

Price. The Pixar Touch. p. 316

For more information on these subjects:

Dundes, Lauren. Psychosocial Implications of Disney Movies. MDPI AG, 2019.

Robinson, Tom, Mark Callister, Dawn Magoffin, and Jennifer Moore. "The Portrayal of Older Characters in Disney Animated Films." Journal of Aging Studies 21, no. 3 (March 18, 2018): 203-13. https://doi.org/10.1016/j. jaging.2006.10.001.

Ward, Annalee. Mouse Morality: the Rhetoric of Disney Animated Film. Austin, TX: University of Texas Press, 2003. 


\subsection{THE PLAUSIBLE IMPOSSIBLE}

In October 1956, Walt Disney hosted an episode

of his weekly television show Disneyland, entitled "The

Plausible Impossible." The purpose of the episode was

twofold: to highlight the animation principle of the plausible

impossible, and to trace its origins and history. The plausible

impossible, as defined by Walt, is "taking something that is

against the laws of nature - something impossible - and

making it appear rational and acceptable, in short, plausible."11

It is the capacity of the author or storyteller to persuade the

audience to suspend their disbelief and give themselves

over fully to the narrative and the truth it holds. The plausible

impossible concept predates the invention of film itself,

however it is with the advent of animation that it reached its

fullest potential. ${ }^{2}$

Animation is not a genre, nor is it a medium.

Practically, animation is the process of assembling a film

퐆

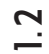



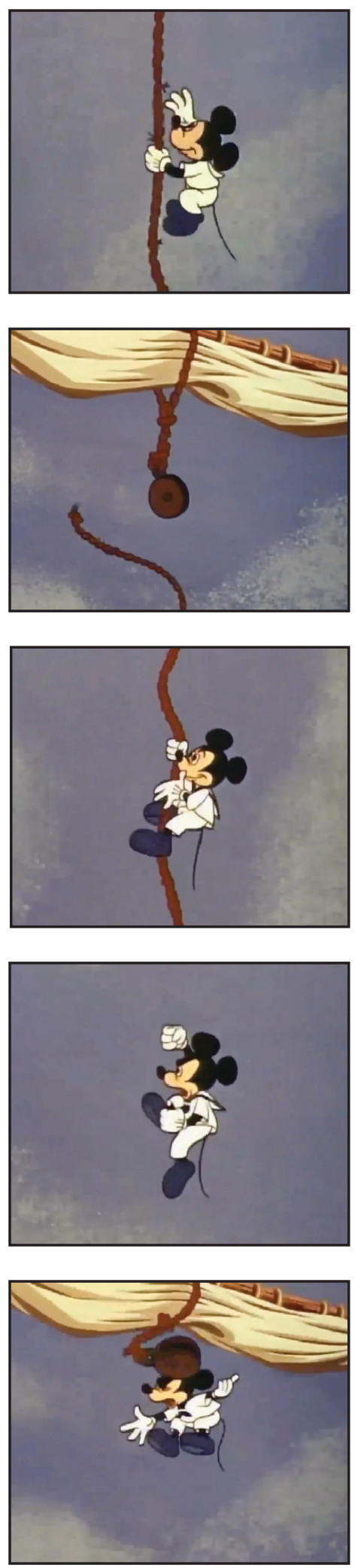

Fig. 29

The Plausible Impossible on display. "frame-by-frame, providing an illusion of movement."

Functionally, however - artistically - the purpose of

animation is "to give life and soul to a design, not through the copying but through the transformation of reality." It is the visual representation of objects and ideas. This is what the plausible impossible achieves. "If it is the live-action film's job to present physical reality, animated film is concerned with metaphysical reality - not how things look, but what they mean." ${ }^{15}$ The plausible impossible is one of animation's most essential principles, drawing on the audience's preconceived notions of reality in order to either satisfy or subvert expectations. $^{6}$

Later in that October 1956 Disneyland episode, Walt outlines the important elements an animated film must have in order to make the impossible seem plausible. "Impossible cartoon actions will seem plausible if the viewer feels the action [they are] watching has some factual basis." ${ }^{17}$ This he illustrates with the example of a cow whose bell is rung when her tail is pulled back. This is of course impossible, yet the anatomical connection between the tail and the bell - the spine - is a factual reality which makes the action seem plausible. Walt continues, "Another important factor in making cartoon action believable is correctness of sensation." ${ }^{\prime \prime}$ This means matching the visual action on the screen to the sensation one would have in a similar situation. Imagine an elevator abruptly beginning to ascend. 

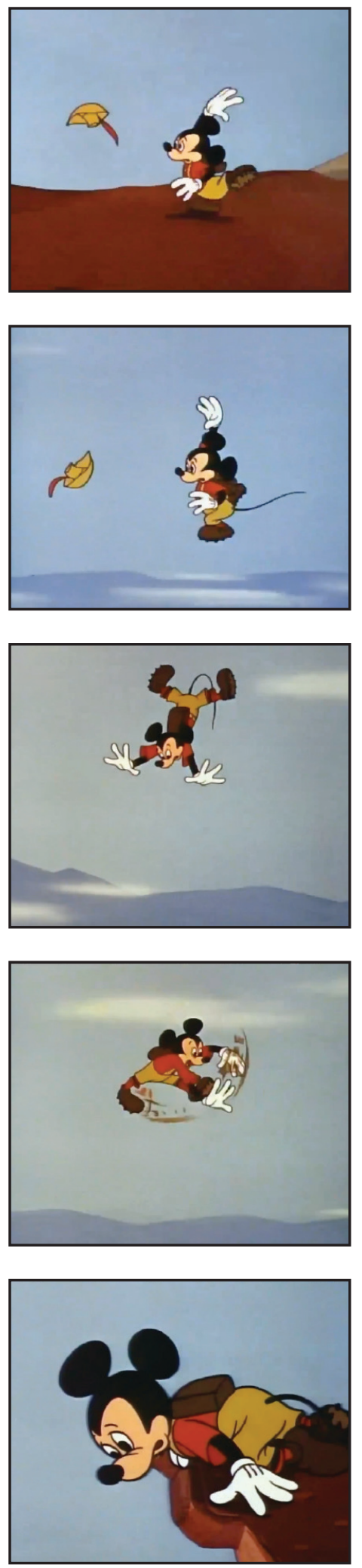

Fig. 30

The Plausible Impossible on display.
It would feel as if your body compresses towards the ground, and then stretches out when the elevator stops again. When Mickey Mouse rides an elevator, his body visually compresses so it is nearly flat to the ground when it starts up. When the elevator stops, his body dramatically stretches so that he appears thin and tall before returning to his normal stature. These principles are the essential elements to the physicality of plausible impossible animation, but there is another important factor: sound. ${ }^{9}$

The plausibility of animated films begins with the plausibility of the characters, but as Walt says, "The problem is that they are not real individuals; they must be created step by step."10 The character begins as a series of drawings on a piece of paper. They are given colour and when viewed in rapid succession, they become animated. "Animation gives movement, which in turn gives life to the drawing," Walt explains while drawing Donald Duck on piece of paper, "But equally as important as animation, is sound. Sound helps to give the character plausibility in two ways. First, by giving the character an appropriate voice., and second, to create convincing sound effects."11 The idea of a convincing sound effect is similar to the example of the cowbell; the sound can be impossible, if the idea of it is grounded in some common reality. To illustrate this point, Walt makes an example out of Donald Duck, hitting him on the head with the pencil that drew him. While the audience knows that his head is not 
hollow, it is this idea which lends plausibility to the sound which Donald's head makes - that of a hollow gourd. The combined effect of sound and action based some way in reality, whether perceived or actual, creates an animation that is impossible, yet remarkably plausible. By making the impossible appear plausible, animated films empower the viewer to inhabit those other analogous worlds and empathize with their characters, and in doing so invites the viewer to reconsider their personal associations with the world and their place in it. 
1.2 The Plausible Impossible Endnotes

$1 \quad$ Walt Disney. "The Plausible Impossible," Walt Disney's Disneyland. (Burbank, California: ABC, October 31, 1956).

2 Aristotle emphasizes the importance of "probable impossibility" in his landmark philosophical treatise on literary theory, Poetics, written around 350 BCE. He writes, "With respect to the requirements of art, a probable impossibility is to be preferred to a thing improbable and yet possible. To justify the irrational, we appeal to what is commonly said to be."

$3 \quad$ Wells, Paul. Understanding Animation. London: Routledge, 2016. p. 10

$4 \quad$ Wells. Understanding Animation p. 10

$5 \quad$ Wells. Understanding Animation. p. 11

6 This concept is closely related to an arm of philosophy known as 'speculative metaphysics', which is concerned with understanding and rationalizing the structure of the universe through theoretical deduction rather than practical observation or experience.

Sprigge, T. L. "Has Speculative Metaphysics a Future?" The Monist 81, no. 4 (October 1998): 513-33. https://doi. org/10.5840/monist199881428.

$7 \quad$ Walt Disney. "The Plausible Impossible." 1956.

$8 \quad$ Walt Disney. "The Plausible Impossible." 1956.

$9 \quad$ Walt Disney. "The Plausible Impossible." 1956.

$10 \quad$ Walt Disney. "The Plausible Impossible." 1956.

$11 \quad$ Walt Disney. "The Plausible Impossible." 1956. 

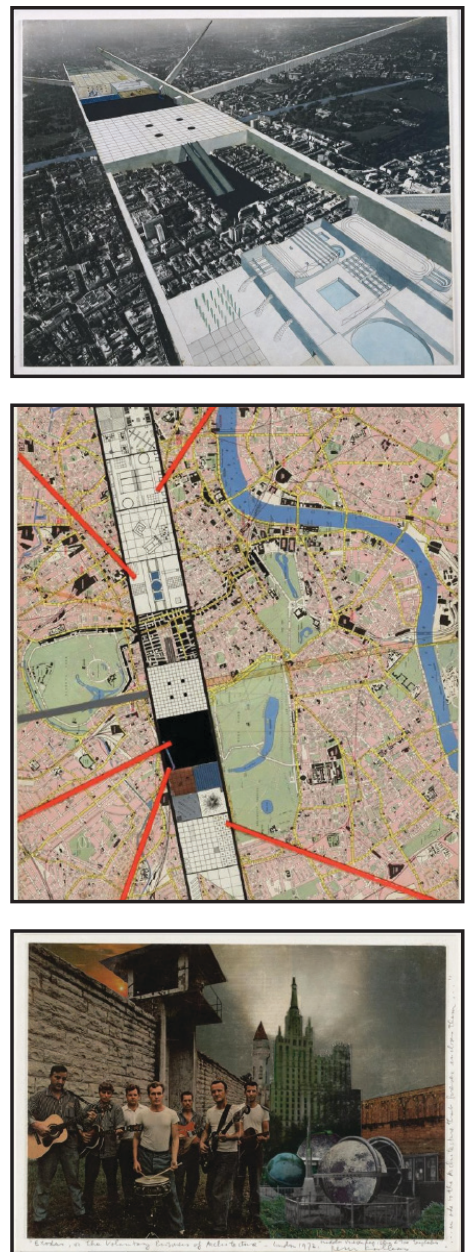

Fig. 31-33

'Exodus; or the voluntary prisoners of architecture.' Rem Koolhaas, 1972. Featured in the 2001 MoMA exhibit on visionary architecture.

\subsection{VISIONARY ARCHITECTURE}

In a 2001 article entitled "Ideals Made of Paper

and the Impact of the Unbuilt," New York Times resident

architecture critic Herbert Muchamps wrote that,

"...architecture is the materialization of metaphor in urban

space. But the materialization process does not begin with

building construction. It starts with the desire to make

something. Or with an attitude, an inclination to sharpen

perceptions or feelings and to share them with others.

Materialization doesn't end with building construction,

either. It continues with the formation of metaphors in other

people's minds, and with the focusing of their desire to

realize projects as enlivening as this show."

The show to which he was referring was the exhibition of the visionary architecture produced by Peter Eisenman, Bernard

Tschumi, Rem Koolhaas, Thom Mayne and Daniel Libeskind.

[Fig. 31-33] 
In analyzing the two practices, I have observed a similarity of concept between visionary architecture and animation; namely, the plausible impossible. In order to understand this association, it is first essential to define the concept of visionary architecture. The term 'visionary' is defined as "having or marked by foresight and imagination; incapable of being realized or achieved; existing only in imagination."2 Visionary architecture can therefore be understood as an exercise in speculative design; projects which exist on paper and not necessarily in the built world. "Unhampered by technical details and uncompromised by the whims of patrons, or the exigencies of finance, politics, and custom,"3 visionary architecture "affords [architects] the sole occasions when [they] can rebuild the world as [they] know it ought to be." ${ }^{4}$ As such, visionary architecture is part of an "essential tradition... that keeps the field [of architecture] intellectually lively and grounds actual buildings in a larger theoretical discourse."

Disney and Pixar Studios use the plausible impossible in the pursuit of fantasy, bringing realistic believability to the unreal characters, settings, and narratives of their films by grounding the unreal in some common reality. In the context of this thesis, I am suggesting that we similarly consider the plausible impossible as a principle of visionary architecture. Today, it is the essential purpose of visionary architecture to address contemporary social or 
environmental crises within the architectural profession and the world at large. This is achieved through the presentation of compelling narratives and provocative designs which often exist just outside the realm of reality. The effectiveness of visionary architecture at conveying these social commentaries and eliciting a reaction relies on its ability to assure the audience of the plausible reality of the unreal design. As in plausible impossible animation, such projects must be grounded in some sense of recognizable reality, for when "Ideal projects are inspired by criticism of the existing structure of society... they may bring forth ideas that make history." In this context the plausible impossible is seen as a conceptual device which facilitates the dissemination of ideas and challenges practitioners as well as the general public to think more critically about the built environment.

Architects have been experimenting with visionary architecture for centuries. Near the end of the Enlightenment,

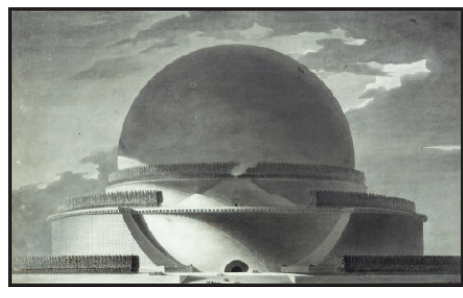
in 1784, Étienne-Louis Boullée drafted A Cenotaph for Issac Newton, an impossibly large monument to the great astronomer, signalling an emergent schism in the theory of architecture as pure art from the science of building.

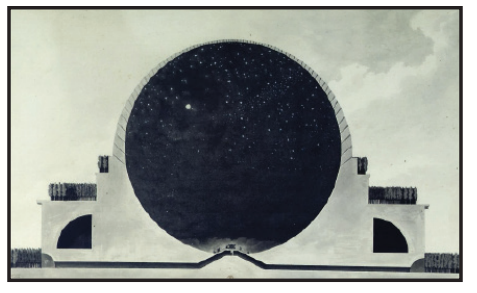
[Fig. 34-35] The design is Boullée's attempt to envision an architecture appropriate to the new ideology and social order emerging, in this case, from the Enlightenment. ${ }^{7} \mathrm{~A}$ century

Fig. 34-35 'Cenotaph for Issac Newton,' 1784 Étienne-Louis Boullée later utopian socialist Charles Fourier reacted to the writings of Karl Marx with his proposal of the Phalanstère, sprawling 
complexes designed to accommodate a cooperative agricultural community which guaranteed "vast profits and numberless pleasures ${ }^{118}$ to all members. The first half of the inter-war period saw the design of several notable visionary architecture projects. In 1935 Frank Lloyd Wright called for a radical transformation of American cities to restore the earlier Emersonian and Jeffersonian values with his proposal of Broadacre City: a technopolitan model which would see American populations return to rural living while maintaining close community bonds through the promises of new technologies like the telephone and the automobile. ${ }^{9}$ [Fig. 36] Even Walt Disney, after finding success in film and television and later amusement parks with Disneyland, contributed to the tradition of visionary architecture with his original plan

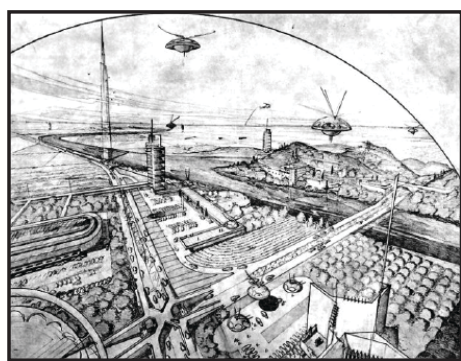

Fig. 36 'Broadacre City,' 1935. Frank Lloyd Wright for E.P.C.O.T. in 1966. ${ }^{10}$ [Fig. 37] Described by Walt Disney himself in a promotional video, the Experimental Prototype Community of Tomorrow would "never be completed, but will always be introducing, and testing, and demonstrating new materials and new systems. And, E.P.C.O.T. will always be a showcase to the world for the ingenuity and imagination

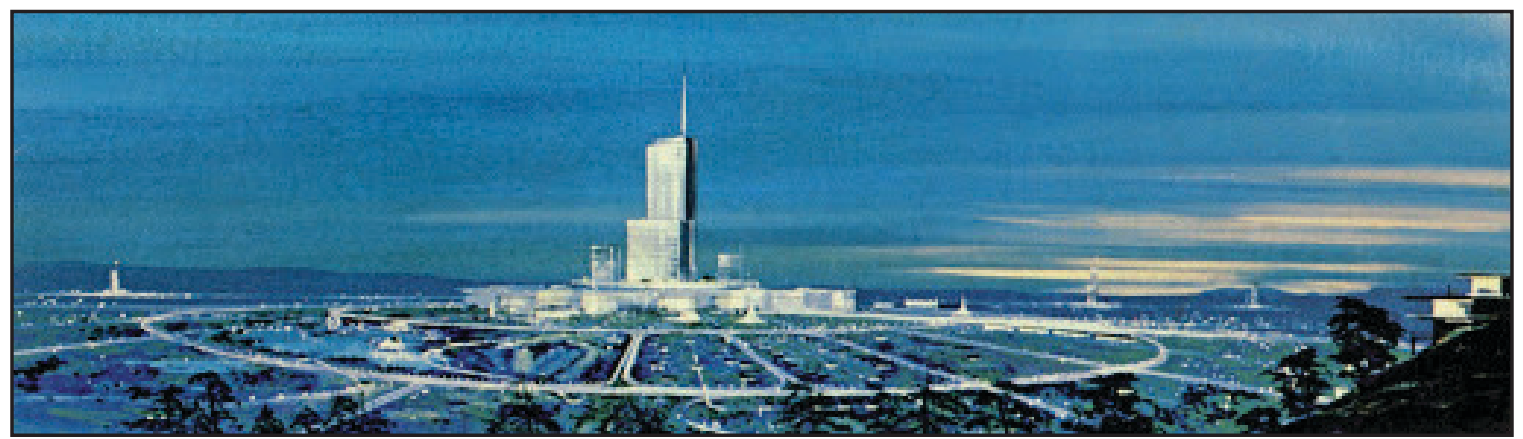

Fig. 37

Walt Disney's original concept for 'E.P.C.O.T. 1966.' Art by Herbert Ryman 
of American free enterprise."11 These are just a few of the many examples of architects and thinkers exploring contemporary architectural and societal issues through visionary architecture in their time. Significant to this thesis is the work of 1960s pop-architecture collective Archigram and twenty-first century architect and film director Liam Young, specifically Plug-in City and Planet City respectively. These two projects will be discussed in more detail in section 1.5 .

Visionary architecture, like animation, is a form of visual communication which is dependent on audience engagement to effectively elicit an emotional, logical, or critical response. I have argued that the plausible impossible native to the character-driven animated films of studios such as Disney and Pixar can also be understood as a conceptual device in visionary architecture, facilitating its commentary and critique on contemporary social concerns. By toeing the line between fiction and reality, "Visionary projects....cast their shadows over into the real world of experience, expense and frustration."12 Since the 1960s, the object of visionary architecture's scrutiny can often be categorized into one of two architectural dilemmas: environmental stewardship and social sustainability. These same issues are often the subject (or subtext) of Disney and Pixar Studios' animated films, especially since the mid-1990s. By understanding how the plausible impossible is used to communicate the 'visions' of visionary architecture, we can refocus the lens to explore 
how it may facilitate a similar phenomena in animated film. In doing so we can recontextualize the potential of animated film as architectural critique and better analyze how character-driven animated film can inspire architects to reassess their professional responsibilities and think more critically about the built environment. "If we could learn what they have to teach... Vision and reality might then coincide."13 
1.3 Visionary Architecture Endnotes

$1 \quad$ Herbert Muschamp, "Ideals Made of Paper and the Impact of the Unbuilt," The New York Times, March 11, 2001, sec. Art/Architecture, p. 34.

2 Merriam-Webster.com Dictionary, s.v. "visionary," accessed April 1, 2021, https://www.merriam-webster.com/ dictionary/visionary.

3 "Visionary Architecture." New York, NY: MOMA, 1960. The Museum of Modern Art. "Visionary Architecture." New York, NY: MOMA, 1960. The Museum of Modern Art Philip Kennicott, "Designing to Survive," The Washington Post, July 13, 2020, https://www.washingtonpost.com/ magazine/2020/07/13/pandemic-has-shown-us-what-future-architecture-could-be/?arc404=true.

$6 \quad$ "Visionary Architecture." New York, NY: MOMA, 1960. The Museum of Modern Art.

$7 \quad$ Miller, Michelle. "AD Classics: Cenotaph for Newton / Etienne-Louis Boullée." ArchDaily, September 10, 2014. https://www.archdaily.com/544946/ad-classics-cenotaph-for-newton-etienne-louis-boullee.

8 Fourier, Charles, and Gareth Stedman Jones. Introduction. In The Theory of the Four Movements, 15. Cambridge: Cambridge Univ. Press, 1996.

9 Dougherty, James, "BROADACRE CITY: FRANK LLOYD WRIGHT'S UTOPIA." The Centennial Review 25, no. 3 (1981): 239-56. Accessed May 22, 2021. http://www.jstor.org/stable/23739336.

10 The Original EPCOT. "Walt Disney's Original E.P.C.O.T Film (1966)"

11 The Original EPCOT. "Walt Disney's Original E.P.C.O.T Film (1966)"

12 "Visionary Architecture." New York, NY: MOMA, 1960. The Museum of Modern Art

13 "Visionary Architecture." New York, NY: MOMA, 1960. The Museum of Modern Art 


\subsection{NARRATIVE THEMES \& ARCHITECTURAL DILEMMAS}

Visionary architecture has long been used as a way of critiquing prevailing architectural ideologies in the realms of aesthetics, technology, politics, and social order. The 1960s marks a critical moment in the tradition of visionary architecture for two reasons: the emerging globalization, various civil rights and gay liberation movements, the space race, and the Vietnam War, among other significant events, triggered an increasing social and environmental consciousness in the general public; second, this emergent consciousness generated a public appetite for visionary architecture that addressed the synthesized issues such as environmental stewardship and social sustainability. Though the specific issues of concern were unique to each continent, North America and Europe were both swept up in this fever of social action. It is within the context of 
this transatlantic phenomenon that architects sought to "reinforce [architecture's] social and political agency towards emancipatory ends,"2 by proposing radical, whimsical, and incisive solutions to the pressing dilemmas surrounding environmental stewardship and social sustainability. Three decades later, these dilemmas would once again dominate popular discourse, this time influencing the narratives of the animated films of Disney and Pixar Studios, however it is the 1960s that began to shape our contemporary understanding of these themes.

\section{ENVIRONMENTAL STEWARDSHIP}

In September of 1962, conservationist Rachel Carson published the influential environmental science book Silent Spring, in which she took aim primarily at the American chemical industry's damaging practices and misinformation tactics. ${ }^{3}$ Particularly provocative is the "Fable of Tomorrow" with which Carson opens her book. It describes a pleasant and bountiful town which has gone silent due to some "grim specter"4 that had crept among the town unseen. That specter was synthetic pesticides. Silent Spring has been credited as triggering a grassroots environmentalism in the United States which would lead to the enactment of several conservationist legislations over the next decade. ${ }^{5}$ Though the information in the book was not unfamiliar to those within the environmental science industry, Carson's 
book effectively introduced the general public to the shady dealings between industry and bureaucracy and made the environmental movement popular.

At the opposite end of the decade, on December 23th, 1968, astronauts in lunar orbit aboard the Apollo 8 delivered an early Christmas present to the humans back on planet Earth; a 'live' television broadcast of a grainy, blackand-white Earth. ${ }^{6}$ The footage caused an immediate stir as humankind got its first moving pictures of their home. The next day, American poet Archibald MacLeish wrote in the

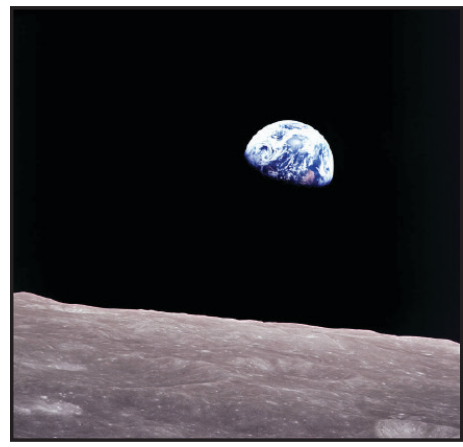
New York Times, "To see the Earth as it truly is, small and blue and beautiful in that eternal silence where it floats is to see ourselves as riders on the Earth together, brothers on that bright loveliness in the eternal cold., ${ }^{17}$ When a colour photo taken on Christmas Eve by astronaut Bill Anders

Fig. 38 'Earthrise,' 1968 was humanity's first glimpse at the planet in highresolution and colour. This photo changed the world

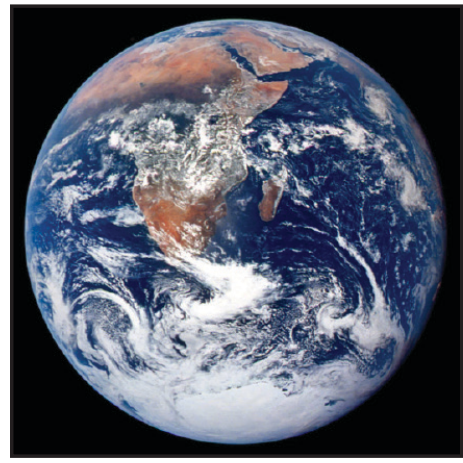

Fig. 39

'The Blue Marble,' taken in 1972, was the first colour photo taken of the fully-sun-lit Earth. It has become one of the most reproduced images in history was published a week later in Life Magazine the world was changed. The photograph, called Earthrise, is the first highresolution, colour picture taken by a human in space. ${ }^{8}$ [Fig. 38] It revealed the planet to be a fragile marble of blue and green in an infinite universe, changing the human perception of the world and their place in it. Specifically, Earthrise exposed the environmental and social fragility of the planet. Together with and can be seen as the impetus of a renewed environmental consciousness as well as a reaffirmation of the interconnectedness of all humankind.

In the many decades since the environmental 
movement began, its lexicon has grown to include a wide variety of terms defining actions, approaches, and solutions to solving or mediating the effects of the crisis. One of the most prevalent resolutions is the concept of environmental stewardship. Environmental stewardship entails the protection, restoration, and sustainable use of the environment. ${ }^{9}$ Stewardship is founded on the notion that every generation inherits the Earth from the previous, and must care for and maintain it in all its beauty and function for the next generation.10 It begins with a sense of respect for and responsibility over the planet, all its natural systems, habitats, and creatures. Effective environmental stewardship is supported by its tripartite actions; protection, restoration, and sustainability, each as essential to the rest as one leg of a tripod.11

In both architecture and animation, the principle of environmental stewardship is evident, albeit in different forms. In architecture, it is the responsibility of the architect to respect the environment and make informed design decisions such as appropriate material choice, envelope design, and building systems. In animated film environmental stewardship is a narrative theme which can either drive the narrative, as in Wall-E, or permeate throughout the plot as in The Lion King; the former a cautionary tale about the detrimental effects of human expansion and unchecked pollution, the latter a coming of age story about a lion prince 
who cannot wait to be king, overlaid with a message of sustainability and the circle of life. Exploring how issues of the environment implicate the fictional worlds within animated films, as well as how the characters and narratives respond to such issues, can open new paths of critical investigation for architects.

\section{SOCIAL SUSTAINABILITY}

When Earthrise was published on New Year's Day 1969, it carried with it a notion of interconnectedness and unity, reinforcing the already growing social movement on Earth. Throughout the 1960s both America and the UK were reckoning with the growing Civil Rights Movement, Women's Liberation Movement, and the Gay Liberation Movement.12 Rising populations on both sides of the Atlantic exacerbated racial and social divisions and put a strain on civic infrastructure leading to a transatlantic housing crisis. ${ }^{13}$ Meanwhile phenomena like Beatlemania bridged the cultural divide between Western nations creating a greater sense of internationalism and anti-Vietnam War protests galvanized a generation that had become disenfranchised with the bureaucracy that ran their world. Everywhere, people were calling attention to systematic and political wrongs and trying to find ways to build stronger communities. In many ways this can be seen as the beginning of the pursuit of 
modern social sustainability.

In 1987, when a United Nations Commission defined sustainable development as, "Meeting the needs of the current generation without compromising the ability of future generations to meet their needs," it also identified three categories of sustainability: environmental, economic, and social. It is important to note that this oft-cited definition was written in the context specifically of development, that is, the development of a country or corporation. As such, since economic growth and environmental impact have more quantifiable targets, they have enjoyed wider attention and understanding, while subordinating the social element, if not overlooking it entirely. Today, as millions continue to challenge racial, gender, and economic inequality, the role of social sustainability has been in greater focus in popular discourse.

Social sustainability can be defined in general terms as, "a life-enhancing condition within communities, and a process within communities that can achieve that condition." A more critical definition may be: "Social sustainability occurs when the formal and informal processes, systems, structures and relationships actively support the capacity of current and future generations to create healthy and liveable communities. Socially sustainable communities are equitable, diverse, connected and democratic and provide a good quality of life." The strength of this definition is that it 
prescribes a series of principles which represent aspirational statements by which social sustainability may be achieved. While not a perfect system, owing to the complex nature of social organizations, this gives social sustainability a quantifiable rubric more in the vein of the economic and environmental. Furthermore, I have amended the principle of social sustainability in the context of this thesis to include the psychological notion of self-actualization/selftranscendence, a tangential concept relating to an individual and community fulfillment.

\section{SELF-ACTUALIZATION / SELF-TRANSCENDENCE}

In 1943, psychologist Abraham Maslow published a paper in Psychological Review entitled, "A Theory of Human Motivation."14 Therein, Maslow introduced his fivetier 'Hierarchy of Human Needs', a theory in psychology which suggests that people are motivated by five basic categories of needs. Illustrating the hierarchy as a pyramid, Maslow contended that one could only hope to fulfill the needs of the next category when the previous had been reasonably satisfied.15 Initially, Maslow considered selfactualization - the need to discover and fulfill one's true potential - to be the pinnacle of human needs. However, as he continued his research in the field of psychology he regularly revisited his 'Hierarchy of Human Needs', effectively revising it by 1969 to include a new apex need beyond 
self-actualization: self-transcendence. ${ }^{16}$ Self-transcendence relates to the need "to further a cause beyond the self and to experience a communion beyond the boundaries of the self."17 Conceptually it is very closely related to the principle of social sustainability and is similarly a product of 1960 s socio-political consciousness. Among the aforementioned political and social turmoil of the 1960s, there was a growing notion of the interconnectedness of people the world over. In 1962, Marshall McLuhan coined the term 'the Global Village' in reference to the phenomenon of the world's interconnectedness due to new media technologies like the television. In 1969 Woodstock brought together hundreds of thousands of people in a celebration of unity, peace, and art. In 1964, Walt Disney foreshadowed the emergent idea of the "global citizen" with his "It's a Small World" pavilion for UNICEF at the New York World's Fair, itself a celebration of international cooperation. It is within this context that Maslow revisited his "Hierarchy of Human Needs," to reflect the rising emphasis being placed on interpersonal and international relations.

Self-transcendence, as described by Maslow, is "a person's ability to obtain a unitive consciousness with other humans."18 One who has achieved self-transcendence is "able to view the world and [their] purpose in the world in relation to other human beings on a more global scale and is aware that they can have an impact, not just within their 
own geographical boundaries or culture, but on the whole world."19 This description reinforces my earlier statement regarding the close relation between self-transcendence and social sustainability, particularly through the principle of interconnectedness. Self-transcendence allows an individual to look beyond themselves and contribute to a sustainable community. As per Maslow's 'Hierarchy', however, selftranscendence can only be reached upon the achievement of self-actualization, and it at this level of the pyramid that architecture can contribute. Such contributions can only be observed with a fuller understanding of Maslow's original Hierarchy, and specifically, self-actualization.

The most basic human needs form the base of the pyramid. These are physiological needs like air, water, food, shelter, sleep, and reproduction, the basic requirements of survival. Next are safety needs: personal security, employment, resources, health, property. Then comes love and belonging, the needs for friendship, intimacy, family, and connections with others. Once satisfied, one seeks to

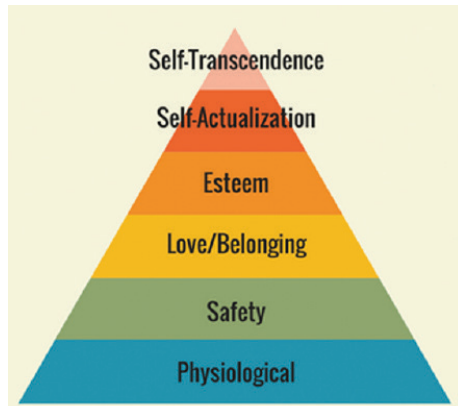

Fig. 40 Maslow's updated Hierarchy of Needs. fulfill their need for esteem: respect, self-esteem, status, recognition, and strength. Atop the pyramid, the highest level of the hierarchy, is self-actualization, the desire to become the most that one can be..$^{20}$ Of Dr. Maslow it has been said that while most psychologists study people who are unwell, he studies the perfectly healthy. For nearly two decades, Maslow studied people who had the "full use and 
exploitation of talents, capacities, potentialities, etc." ${ }^{\prime 21}$ in an effort to understand their apparent success. He defines self-actualization not as a terminable achievement, but as a continuous pursuit to "become more and more what one is, to become everything that one is capable of becoming."22 In short, "What a [person] can be, [they] must be."23 The lower four 'needs' are perhaps most easily understood, as most of us can relate to the pursuit of each. Self-actualization however, ostensibly the state to which all should aspire, is more elusive. ${ }^{24}$

As designers of private and public space, architects are capable of directly addressing several of the human needs identified by Maslow, but more significantly they are capable of providing built space which can aid in one's own pursuit of self-actualization and ultimately, selftranscendence. Architecture has the ability to serve the individual, just as it is capable of serving the public, and it can create an environment in which one can experience fully, be comfortable in their own sense of self, and allow them to pursue their goals. Many animated films tell the story of an individual in search of themselves, their identity, their place in society. The built, or drawn, environments of these films can contribute to a character's sense of self, or contrastingly, to their discomfort. Consider the film Up, in which, in the first five minutes, we see the protagonist and his wife meet, marry, and physically build a home together. 
They pour their personalities, their hopes, and their dreams into the very fabric of the house. As we watch them age, we see the house serve as a place of comfort, support, and reassurance, facilitating the couple's achievement of selfactualization together. Later in the film the house serves as metaphorical burden which the protagonist must let go of in order to look beyond himself and reach self-transcendence. This illustrates the relevance of architectural space to one's understanding of themselves and their place in the world. Looking to examples like these from animated films offer unexplored avenues to challenge the conventional thinking regarding issues of self-actualization and self-transcendence in architecture.

The purpose of this thesis is to open a dialogue between architecture and character-driven animated film as a viable source of inspiration regarding urgent design dilemmas relating to environmental stewardship and social sustainability. Though I have observed that this is an underexplored relationship, such a study is not entirely without precedent as it shares a close parallel to works of visionary and narrative architecture. 
1.4 Narrative Themes and Architectural Dilemmas Endnotes

1 The Civil Rights Movement:

Crystal, Gary. "Civil Rights in the Uk." Civil Rights in the UK. Accessed May 22, 2021. http://www.

civilrightsmovement.co.uk/civil-rights-uk.html\#:text=Racial\%20discrimination\%20in\%20Britain\%20during,first\%20 to\%20lose\%20their\%20jobs.

Hall, Simon. Peace and Freedom: The Civil Rights and Anti-War Movements of the 1960s. Philadelphia: University of Pennsylvania Press, 2011. https://doi.org/10.9783/9780812202137.195

Street, Joe. "Malcolm X, Smethwick, and the Influence of the African American Freedom Struggle on British Race Relations in the 1960s." Journal of Black Studies 38, no. 6 (July 2008): 932-50. https://doi. org/10.1177/0021934706291192.

Gay Liberation Movement:

Kuhn, Betsy. "So Bold Sixties." Essay. In Gay Power!: the Stonewall Riots and the Gay Rights Movement, 1969, 48-63. Minneapolis, MN: Twenty-First Century Books, 2011.

Robinson, Lucy. "Three Revolutionary Years: The Impact of the Counter Culture on the Development of the Gay Liberation Movement in Britain," Cultural and Social History, (2006). 3:4, 445-471, DOI: 10.1191/1478003806cs077oa Shariatmadari, David. "How 1967 Changed Gay Life in Britain." The Guardian, July 23, 2017. https://www.theguardian. com/world/2017/jul/23/how-1967-changed-gay-life-in-britain-i-think-for-my-generation-were-still-a-little-bituneasy.

Vietnam War:

M. Schreiber, E. (1975) "American politics and the Vietnam issue: Demonstrations, votes and public opinion," Politics, 10:2, 207-209, DOl: 10.1080/00323267508401522

Mansour, Claire, "The British Movement against the Vietnam War: An example of Transnational Solidarity?" Revue Miroirs (online), 5 Vol.l, 2017, http://www.revuemiroirs.fr/links/5/article2.pdf Small, Melvin. Antiwarriors: the Vietnam War and the Battle for America's Hearts and Minds. Wilmington, DE: Scholarly Resources, 2004.

Women's Liberation Movement

Smith, Harold L., and Elizabeth Meehan. "British Feminism from the 1960s to the 1980s." Essay. In British Feminism in the Twentieth Century, 189-204. Meherst: University Of Massachusetts Press, 1990.

Evans, Sara M. "Women's Liberation: Seeing the Revolution Clearly." Feminist Studies 41, no. 1 (2015): 138-49.

Accessed May 22, 2021. doi:10.15767/feministstudies.41.1.138.

Giardina, C.. "Freedom for Women: Forging the Women's Liberation Movement, 1953-1970." (2010).

Doucet, Isabelle. "Learning in the 'Real' World: Encounters with Radical Architectures (1960s-1970s)." Journal of

Educational Administration and History 49, no. 1 (2016): 7-21. p. 07

Carson, Rachel. Silent Spring. Boston: Houghton Mifflin, 1962.

Carson, Rachel. "A Fable of Tomorrow." Silent Spring. Boston: Houghton Mifflin, 1962

Griswold, Eliza. "How 'Silent Spring' Ignited the Environmental Movement." The New York Times. September 23, 2012. https://www.nytimes.com/2012/09/23/magazine/how-silent-spring-ignited-the-environmental-movement. html.

Griswold, Eliza. "How 'Silent Spring' Ignited the Environmental Movement." The New York Times. September 23, 2012. https://www.nytimes.com/2012/09/23/magazine/how-silent-spring-ignited-the-environmental-movement. html.

MacLeish, Archibald. "Riders on Earth Together, Brothers in Eternal Cold." The New York Times. December 25, 1968, sec. Cover. https://www.nytimes.com/1968/12/25/archives/a-reflection-riders-onearth-together-brothers-in-eternal-cold.html. 
https://www.theguardian.com/artanddesign/2018/dec/22/behold-blue-plant-photograph-earthrise.

Jennifer Welchman, "A Defence of Environmental Stewardship," Environmental Values 21, no. 3 (January 2012): pp. 297-316, https://doi.org/10.3197/096327112x13400390125975, 301. Jennifer Welchman, "A Defence of Environmental Stewardship," Environmental Values 21, no. 3 (January 2012): pp. 297-316, https://doi.org/10.3197/096327112x13400390125975, 301.

Environmental stewardship actions can be targeted for individual or multiple species, individual habitats, entire ecosystems, or integrated human-environment systems at a variety of scales ranging from neighbourhoods and municipalities to whole landscapes and ecological zones. Protection is the conservation and safeguarding of a species, habitat, or ecosystem. Efforts range from a bureaucratic protection of a natural wilderness from human intervention and habitat destruction through legislation, to a community movement to save a hundred-year-old tree from being bulldozed to put up a parking lot. Additionally, protective action can take the form of deliberate, passive inaction, by simply choosing not to disturb a natural system despite no active preventative restrictions. In short, the environmental stewardship principle of protection concerns that which has yet to be damaged or implicated by human interference. Conversely, the principle of restoration addresses those things which have been negatively impacted by human expansion. Restoration efforts seek to return a natural entity to a former state of balance, be it national or even global action to restore an endangered species or a local effort to repopulate an over-cultivated forest. The final principle of environmental stewardship ensures the efforts of the other two are not for nothing. Sustainability, another buzz-word of the environmental movement, is the principle defined broadly by a United Nations Commission in 1987 as, "Meeting the needs of the current generation without compromising the ability of future generations to meet their needs." This definition speaks to the principle of self-control and constraint in the pursuit of self-interest, to the benefit of the collective. However, due to the complexity of sustainability, particularly in the environmental context, this principle requires further analysis.

The aforementioned definition by the United Nations Commission is for the greater concept of sustainable development, which includes social, economic, and environmental sustainability. Various attempts have been made to define environmental sustainability, including by the UN Commission. One effective definition comes from a paper published in the Journal of Environmental Sustainability. Building on that of the UN Commission, this paper defines environmental sustainability as "a condition of balance, resilience, and interconnectedness that allows human society to satisfy its needs while neither exceeding the capacity of its supporting ecosystems to continue to regenerate the services necessary to meet those needs nor by our actions diminishing biological diversity." This definition emphasizes the importance of recognizing the value of natural ecological services and their interconnectedness with human-kind. The paper separates these services into four categories: provisional services, regulating services, supporting services, and cultural services.

Provisional services include any product obtained from ecosystems, such as food, biochemicals, natural medicines and pharmaceuticals, fresh water, and all forms of energy sources. Regulating services are the benefits obtained from natural ecological processes. This includes air quality regulation, water purification, waste treatment, pest and disease regulation, climate and water regulation, pollination, etc. Supporting services include soil formation, photosynthesis, nutrient cycling and dispersal, and water cycling. Cultural services cover the intangible, nonmaterial benefits obtained from ecosystems through spiritual enrichment, cognitive development, recreation, reflection, and aesthetic experiences.

David R. Farber and Beth L. Bailey. "The Great Society," The Columbia Guide to America in the 1960s. New York: Columbia University Press, (2005). p 23-33.

Watt, Paul, and Anna Minton. "London's Housing Crisis and Its Activisms." City: analysis of urban trends, culture, theory, policy, action 20, no. 2 (2016): 204-21. https://doi.org/10.1080/13604813.2016.1151707. Saul McLeod, "Maslow's Hierarchy of Needs," Simply Psychology, May 21, 2018. Abraham Maslow, Self-Actualization and Beyond (Winchester, MA: New England Board of Higher Education, 1965). Venter, Henry J. "Maslow's Self-Transcendence: How It Can Enrich Organization Culture and Leadership." International Journal of Business, Humanities and Technology 2, no. 7 (December 2012): 64-71. p. 67 
doi.org/10.1037/1089-2680.10.4.302. p. 303

Koltko-Rivera, Mark E. "Rediscovering the Later Version of Maslow's Hierarchy of Needs: Self-Transcendence and Opportunities for Theory, Research, and Unification." p. 67

Koltko-Rivera, Mark E. "Rediscovering the Later Version of Maslow's Hierarchy of Needs: Self-Transcendence and Opportunities for Theory, Research, and Unification." p. 67

Abraham Maslow, Self-Actualization and Beyond (Winchester, MA: New England Board of Higher Education, 1965).

5. Dare to be different. Be unafraid of unpopularity. Trust in your own senses to form your own opinions, even if they are not popular.

6. Work hard to do well the thing that you want to do. Use your skills and intelligence to become the best at the task you wish to.

7. Recognize peak experiences and set up the conditions to make them more likely. Peak experiences are moments of ecstasy which cannot be bought nor sought. Learn what you are good at and identify what your potentialities are and are not.

8. Find out who you are, what you are, what you like, what you don't like, what is good for you and what is bad, where you are going and what your mission is. Open yourself up to yourself. Identify defences and give them up. According to Maslow, these pursuits are an intrinsic part of being human. He claims that each person has within them "a pressure toward unity of personality, toward spontaneous expressiveness, toward full individuality and identity, toward seeing the truth rather than being blind, toward being creative, toward being good, and a lot else. That is, the human being is so constructed that he presses toward what most people would call good values, toward serenity, kindness, courage, honesty, love, unselfishness, and goodness." This philosophy of self satisfies the need for a "framework of values, a philosophy of life, a religion or religion-surrogate to live by and understand by" which Maslow asserts is fundamental to all human beings. When those external institutions (religion, politics, etc.) have failed to fill that void, "we need a validated, usable system of human values that we can believe in and devote ourselves to." Self-actualization represents that system of values Abraham Maslow, Self-Actualization and Beyond (Winchester, MA: New England Board of Higher Education, 1965). 


\subsection{A TALE OF TWO CITIES}

Two projects in particular serve as a bridge between the field of architecture and the ambitions of this thesis. Archigram's mid-1960s Plug-In City is a speculative future city, derived from the megastructures and machine-forliving concepts of early modernism, yet unlike any proposal that came before it. Represented using characteristic 'pop' iconography, with Plug-In City, Archigram suggests what might be born of a marriage between architecture and science-fiction. Architect and film director Liam Young continues to navigate that relationship today with his own brand of visionary architecture, utilizing animation and film to represent his ideas. His most recent project, a 15 minute, immersive animated film and accompanying book entitled Planet City explores "the productive potential of extreme densification, in a speculative future where ten billion people surrender the rest of the planet to a global wilderness."1 
Though these projects differ from my own analysis of

animated film, they are nonetheless relevant to understand as precedents within the field of architecture.

Formed around 1960 in London, Archigram was

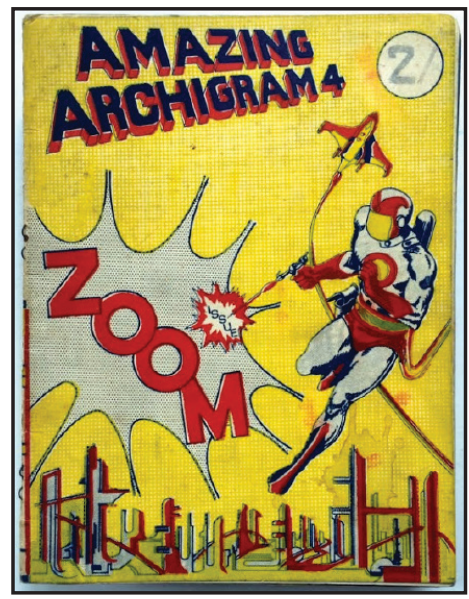

an architectural collective of individuals founded on a shared belief that the original, radical spirit of modernism had by the mid-century, become "gutless;"2 specifically, it had "lost its technological nerve."3 Much of their work was motivated by a desire to see modernism "try again at being technologically determined-really fabricating the 'machine for living in' promised by early modernism." ${ }^{4}$

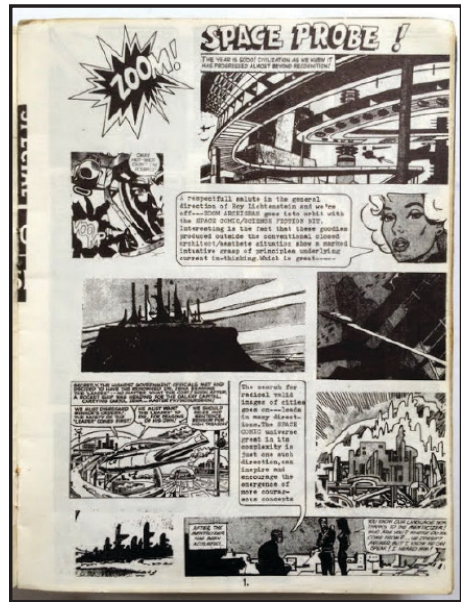
Operating within the context of the transatlantic appetite for social and cultural reform, Archigram published an eponymous magazine in 1961 full of pop-styled works of visionary architecture, demonstrating the "artful proximity in Archigram's work between the buildable and caprice." ${ }^{5}$ For the next decade the "Archigram newsletter became the focal point of radical architecture locally and globally, ${ }^{\prime \prime}$ at

Fig. 41-42

Cover and Page 1 from 'Amazing Archigram 4: the Zoom Issue,' May, 1964. The British collective was clearly inspired by American comics like Superman.

Fig. 43

'Plug-In City' is introduced on page 16 of 'Amazing Archigram 4: the Zoom Issue,' May, 1964.

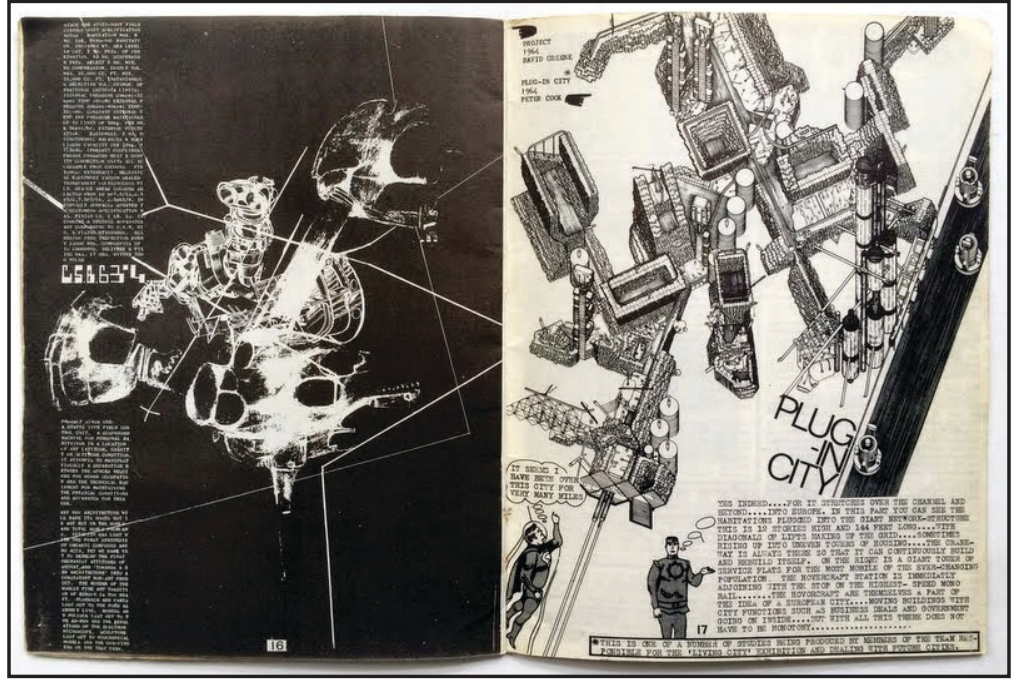


various times addressing issues related to the UK housing crisis, population growth and urban overcrowding, the rising trend towards individualism in both the UK and America, and human-caused environmental degradation. Beyond their contributions to theoretical discourse within the field of architecture, Archigram also successfully attracted the attention of the general public. Archigram's pop-infused approach to radical architectural thinking, characterized in their irregular magazine publications throughout the 1960s, reimagined architectural representation and sought influence from "outside the conventional closed architect/aesthete situation."7 This is best exemplified in their 1964 Zoom Issue (Amazing Archigram/Archigram 4) in which Plug-In City first appeared. [Fig's, 41-43]

Illustrative of the authors' professed obsession with 'Americana', Zoom borrows imagery from 'Space Comics' popular in America at the time, emphasizing an overlap between science fiction, science fact, architecture, and

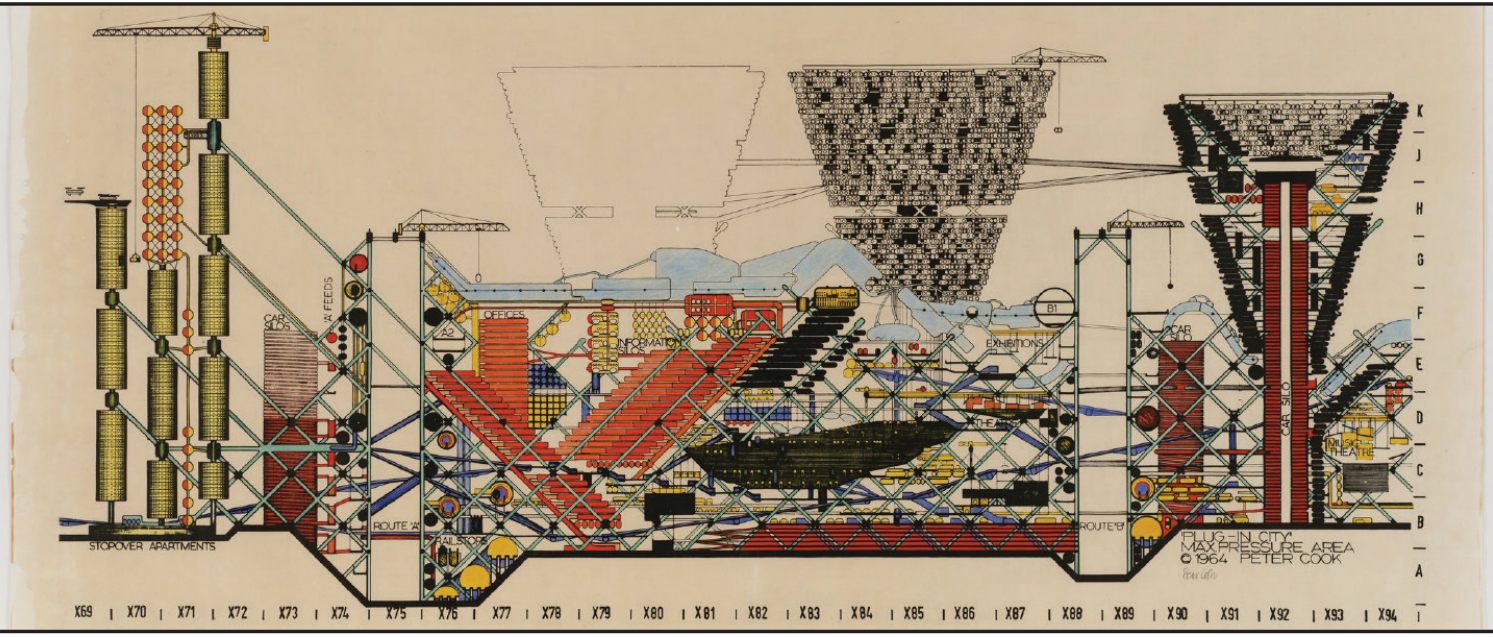

Fig. 44 Archigram's 'Plug-in City: Maximum Pressure Area,' Project Section, 1963-1966 
technology. ${ }^{8}$ It is within this graphic framework that PlugIn City is first presented, introduced by a Superman-like character flying above the speculative city. Plug-In City is a "megastructure devoted to continual circulation, its functions scrambled, its boundaries blurred, it reprieved the promise of collective living from a creeping pessimism about 'urbanism.'"' [Fig. 44] The plug-in concept was based in part on the Japanese metabolists' principle of designing long-term structures to support short term components and on the early modernist principles of "collectivity, of interchangeable apartment units, and... rapid transport links." ${ }^{\prime 10}$ The images Archigram produced of Plug-in City are reminiscent of "property-boom-fueled London of the 1960s, as the service cores of office blocks rose above the city prior to the addition of floor slabs and curtain walls."11 These highly detailed drawings, appearing in various iterations from 1964-1966, conveyed a "disarming reasonableness"12 despite their apparent unbuildability. By using contemporary issues such as urban densification, slum conditions, and social inequality as a springboard for their fantastical ideas and expressing them through legible architectural drawings, Archigram was able to address "an 'expanding field' of social, cultural, and technological facts."13 Thus, "The gap between fantasy and fact narrows."14 Archigram's use of popular media to explore and represent architectural possibilities as well as their investigation of urgent architectural dilemmas through 
plausible impossibilities speaks to the viability of my own study, and therefore serves as an important precedent.

Liam Young has a similar interest in science fiction.

Trained as an architect, Young has spent the last decade experimenting with space and world-building as a film director. His work "explores the blurred boundaries between filmmaking, storytelling and design,"15 believing that "...the telling of stories is actually a critical act of architecture."16 Unlike constructing narratives around specific plots or characters as in the tradition of Disney and Pixar animated films, Young "starts by imagining environments and contexts in which those stories might start to emerge."17 In his own words, he uses film to "imagine and visualize alternative worlds as a means to understand our own world in new ways... A lot of times, the problems that we're faced with

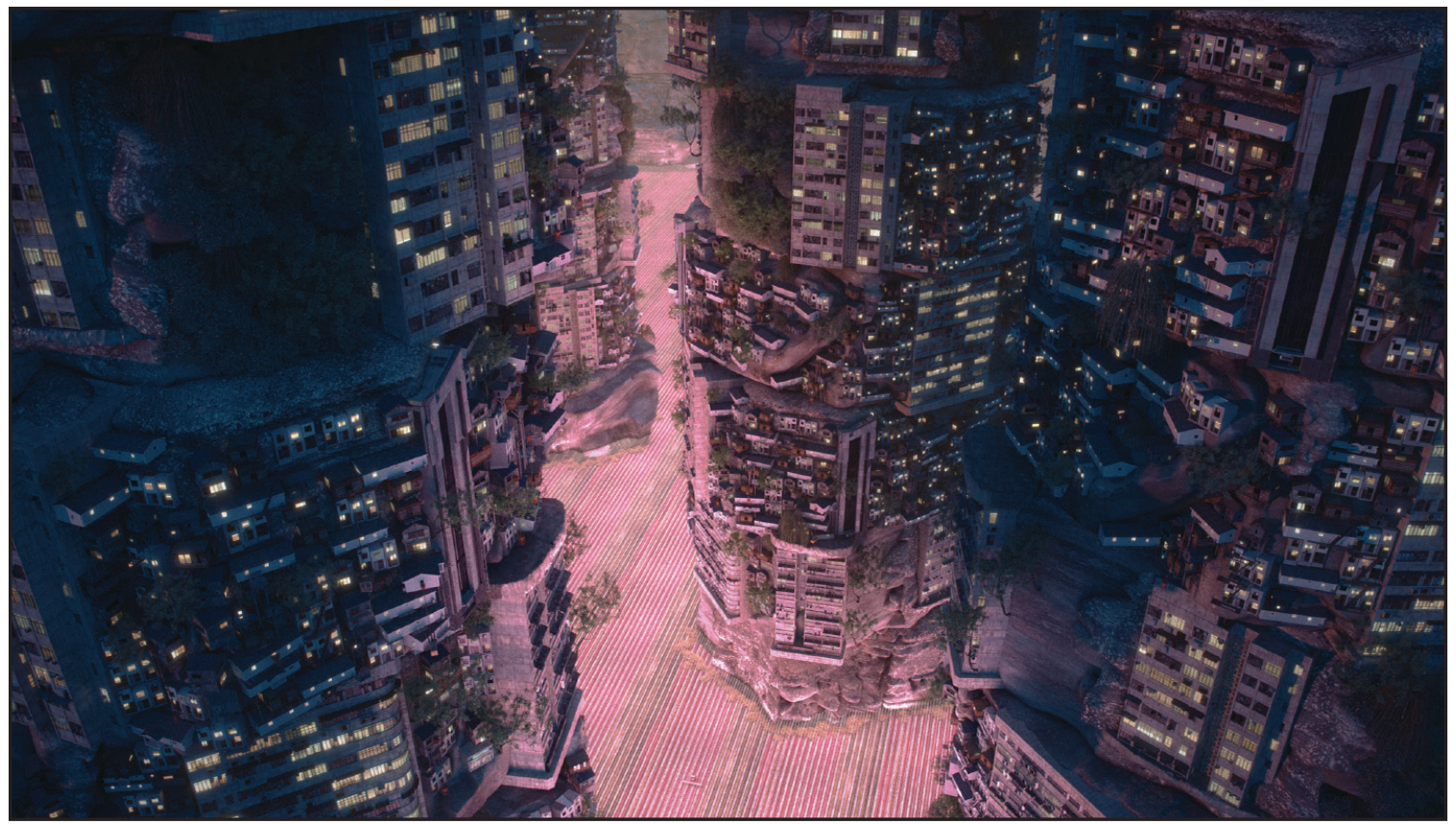

Fig. 45 Still from the short film, 'Planet City' (2020). Liam Young 
are almost hiding in plain sight. They're so familiar that we can't get any critical distance through which to look back in on them."18 For Young, film offers an opportunity to step back and gain that necessary distance and uncover new perspectives. Planet City, which is currently on exhibit at the National Gallery of Victoria's Triennial, takes this approach, toeing the same line between plausibility and impossibility that characterizes the work of Archigram and the worlds of Disney and Pixar films.

Planet City is "a fiction shaped like a city."19 It is Liam Young's answer to "centuries of colonisation, globalisation and never-ending economic extraction and expansionism;"20 a global reversal of human sprawl into one ultra-dense metropolis designed to house the entire population of the Earth in the space of an average US State leaving the remaining $99.98 \%$ of the planet to become wilderness once again. ${ }^{21}$ Working with a team of international environmental

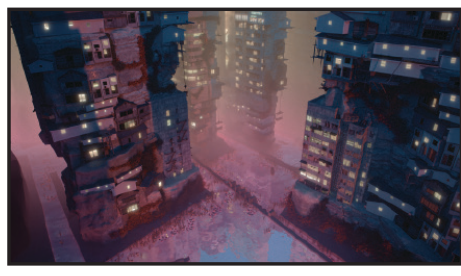
scientists and theorists, Young has designed a work of speculation which "provides a window into an alternative urban future that has been created as an antidote to the climate crisis."22 Operating as a closed-loop and generating

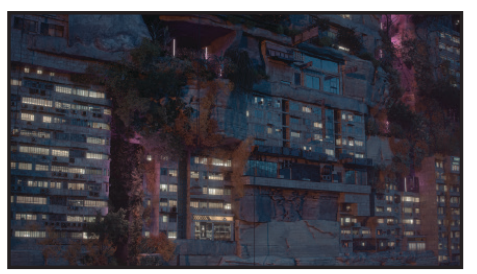
zero waste, Planet City boasts "221,367 square kilometres of buildings up to 165 storeys tall and 4,311,543, 982 bicycles. Power would come from 49,445,671,570 solar panels

Fig. $46-47$ Stills from the short film, 'Planet City' (2020), Liam Young while 2357 algae farms would filter pollution and provide supplementary food."23 Although a work of speculative 
fiction and not an executable proposal, Young maintains that Planet City uses only technologies that already exist or are in development, stressing that "climate change is no longer a technological problem, but rather an ideological one, rooted in culture and politics." 24

The short film in which Planet City is presented follows an unbroken global festival that moves through the metropolis, catching up with celebrations held by unique cultures throughout the year, each one bleeding into the next. ${ }^{25}$ Young's project extends beyond environmental reaction. It is also a social proposal, uniting the world in a common purpose and celebrating the uniqueness of culture. It is a break from what he calls 'neo-colonialist' masterplans which only perpetuate the same inequality and exclusion that reinforces existing systems of power which created the current environmental crisis in the first place. ${ }^{26}$ With Planet City, Liam Young uses the technological freedom of animation, and the engaging power of narrative to study the spatial potentialities of environmental stewardship and social sustainability in the context of an imagined future condition. It is "Simultaneously an extraordinary image of tomorrow and an urgent examination of the environmental questions facing us today."27 As such, Planet City is a compelling example of an architect exploiting the capability of animation (the concept) to explore relationships of space, place, and technology. My thesis however, considers character- 
driven animated film as an autonomous narrative art form,

not driven by architectural inquiry, yet viable as such

nonetheless.

\author{
1.5 A Tale of Two Cities Endnotes \\ Young, Liam. "Planet City" Liam Young. https://liamyoung.org/project/planet-city \\ Sadler, Simon. Archigram: Architecture without Architecture. Cambridge, MA: MIT Press, 2005. p. 11 \\ Sadler, Simon. Archigram: Architecture without Architecture. Cambridge, MA: MIT Press, 2005. p. 5 \\ Sadler, Simon. Archigram: Architecture without Architecture. Cambridge, MA: MIT Press, 2005. p. 5 \\ Sadler, Simon. Archigram: Architecture without Architecture. Cambridge, MA: MIT Press, 2005. p. 5 \\ Sadler, Simon. Archigram: Architecture without Architecture. Cambridge, MA: MIT Press, 2005. p. 3 \\ Archigram. "Amazing Archigram 4: Zoom Issue," May 1964. \\ Olóriz, Clara, and Koldo Lus Arana. "Amazing Archigram!" Mas Context, no. 20 (2013): 48-61. https://www. \\ mascontext.com/issues/20-narrative-winter-13/amazing-archigram/. \\ 9 Sadler, Simon. Archigram: Architecture without Architecture. Cambridge, MA: MIT Press, 2005. p. 14 \\ 10 Sadler, Simon. Archigram: Architecture without Architecture. Cambridge, MA: MIT Press, 2005. p. 14 \\ 11 Sadler, Simon. Archigram: Architecture without Architecture. Cambridge, MA: MIT Press, 2005. p. 12 \\ 12 Sadler, Simon. Archigram: Architecture without Architecture. Cambridge, MA: MIT Press, 2005. p. 14 \\ 13 Sadler, Simon. Archigram: Architecture without Architecture. Cambridge, MA: MIT Press, 2005. p. 5 \\ 14 Archigram. "Amazing Archigram 4: Zoom Issue," May 1964 \\ 15 MacDonald, Fiona. "Liam Young: The Man Designing Our Futures." BBC, December 18, 2019. \\ 16 "Liam Young - Tomorrow's Thoughts Today." WIA - What is architecture? Accessed May 23, 2021. https://olaf- \\ grawert.squarespace.com/liam-young-los-angeles-2018. \\ 17 MacDonald, Fiona. "Liam Young: The Man Designing Our Futures." BBC, December 18, 2019. \\ 18 MacDonald, Fiona. "Liam Young: The Man Designing Our Futures." BBC, December 18, 2019. \\ 19 Young, Liam. "Planet City" Liam Young. https://liamyoung.org/project/planet-city \\ 20 Young, Liam. "Planet City" Liam Young. https://liamyoung.org/project/planet-city \\ 21 Fairs, Marcus. "Liam Young's 'Planet City' Could Tackle Climate Change by Housing 10 Billion People in a Single \\ Metropolis." Dezeen, January 6, 2021. https://www.dezeen.com/2021/01/06/liam-young-planet-city-climate- \\ change-10-billion-people-metropolis/. \\ 22 "Liam Young Planet City." NGV. National Gallery of Victoria. Accessed May 23, 2021. https://www.ngv.vic.gov.au/ \\ liam-young-planet-city/. \\ 23 Fairs, Marcus. "Liam Young's 'Planet City' Could Tackle Climate Change by Housing 10 Billion People in a Single \\ Metropolis." Dezeen, January 6, 2021. https://www.dezeen.com/2021/01/06/liam-young-planet-city-climate- \\ change-10-billion-people-metropolis/. \\ Fairs, Marcus. "Liam Young's 'Planet City' Could Tackle Climate Change by Housing 10 Billion People in a Single \\ Metropolis." Dezeen, January 6, 2021. https://www.dezeen.com/2021/01/06/liam-young-planet-city-climate- \\ change-10-billion-people-metropolis/.


PART TWO

LET'S GO TO THE MOVIES! 


\subsection{EVERYTHING'S A REBOOT THESE DAYS}

Beginning with the landmark Snow White and the Seven Dwarfs in 1937, Walt Disney Animation built their entertainment empire by adapting traditional fairytales like Cinderella (1950) and The Little Mermaid (1989). These films promote "a range of fundamental notions and ideals ... [like] universal love, good conquering evil, and simple happy endings."11 Rarely do these films address more deeply meaningful or mature themes in any substantial way. This began to change in the mid-1990s with the release of The Lion King (1994). This film represents a watershed moment in the history of Disney Animation feature films, marking a shift in the kinds of stories they tell and the narrative themes they employ. The first major break from tradition is that The Lion King is the first Disney Animated film to be based on an original story, allowing the animators and story artists 
more narrative flexibility in order to convey the desired messages. More significantly, The Lion King is the first of Disney's animated films to address death in a deeper way, touching on grief and survivor's guilt. Another breakthrough is the presence of environmental stewardship at the core of the narrative. This shift away from traditional fairytales towards original stories with more socially conscious themes represents a maturation of the Disney brand and coincided with a greater social reawakening happening in the 1990s.

The dilemmas that inspired the visionary architecture of the 1960s - namely environmental stewardship, social sustainability, and self-actualization/self-transcendence would not attain such widespread awareness and popularity again until the 1990s. In many ways, the last decade of the twentieth century mirrored the Swingin' Sixties. The decade began with the celebration of "Earth Day 1990," where, "two decades after the birth of the modern environmental movement, millions of people around the nation and the world renewed the call to arms for an endangered planet."2 The coordinated global event became "the largest grassroots demonstration in history."3 That same year saw the introduction of two new environmental policies in the US; the Oil Pollution Act and the Clean Air Act. ${ }^{4}$ Social sustainability had also found new resonance in the 1990s in the lyrics of political hip hop. In place of 1960s icons like Bob Dylan and Jimi Hendrix, the 1990s had Tupac Shakur and N.W.A. 
giving voice to continuing social inequalities of the day. This was also an era when global citizenry resurfaced again in response to "new technologies of communication [as well as] the global nature of threats posed to the survival of the human race and of the planet by nuclear and chemical weapons and environmental degradation, and [to] the trend towards a global economy."

The reignited social consciousness of the 1990s established real-world issues around which Disney and Pixar would begin to craft their films. While I have identified The Lion King as a seminal film in the Disney canon, this does not mean that every Disney film released after 1994 contained a deeper social or environmental imperative. Rather, The Lion King was a first step into a realm that Disney would not fully inhabit for more than a decade. Pixar Studios, however, deliberately built their brand on the idea that "animated feature could eschew fairy-tale plots and instead focus on adult like characters with adult like problems." ${ }^{\prime 6}$ After the landmark success of Toy Story validated their convictions, Pixar Studios has continued to explore the common humanity in their characters, delving deeper into the human mind, heart, and soul, and challenging its viewers to carefully consider the world around them.

Pixar's partnership with Disney since the mid-1990s proved to be a boon for both studios; Pixar's association with Disney helped establish themselves as an equally 
trust-worthy brand of family entertainment, and Disney benefitted from the commercial success of Pixar's films through the early 2000s when the Disney Studio seemed to be going through a commercial drought. The young computer animation studio had a spotless record of six hit films including a sequel to Toy Story (1999), as well as the now classic Monsters, Inc. (2001) and Finding Nemo (2003). Conscious of the import the Pixar brand now had on the Disney organization, in 2006 Walt Disney Studios finalized the acquisition of Pixar Studios. Both studios continued to operate independent of each other, with Pixar co-founder Ed Catmull becoming President of both. John Lasseter became Chief Creative Officer. ${ }^{7}$ Under the creative direction of Lasseter, Disney's films began to edge towards the Pixar approach of telling non-traditional stories addressing modern, non-traditional ideals. Today, Disney and Pixar continue to respond to the fraught social climate of America and the world at large. In recent years the public push for racial and gender representation has led to films such as Pixar's Coco (2018) and Soul (2020), and Disney's Moana (2016) and Raya and the Last Dragon (2021). 


\subsection{NOW PLAYING: THE LION KING, WALL·E, UP, AND ZOOTOPIA}

In the following section I analyze four animated films

from Walt Disney Animation Studios and Pixar Animation

Studios: The Lion King, Wall-E, Up, and Zootopia. Since

1937, Walt Disney Animation Studios has produced fifty-

nine feature films. Pixar Animation Studios has added

another twenty-three. Presented with eighty-two films

to choose from, I used the context surrounding The Lion

King, discussed in the previous chapter, to limit the scope

to films produced after 1994. Having seen all of these films

before, I was familiar enough with their general narratives

and plot lines to assess which ones would provide the most

fruitful analyses. I therefore compiled a shortlist of the films I

believe address issues of either environmental stewardship

or social sustainability. Upon rewatching those films I was 
able to narrow the list down to these four films, which I then watched again with a more critical lens. They are used to consider environmental stewardship and social sustainability as links between the narrative themes of animated films, and urgent concerns relevant to the built environment. I was specifically interested in how these spaces impacted the narratives of the film or contributed to the underlying environmental or social messaging.

Once I had selected the final four films, I began to develop a concept for my own story which I see as a bridge between visionary architecture and characterdriven animated film. The piers for such a bridge are

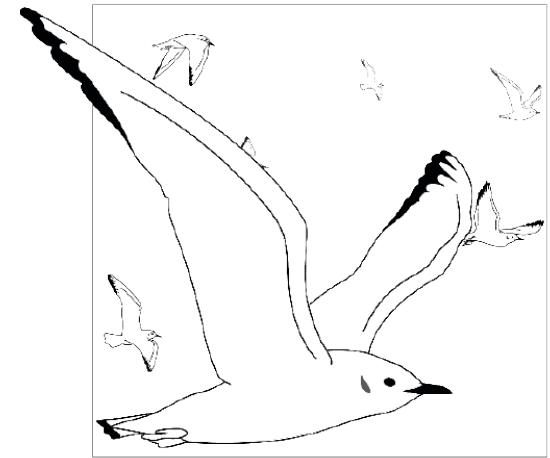

Fig. 48 Meet Ollie in 'Gull Story'

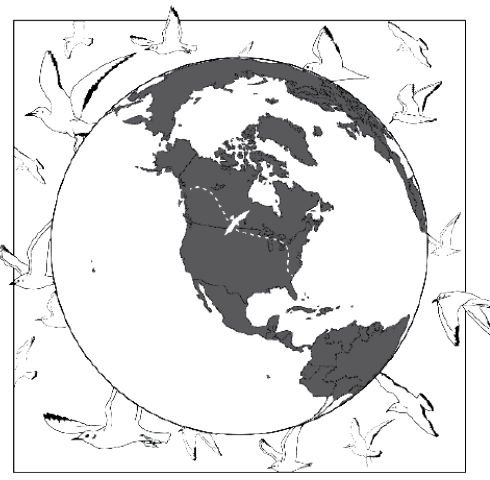

Fig. 49

The migratory journey of Bonaparte's Gulls already established: both endeavours use the concept of the plausible impossible to communicate serious ideas or intentions. The goal with my story is to use the characterdriven narrative style of a Disney film, to address a real-world issue which can be impacted by architecture. The result is a series of vignettes, in the manner of a loose storyboard, each exploring the various lessons I was able to identify in the various films. Gull Story follows a young Bonaparte's Gull named Ollie ${ }^{8}$ on his first migration south. [Fig. 48] On the journey from the northernmost parts of North America to the

South-East coast of the United States hundreds of thousands of gulls spend a portion of their journey migrating along the Niagara River Corridor, between Lake Erie and Lake Ontario. [Fig. 49] Due to this annual migration, the Corridor 
has been designated as a "Globally Significant Important Bird Area." ${ }^{\prime 9}$ Unfortunately, the Corridor is at risk due to water contamination from industry and continuing development on the riverbanks.10 Through Gull Story I begin to explore how these issues of environmental stewardship and correlating issues of social sustainability might be presented in a way that informs while entertaining, as well as offer moments for architects to reflect on real-world design problems.

While I have made every attempt to remain objective in my analysis of these films, it would be irresponsible to claim neutrality. Therefore, the assumptions, interpretations, and conclusions I make in the following section should be understood simply as my unique experience with these films. Each viewer who seeks to critically analyze any of these films in a similar way will inevitably draw differing conclusions than my own, based on their own experience. Rather than making unequivocal generalizations, the goal of these analyses is to illustrate the potential these films hold to generate meaningful and critical discussion in the architectural field. 


\section{THE LION KING I DISNEY, 1994}

In this thesis, for the sake of analytical efficiency,

I have identified two separate architectural dilemmas to explore through animated film, however real world conditions are rarely so decisively categorized. Such is the case with Disney's The Lion King. Set against the backdrop of the Serengeti, The Lion King can be understood as a study of the delicate balances that exist in our environments, both natural and social. These lessons are shown through plausible impossible contrasts; the first half of the film demonstrating how effective environmental stewardship and social sustainability both support the other to foster a productive community, and the second half of the film starkly expositioning the fragility of that system. Beneath the colourful musical numbers and Shakespearean drama, The Lion King offers a case study of the complex intersections of

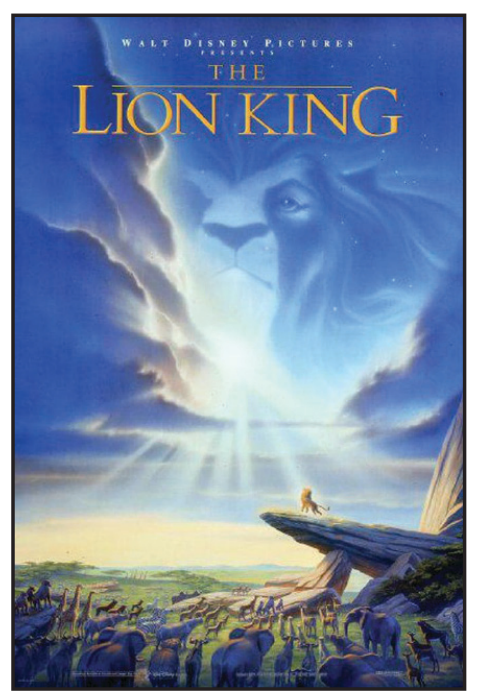

Fig. 50

'The Lion King' poster, 1994 environmental stewardship and social sustainability.

Whenever one engages critically with a film such as The Lion King, in which the narrative is set within a specific cultural context and features characters which at best caricature and at worst stereotype people of certain cultures, it is important to recognize that there are many viewers for which the film is not an inspiration, but an affront and an offense. Of particular concern in The Lion King is the appropriation of African culture, both within the film and surrounding its production and marketing, 
exemplified by Disney's trademarking of the traditional Swahili phrase "Hakuna Matata."11 Although the story is original, the film benefits from a strong influence of African culture - including traditional phrases and musical motifs - and a common Western falsity that Africa is a wild and unhistorical place.12 These are important discussions to have regarding how seemingly innocuous children's films may intentionally or unconsciously reinforce negative stereotypes about different cultures. These critiques do not, however, preclude such films from other meaningful discussion. My analysis of the film which follows, is not intended to diminish or ignore those critiques, rather it is an attempt to highlight opportunities for architectural discourse present in the narrative of the film.

The Lion King follows the story of Simba, a young lion who must embrace his role as the rightful King and restore his homeland to its former glory. The film begins with Simba as a young cub, curious about the world and desperate to live up to his father, the benevolent King Mufasa. Under the tutelage of his father, Simba learns what it means to be King of the Pride Lands. His lessons come to a premature end however, when Simba's villainous uncle Scar launches a murderous coup d'état with his hyena accomplices. The plot is only half successful however, leaving Mufasa dead and Simba exiled from the Pride Lands, believing himself to be responsible for his father's death. Simba spends the 
next several years living "problem-free" in a jungle oasis, neglecting his family, his home, and his kingdom. Meanwhile, Scar has assumed the throne, allowing the hyenas to overrun the Pride Lands. It is not long before the hyenas have over-hunted the plains, decimating the local ecosystem and driving the game herds away. After some convincing from an old friend, and a visit from Mufasa's ghost, Simba resolves to return to the Pride Lands and challenge his uncle for the throne. During the ensuing battle Scar reveals that he murdered Mufasa, freeing Simba from the burden of guilt which had consumed him for years. The battle ends in triumph for Simba, as Scar gets his comeuppance from his former allies the hyenas, whom he had subsequently blamed for the decimation of the Pride Lands. A rejuvenating rainfall washes away the detritus of Scar's failed occupation of Pride Rock, and the Pride Lands are returned to their former lush and vibrant state. The film ends as it began, with all the animals of the kingdom rejoicing in the presentation of the newborn heir to the throne. ${ }^{13}$

A prominent theme of The Lion King is the philosophy of "the circle of life," an idealistic notion which constitutes the central belief system and governing style of King Mufasa. It is most explicitly defined by Mufasa during Simba's first tour of the Pride Lands:

"Everything you see exists together in a delicate balance. As King you need to understand that balance and respect 
all the creatures - from the crawling ant to the leaping antelope...When we die, our bodies become the grass, and the antelope eat the grass. And so, we are all connected in the great circle of life."14

The environmental lesson of The Lion King is clear: respect nature and be stewards of the Earth. However, by telling this story with anthropomorphic animals, Disney has imbued the film with a second, social lesson: respect your neighbour and foster a sustainable community. Had Disney chosen to make "The Human King," this social implication would have been lost on an audience that considers themselves (humans) as separate or other from the animal kingdom. It is by replacing humans with anthropomorphic animal characters - a staple of Disney's plausible impossible - that we are able to bypass that common hubris and understand the social implications as well as the environmental, and how interrelated those two issues truly are.

The 'circle of life' lesson espoused by Mufasa at the start of the film and its constituent implications on environmental stewardship and social sustainability are reinforced in the film through both positive and negative example. In the following section I examine the reigns of Mufasa and Scar to contrast how each ruler's understanding and adherence to the circle of life philosophy impacts the kingdom of the Pride Lands, drawing attention to the 
need for a more nuanced understanding of environmental stewardship and social sustainability.

The Pride Lands under Mufasa are a lush, active, tranquil socio-ecological system. This can be attributed to Mufasa's deference to the circle of life. His protection of the circle of life amounts to a commitment to sustainability in the Pride Lands. Mufasa fiercely defends his kingdom from those who would exploit its vitality for immediate satisfaction to the detriment of later survival, namely the hyenas who have been banished to the Outlands for hunting in excess of their need. Save for those who eschew the circle of life, all animals are welcome in the Pride Lands where, so long as the circle of life is maintained, they are guaranteed a good quality of life. As a ruler, Mufasa has a respect for his people, seeing them as interconnected to each other and himself in the circle of life. While the title of King precludes the Pride Lands from exhibiting true equality, Mufasa acknowledges a sort of cosmic equality; an equality in death as all beings rejoin the circle of life. Mufasa is seen as a figure to be admired and respected, as a steward of the Pride Lands sure of his place in the circle of life. Under his leadership the Pride Lands flourish, proving to be both environmentally and social sustainable.

From the outset of his reign, Scar makes clear his indifference towards the circle of life, giving the hyenas freerein over the Pride Lands in return for their loyalty. Driven 
by vanity and jealousy rather than some sense of greater purpose, Scar becomes a reclusive tyrant, ruling from within the caves of Pride Rock and displaying nothing but contempt for those he believes are beneath him. Without the oversight of Mufasa, the hyenas begin hunting well beyond their needs, driving the quality of life in the Pride Lands down, eventually leading the remaining herds to migrate out of their reach. The once vibrant Pride Lands had been decimated by pride and greed; the grasslands withered, the river dried up, and the trees stripped bare. The circle of life had been broken. Scar's reign is characterized by indifference and neglect, resulting in a community that is neither environmentally nor socially sustainable.

Issues of social sustainability and environmental stewardship are more urgent now than perhaps ever before. As architects it is vital that we understand what each of these mean in the context of our communities as well as how they affect each other. The plausible impossible animal kingdom of The Lion King offers architects the opportunity to rethink/reasses our understanding of environmental stewardship and social sustainability on the whole, and to reconsider our relationship as humans to the animal world. This is the lesson I emphasize in Gull Story: that animal welfare is not disconnected from humanity but is in fact intrinsically bound up with human activity.

When trying to conceive a plot for my own 


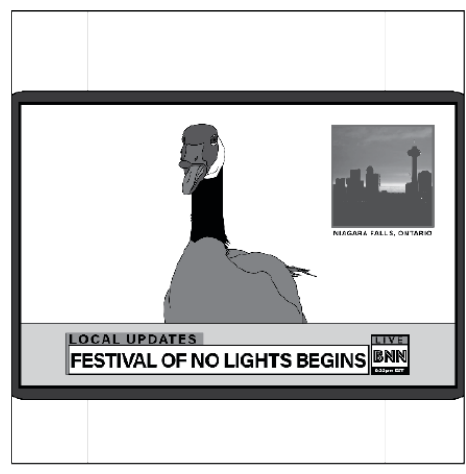

"IN OTHER NEWS, TODAY IS THE FIRST DAY OF THE FESTIVAL OF NO LIGHTS, AN ANNUAL PROGRAM TYPICALLY A CAUSE FOR CEELDRATION IN THE AVIAN

COMMUNITY SOME EXPERTS ARE SAYING THE

HUMANS ARE NOT DONG ENOUGH."

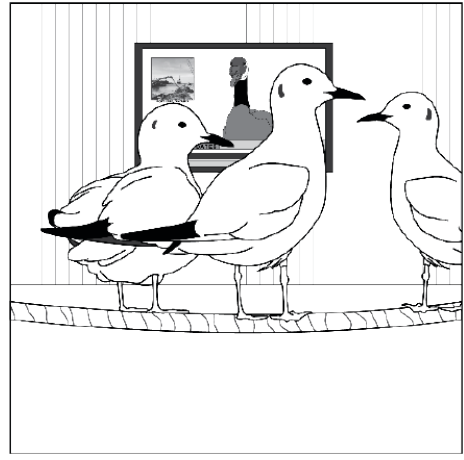

"WHAT'S THE FESTIVAL OF NO LIGHTS?" "WELL OLLIE, ITS A MONTH-LONG FESTIVAL HERE IN NIAGARA, WHEN ALL THE HUMANS IN THE CITILS
ALONG THE RIVER DOUSE THEIR ARTIFICIAL LIGHTS FROM DUSK TIL DAWN."

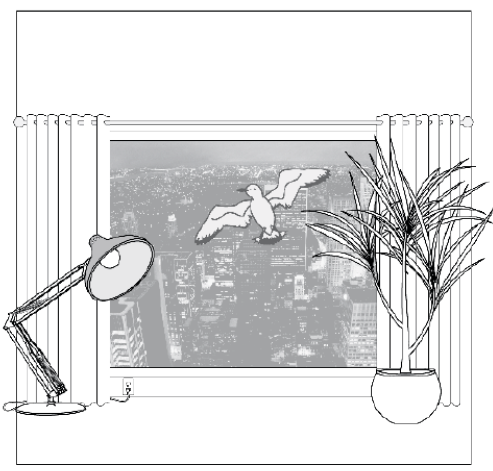

"THAT WAY, POOR CONFUSED BIRDS LIKE YOURSELF DON'T GET DISORIENTED BY THE LIGHTS AND FIND THEMSEVVES FLYING 25KM/H INTO A PLATE-GLASS WINDOW. WE'VE LOST TOO MANY GOOD GULLS

Fig. 51-53

Ollie learns about the 'Festival of No Lights' experiment in character-driven storytelling based on gulls in the Niagara River Corridor, I was interested in creating a situation in which humans consistently play an active role in the stewardship of the river environment, rather than an explicitly infrastructural or technological solution. The intention is to suggest an opportunity for people to realize that we should live in communion with the natural world rather than in domination of it. I began to consider what that community might look like, what events might take place, and how would the gulls respond? [Fig's, 51-53] More a lesson of ideology or philosophy than a practicable one, it challenges architects to recontextualize our relationship to the natural environment which we are designing buildings within. Rather than consider conservation and protection of species on building sites as obstacles to overcome, we may embrace the opportunity to build a socially sustainable community with the environment.

community with the environment. 


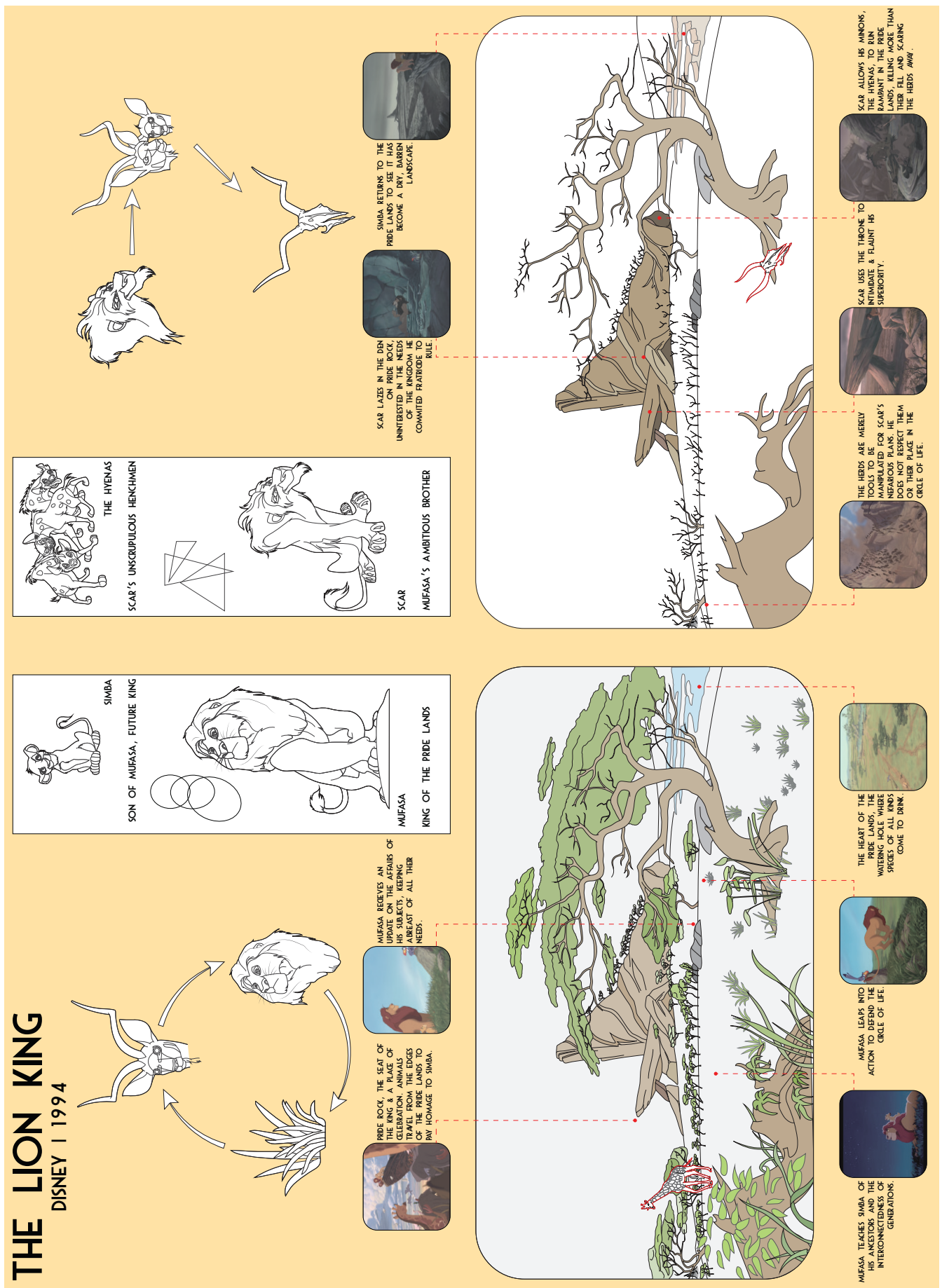

Fig. 54

Illustrative analysis of Disney's 'The Lion King'

ơ 


\section{WALL-E I PIXAR，2008}

What might the future look like if we continue on our present course? After the Second World War, the future was anticipated with optimism and hope as technological progress and economic prosperity promised endless possibilities. Flying cars and smart appliances would make everyday life easier for all. The future was something to look forward to. Contemporary speculations, however, of what the future might hold for humankind are less optimistic and increasingly apocalyptic. The future is not what it used to be. In the following section, I examine the themes of environmental stewardship and self-actualization in Pixar Studio's 2008 film WALL.E in order to show how architects might respond to these urgent crises.

The production design and narrative of WALL.E is an exercise in world-building. Within the first five minutes

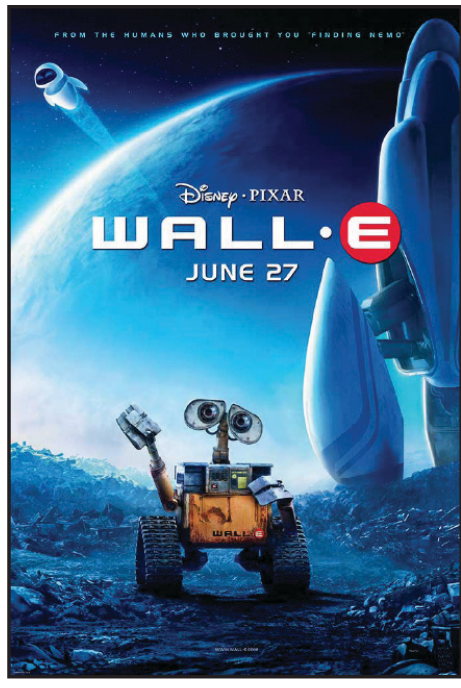

Fig. 55

'WALL:E' poster, 2008 of the film, the audience is introduced to the protagonist, WALL.E, the world he inhabits and its history. The film takes place, in part, on Earth sometime in the future. The planet is surrounded in a dense layer of space junk, and the atmosphere is shrouded in a heavy, tinted smog. The cycle of human consumption and waste disposal has left the surface of the world literally buried under mountains of litter. Familiar metropolitan skylines are cluttered by looming towers of compressed trash. The face of this man-made disaster is Buy N Large (BNL), a global corporation which has monopolized 
every industry in every corner of the world and has assumed governmental control over the planet. The culture and economy of consumption incited by BNL triggered a global emergency, forcing humans to evacuate the Earth for a five-year period during which "Operation Clean-Up" would restore the Earth to a hospitable state. Seven hundred years later, the human race continues to self-exile in space, blissfully ignorant of the cataclysmic failure of their ancestors on Earth.

Environmental stewardship is a tripartite concept, equally emphasizing the principles of protection, restoration, and sustainability. No single action can wholly address the current environmental crisis. In WALL.E, we see a society which irresponsibly neglected protection and especially sustainability, and by the time they realize the need for restoration, the devastation had gone too far. It is not likely that we will ever see towers of neatly compacted trash soaring high above even our tallest skyscrapers, however it would be remiss to suggest it is an impossibility. It is this remarkable plausibility which renders the opening moments of WALL.E so powerful. The poignant imagery is a stark reminder of the threat we pose to ourselves and to the delicate ecosystems of the planet.

Whereas WALL.E demonstrates the implications of a belated technological response to a failure of environmental stewardship, with Gull Story I sought to explore what a 
more proactive technological response would look like.

Still driven by a desire to dissolve the perceived division between the human and animal world, I decided to have people intervene directly in the migration of the gulls.

To compensate for the reduction of river-bank habitat, a river-cruise will ferry gulls along the river from Lake Erie to Ontario, captained by a human who dedicates months of the year in stewardship of the boat. Furthermore, it also serves to remediate the Niagara River. Powered by the sun, the boat filters water from the river, filling all the on-board pools and returning the surplus back into the river. The strength of WALL.E's opening is in its subversion of expectations.

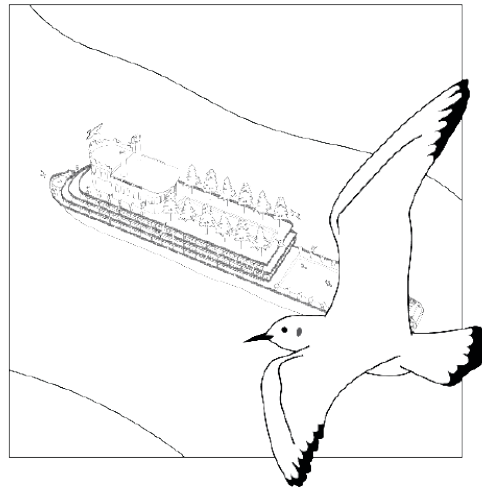
The skyline images trigger in us a memory of the skylines we've seen, and we subconsciously begin to imagine what those skyscrapers might look like beyond the smog. When suddenly it is revealed that they are not skyscrapers at all, but towering piles of trash, our preconceived notions are shattered, engaging our curiosity to find out 'what happened

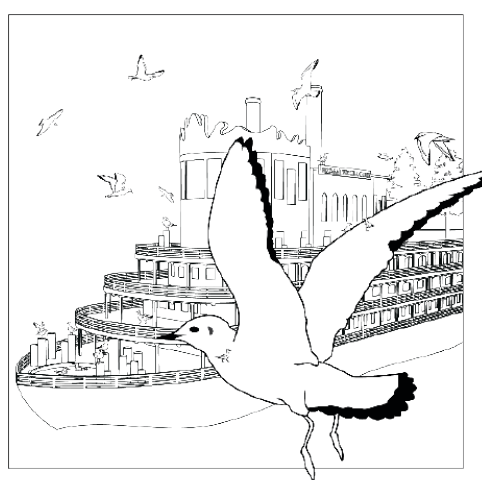
here.' This was a technique I adapted for my own story. The riverboat at first appears to be just that - an ordinary riverboat. The sudden revelation that it is in fact an exclusive gull cruise takes the viewer by surprise, opening them up to the possibilities the narrative offers. [Fig's, 56-57] The idea of a river-cruise specially designed for gulls is the plausible

Fig. 56-57 Ollie finds the Niagara River Gull Cruise impossibility at the heart of Gull Story, from which we can investigate the relationships between gulls and each other, 
gulls and humans, gulls and the boat, and the boat and the surrounding environment. From there we can refocus the lens on real-world practice to reexamine how we think about environmental stewardship and social sustainability, not as two disparate challenges but as interconnected opportunities for better design.

Self-actualization is a difficult condition to define, as it looks different for each individual. It is an equally difficult condition to achieve, and so for many it remains an ongoing process. As members of the architectural profession which is so concerned with human behaviour and experience, it is important to understand the implications of an individual's space on their pursuit of self-actualization. WALL.E - the film - uses the plausible impossible to fill WALL.E - the robot - with personality and give him a human spirit. This film about a robot is in fact an insightful examination of what it is to be human: to be lonely, to feel loved, to build community, hold accountability, and have independent agency.

At the start of the film, Earth remains completely uninhabited, save for WALL.E, the only remaining agent of "Operation Clean-Up." WALL.E is the architect and builder of those monumental towers of refuse which dominate the cityscape. He was designed and programmed to clean up the detritus of human consumption, compress it into cubes and make piles. He has been dutifully carrying out 
his directive for centuries, long after all his fellow robots fell into disrepair. After seven hundred years of sifting through the sad legacy of human existence, WALL-E has suffered a sort of glitch - he has developed a human personality. He is very curious, examining anything which he finds interesting and saving them in a plastic cooler for his collection. Back inside the truck he calls home, WALL-E has thousands of knick-knacks filling the shelves (WALL-E docking stations). He has a cup full of spoons and one full of forks, teddy bears and pylons, dozens of lighters and ring boxes. He has a pile of car batteries which he uses to power the strings of twinkle lights he has hung from the ceiling. And he has a VHS copy of Hello Dolly, from which he learned how to dance, how to sing, and how to hold hands. WALL.E has surrounded himself with the objects that inspire awe and wonder in him. Despite fulfilling his programming and dutifully collecting trash for seven hundred years, you get the sense that WALL.E feels like he is capable of so much more, he just does not know what. The space he creates for himself is one in which he can explore the possibilities and feel inspired to dream.

Architect's often endeavour to produce a design which inspires one to make a small difference in one's corner of the world. To believe in the possibility of tomorrow. To dream. These things may be accomplished through architecture, but need not be limited to the monumental. 
$W A L L \cdot E$ is a reminder that inspiration, self-actualization, begins at home. This is a concept I was able to adapt into the story of Ollie, aboard the Niagara River Gull Cruise. When Ollie first arrives on the boat, he is quite alone and unsure of

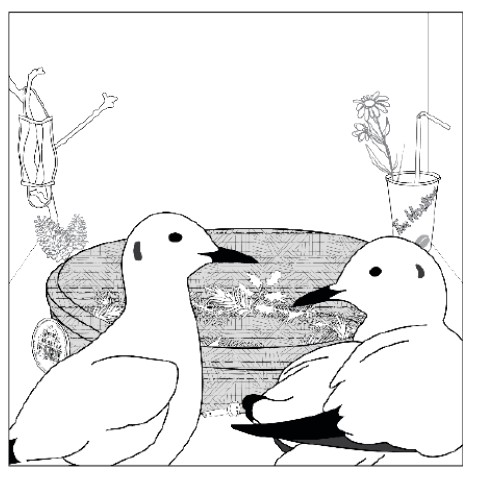

Fig. 58 Frank shows Ollie his cabin

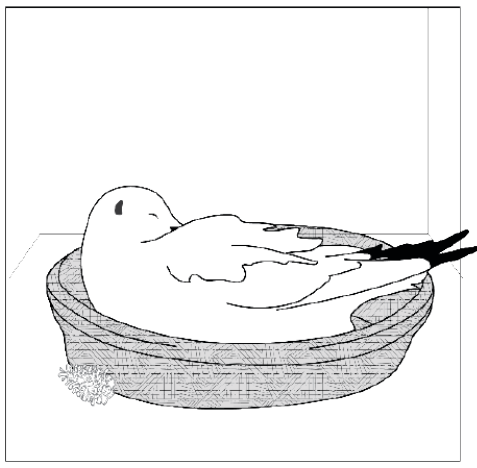

Fig. 59

Ollie begins decorating his cabin where he is going. It isn't until he meets Frank, a one-year older gull, that Ollie begins to feel a little bit at ease. Frank tours Ollie around the boat before taking him to his own cabin which he has already decorated with knick-knacks and assorted treasures he's found on his flights into towns along the river. [Fig. 58] With this collection filling the cabin, it feels comfortable and homey. Ollie finds a cabin a few down from Frank, and when he goes to sleep that night he finds a pine-cone from Frank's collection there on the floor. Ollie falls asleep that night happy to have a friend and excited to decorate his own space. [Fig. 59] By the end of the journey on the boat, his cabin is full of little treasures, each one with a memory attached. When he takes off for the south, Ollie knows that when he returns for the journey north his cabin will be there, full of his memories. 

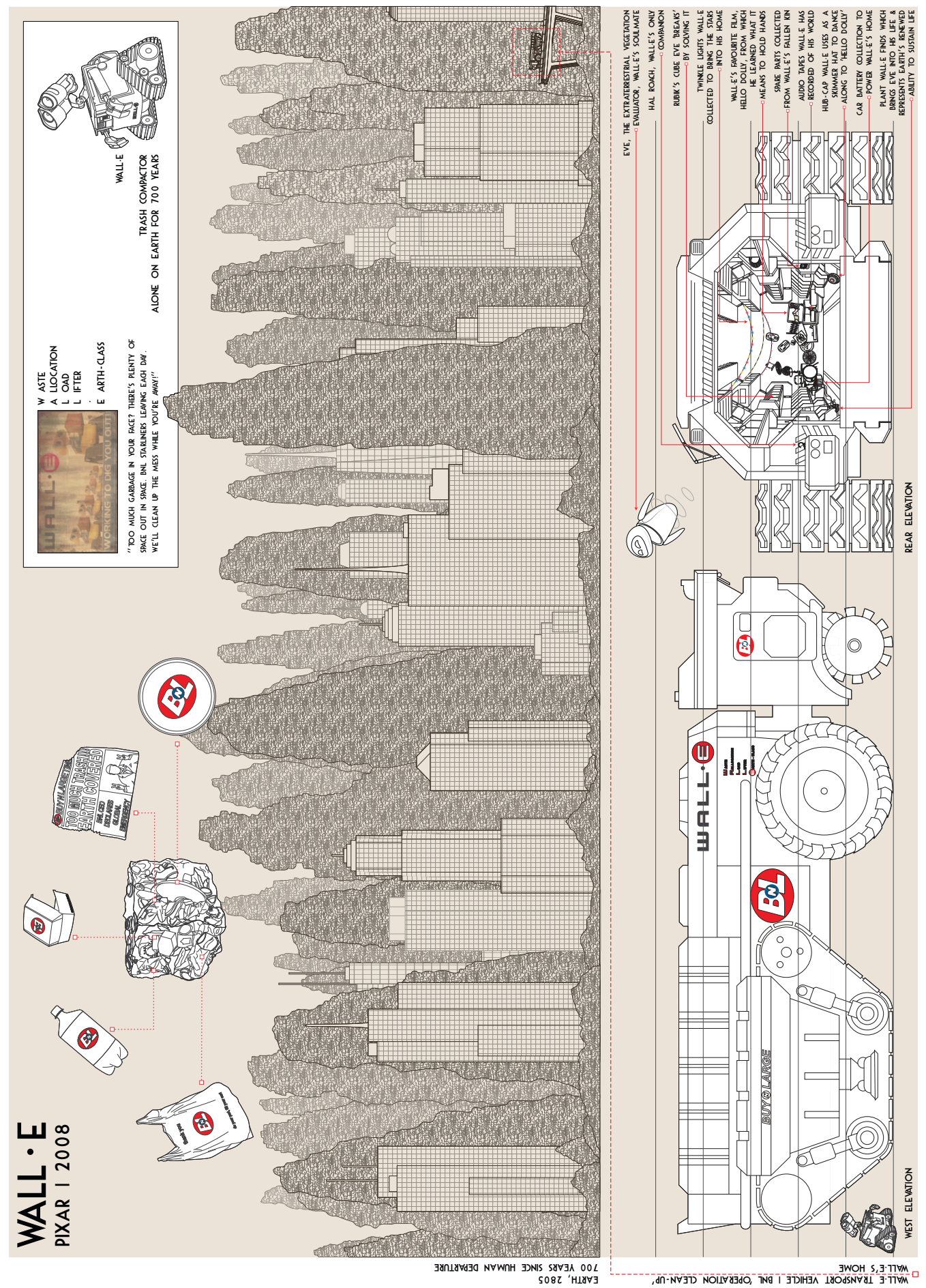

Fig. 60

Illustrative analysis of Pixar's 'WALL-E' 


\section{UP I PIXAR, 2009}

When does a house stop being a house and become a home? And when does a home become something more? Pixar Studio's 2009 film, Up, is a colourful adventure story in which a lonely widower endeavours to fulfill a lifelong promise made to his departed wife: to build their house on the precipice of Paradise Falls in South America. With the unwelcome assistance of Russell, the young Wilderness Explorer, Carl Fredricksen successfully flies his house to Venezuela, tied to thousands of helium-filled balloons. It is a heartwarming story full of wonder, action, and tension. Stripped of the fantastically impossible balloons and the talking dog, Up is a profound commentary on identity. In particular, the role architecture has in defining our own identities and in supporting our self-actualization.

The story of Up centers on three main protagonists,

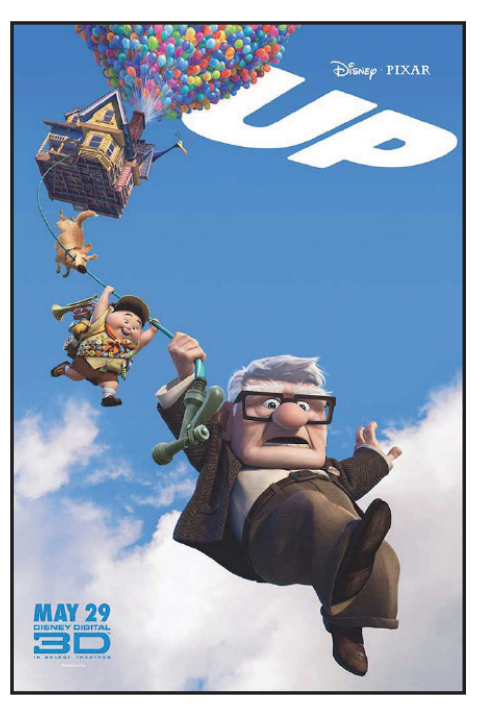

Fig. 61

'Up' poster, 2009
Carl Fredricksen, his wife Ellie, and their house. We are introduced to all three at virtually the same moment. A young Carl, aspiring adventurer donning a pilots helmet and goggles, runs down the street carrying a balloon on a string, imagining it is the dirigible of his hero, "The Spirit of Adventure." As he runs past an abandoned house in a state of disrepair he hears the voice of a young girl shouting from within. Carl is shy, but the words "Spirit of Adventure" painted on what was left of the front door compelled him to go inside. This is how Carl met Ellie, who was wearing the 
same goggles and helmet as he was. Carl's shyness was contrasted in equal measure by Ellie's exuberance. That night, when Ellie returned Carl's balloon to him (he had lost it in the rafters of her clubhouse), she initiated him into her club. She showed him her scrapbook full of newspaper articles and magazine spreads covering their hero's exploits in South America and unveiled to him her plan for the future. She was going to fly her clubhouse to Venezuela and live on the edge of Paradise Falls, and she made Carl promise to take them there.

In time, Carl and Ellie get married and move into that old abandoned house. Together they fix it up and paint it according to the drawing Ellie had in her scrapbook, green, yellow, and lots of magenta - Ellie's favourite colour. Inside the house is furnished with an eclectic mix of furniture, some conforming to Carl's more subdued and shy personality, and others expressing Ellie's outgoing nature. They fill walls with pictures of their times together and the shelves with knickknacks, each holding some special memory to them. All of this happens in the span of a few minutes at the opening of the film, establishing the house as an extension Carl and Ellie's relationship; a physical manifestation of their individual and collective identities and a symbol of their shared hopes and dreams.

Up is a testament to the capability of animation to develop a story which exaggerates the real human 
experience in order to develop compelling characters and elicit a strong emotional response to the story. We, the audience, can see the house becoming Carl and Ellie's not because we see them sign the deed, but because we see them transfer their own identities into the character of the house in a physical way. Carl has been animated to have quite square features, from his head and torso to his ears and even his glasses. This geometry is a physical representation of his "square" personality - quiet, reserved, introverted. Conversely, Ellie, whose personality is much more extroverted and loud, has been drawn to have very round features; a perfectly round head and a small round nose supporting round-rimmed glasses. The animators are able to exaggerate these features based on the audience's preconceived associations between these specific geometries and personality traits. These associations continue beyond the character design and begin to inform the spatial conditions of the house. All of the furniture in the house can clearly be identified as being Carl's or Ellie's. Carl's bedside lamp is a simple rectangular, cloth shade; Ellie's is an ornate Tiffany-style shade of colourful glass. In the living room, we see the contrasting personalities living comfortably side-by-side, complimenting each other. Carl sits in a low, square armchair and has a stacked rectangular end table at his side. Ellie sits in a high-backed, flowery, curvilinear chair next to a slender, delicately carved, round-topped end table. 
The effect that this exaggerated geometry has is to establish an emotional connection between the furniture and the characters, such that in the absence of the human character, their corresponding furniture can stand as a replacement. This becomes especially significant as the film progresses.

This animation of geometries serves an additional function beyond narrative development. The plausible impossible at work in Up, from the design of the characters to the set, serves to illustrate the important role our architectural spaces, particularly our domestic spaces, have in supporting individual and community self-actualization. As the film begins, we watch an entire lifetime flash by in the span of a couple minutes, the ups and downs and quiet moments that when assembled together make up a life. Carl and Ellie grow old together, fully satisfied just to have each other. Their house, redesigned and renovated with their own hands to reflect their personal identities, became a space in which they could reach true self-actualization together, fulfilling their greatest potential to be there for each other and build a happy life. As they aged and changed, the house did too, becoming imbued with new memory and meaning each year, and always reflecting the hearts of its inhabitants. Beyond the basic physical needs of shelter and security, Carl and Ellie's house provided a haven from the world, a place in which they felt represented, recognized, and important. Carl and Ellie built their house to reflect their individual and 
collective hopes, desires, and interests, and in turn the house fulfilled its role as a home; providing a safe and comforting space in which Carl and Ellie could have the adventure of a lifetime together.

Can a house be more than a home? What becomes of a house which is so wholly representative of two individuals, their dreams, hopes, desires, and memories, when one of those individuals is no longer there? The prologue of Up closes with the heartbreaking death of Ellie, leaving Carl alone in the world. Moving forward a couple of years, we see that Carl and Ellie's quiet neighbourhood has transformed into a metropolitan street. The house is now surrounded on all sides by soaring skyscrapers and Carl, stubbornly refusing to sell his house, watches on in bemused disappointment. "Some sight, huh Ellie?" he says while looking up at the house. When Ellie died, Carl's house, which had long ago become his home, became something more. It became a surrogate for his late wife, a repository of her memory in the walls, in the paint, and in the furniture. The house came to represent the very essence of his marriage. Such a transference is only possible due to the strong emotional connection established between Carl, Ellie, and their house; a connection which has been strengthened for the audience by the animation of simple geometries. The house also becomes as symbol of the burden of grief which hangs around Carl. Clinging desperately to the memory, Carl 
sets out on a journey to fulfill his childhood promise to Ellie and fly their home to Paradise Falls.

Balloons, which brought young Carl and Ellie together all those years ago, would now help Carl fulfill their dream. He ties thousands of helium-filled balloons through the chimney to the house. He pulls down the curtains and stitches them to the bedsheets to make sails and rigs up a navigating system of Ellie's invention, from back when the house was still just a clubhouse. With that, the house is torn off its foundations and thrown high into the sky and the film truly begins. After a series of misadventures, Carl (and his unwitting stowaway Russell) find themselves in South America. For much of the film, Carl must travel on foot, towing the floating house tied to his back behind him. The emotional transference of his marriage to Ellie into the house has become a very real, physical burden he must contend with in the wilds of South America. Throughout the film, Carl repeatedly risks everything in order to save his house - to save Ellie. Carl's final moment of self-actualization comes with the realization that to let go of the house is to let go of the grief, but not to lose the memories. At the climax of the film, Carl lets go of the house, and we see it slide away, gently into the clouds. It is a bittersweet moment of heartbreak and triumph because the audience understands that the house is not just a house, that the home is not just a home. It is the manifest essence of two souls intertwined 
with lumber, nails, paint and upholstery. The film's prologue so powerfully establishes these truths, significantly through plausible impossible geometries which reflect a very real human condition: that our homes are a reflection of our selves, and they hold much more value than the sum of their parts.

Up is illustrative of the notion that architecture can be a significant support in the self-actualization process by reinforcing an individual's sense of self. In Up, Carl and Ellie personally redesign their house and get their hands dirty doing the renovations. The result is a very personal house, customized to their very individual identities. The house also represents a new, shared identity which they crafted together. Within this space, both Carl and Ellie feel the kind of reassurance which enables them to aspire to greater things. While it is unreasonable to suggest that every person build their own house, it is very possible to design homes and other buildings that are individual-oriented. 


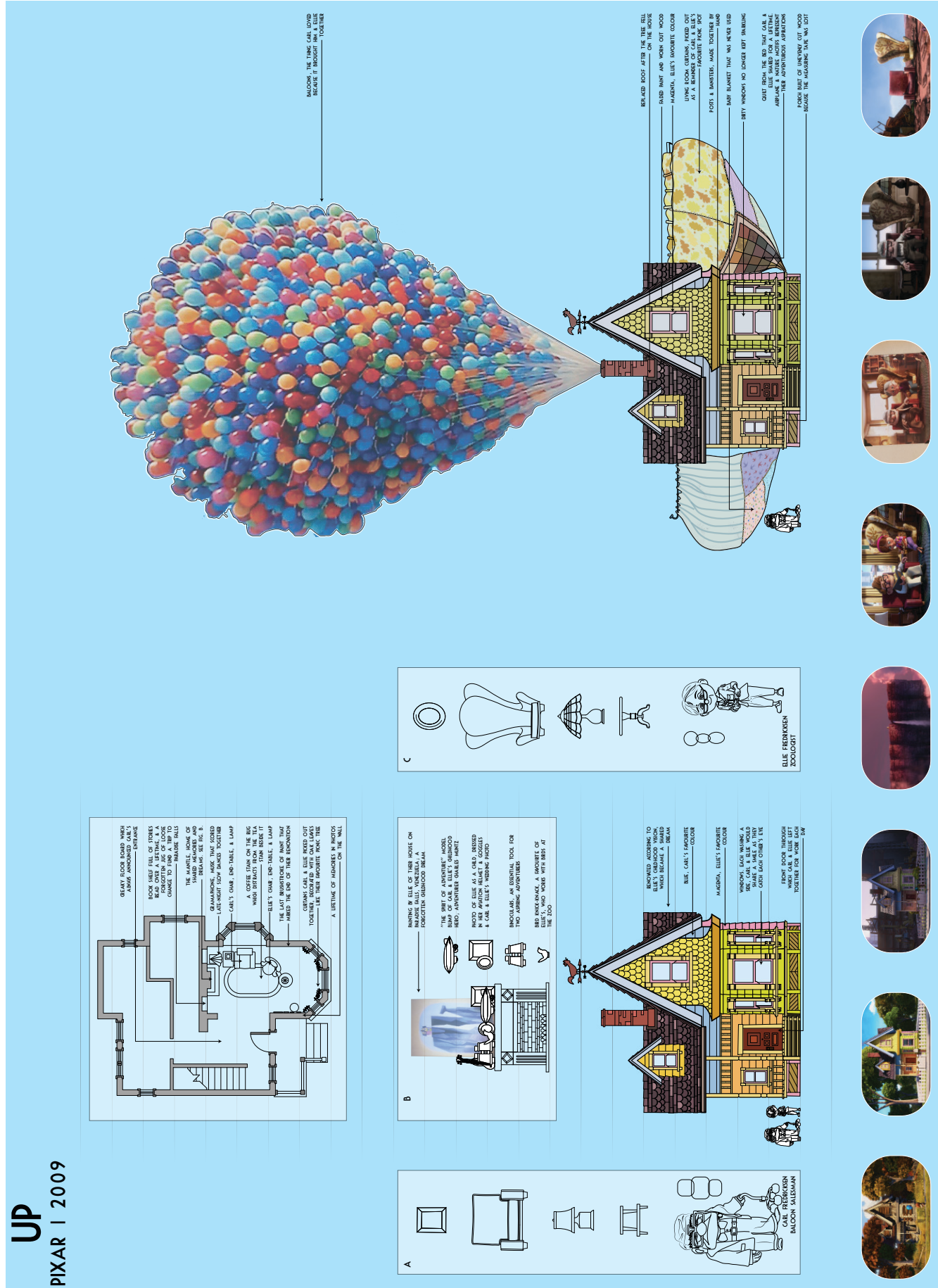

Fig. 62

Illustrative analysis of Pixar's 'Up' 


\section{ZOOTOPIA I DISNEY, 2016}

The quest for utopia is one which has occupied the imaginations of humankind since the Ancient Greeks. It is a fundamental part of the human experience, stemming from our unique ability for self-reflection; a consciousness and awareness of self that demands to be reconciled with. We imagine utopias to address human problems of inequality, injustice, and environmental negligence. The term "utopia" first appeared in Thomas More's sociopolitical satire Utopia, in 1516. The term is derived from the Greek ou-topos, meaning "no-place," and eu-topos, meaning "good-place."15 The utopia, therefore, is a good place that can exist in no place - a plausible impossibility. Utopia is intrinsically bound up with the concept of visionary architecture, most often taking the form of a city - Broadacre City, Plug-In City, Planet City, etc. It is also a common theme explored through animated film, albeit with less critical intention.

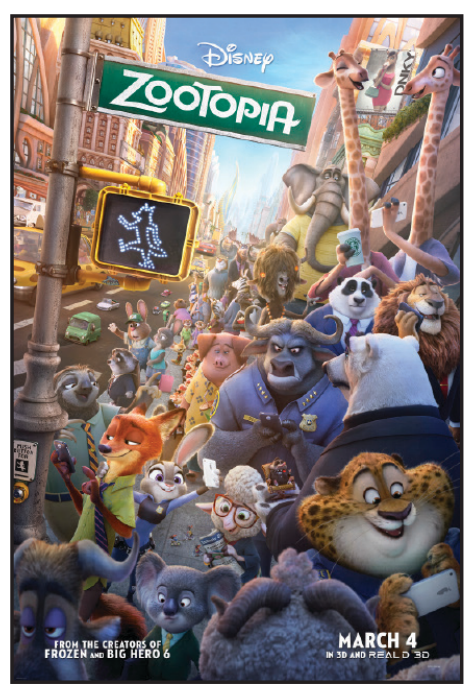

Fig. 63

'Zootopia'poster, 2016
The 2016 animated feature Zootopia is perhaps the closest Disney Studios has come to producing something that may be considered a work of visionary architecture. The film features a new kind of utopia in which, in the absence of humans, mammalian predators and prey have evolved beyond their primitive instincts to cohabitate the world in harmony. Zootopia, which has been praised for its allegory to racial inequality and political power structures ${ }^{16}$ also provides a great, as yet unexplored, case study of the role of 
architecture and urban planning in actively supporting the creation of a socially sustainable society.

Zootopia is a feature film not-so-subtly about race, prejudice, class division, and self-determination, set against the backdrop of the 'utopian' city. Drawing clear analogy to the real world, the film presents an alternate reality in which humans do not exist, and mammals have overcome their natural state, in which prey live in constant fear of predators, to live together harmoniously. This is the founding myth which establishes the basis of the city of Zootopia, a place "where anyone can be anything,"17 without the limitations of discrimination and prejudice. As with the majority of historical utopias, architecture and urban planning are central to the success of the ambitions of Zootopia. Following the story of Judy Hopps, the determined young bunny who becomes Zootopia's first police officer of her species, and Nick Wilde, the sly fox making a living as a con artist, as they uncover a conspiracy that threatens to overturn the peace, the narrative takes us through Zootopia, offering glimpses at the complex social and urban mechanisms in place to ensure the city functions as harmoniously as its myth claims.

As the home to a vast, multi-species population, Zootopia has two primary obstacles when it comes to urban design: varying climactic and habitat requirements, and a great variety of sizes, shapes, and abilities. The result is a series of districts designed to suit the varying needs of the 
city's inhabitants, each representing a different climactic region - Tundratown, the Rainforest District, Sahara Square — and unique neighbourhoods like the miniature village of Little Rodentia where the mice and shrews of Zootopia live. Special consideration is given to ensuring every animal is afforded the same opportunities and experiences moving through the city and its buildings, no matter how big or how small. Infrastructure is designed to facilitate various users, sometimes playfully as in the lemming elevators which resemble hamster tubes, and sometimes more pragmatically as in the gently inclining path that surrounds a reception desk, allowing smaller animals to reach a comfortable height at the countertop. These carefully designed elements are essential to reinforcing the utopic ambitions of Zootopia; simultaneously facilitating and determining the parameters in which the society functions.

There are many instances of this thoughtful design through out the film, however I've chosen to illustrate the police headquarters as a microcosm of all these things. It is fitting that the police station, ostensibly a symbol of democracy, equality and justice would be emblematic of Zootopia's designed utopia. ${ }^{18}$ Here, variously scaled stairs provide all animals a comfortable approach to the building. Three different sized doors welcome visitors, each with push bars at varied heights. However as the definition states, social sustainability is also dependent on processes within 
the community. Throughout the film we experience the city through the unique perspectives of the optimistic Judy and the cynical Nick. By the film's end, both characters learn that "life is more complicated than a slogan on a bumper sticker... [but] the more we try to understand each other"19 the better off we all are. Beyond infrastructure, social sustainability is dependant on individuals, recognizing the humanity in others and their role within the community. By eliminating the physical obstacles that separate various people's experiences with a space from others, it becomes easier to put our efforts towards building socially sustainable communities.

For a city like Zootopia to be built is entirely impossible, yet the animators have developed its structure to a level of such detail as to make it remarkably plausible and something worth considering for its allegorical parallels to the real world. The circumstances of the film, a multispecies city of wildly differing inhabitants, exaggerates the same, very real human condition. Human society is made up of many different kinds of people, of different size, shape, culture, belief, and ability. Why then, should the designs of our cities not follow the example of Zootopia and be carefully designed for individuals rather than for the lowest common denominator. There are many instances in the film that offer hints and suggestions at a possible 'other' way to approach city design, where, for the sake of harmony among people, consideration is given to ensuring equal opportunity and 


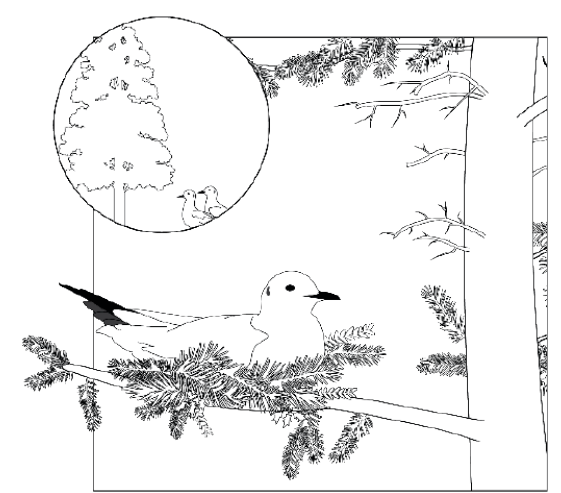

Fig. 64

Gulls may choose to sleep in a cabin, or a nest in the onboard trees

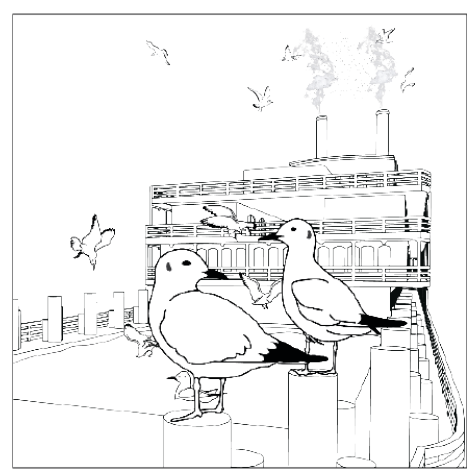

Fig. 65 Frank shows Ollie the onboard all-you-can-eat fishing pool

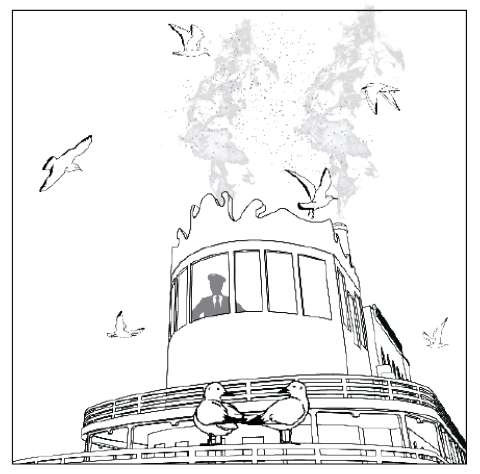

Fig. 66 Honey-water steam attracts flying insects for the gulls to feed on democratic space for all users. Zootopia places urban design and architecture at the fore of its storytelling, challenging us to reconsider the way public space is designed and the way it can implicate social sustainability.

For Gull Story, I designed the boat to be reflective of its specific users, providing variety and equality for all gulls aboard. A boat designed for gulls, and a solitary human occupant has some unique requirements. The captain's quarters occupy the highest deck on the boat, where they remain for the entirety of the journey, as to not disrupt the gulls. This area fits the proportions of its human user, while the remainder of the boat is scaled to the gulls. A runway pool is provided, allowing gulls to make a water landing if they so choose. Sleeping accommodations vary from private and shared cabins to mature coniferous trees with ready-made wicker nesting beds. [Fig, 64] A large pool is automatically kept stocked with fish from the river, offering the gulls an all-you-can-eat buffet, and a mixture of honeywater is boiled beneath the smokestacks to create a steam that attracts swarms of the insects, to give the gulls a little dietary variety. [Fig's. 65-66] Multiple pools around the boat allow the gulls to swim in refined water. And rather than lounge chairs, wooden posts surround the pools, offering gulls a comfortable perch to rest on. On the whole, the Niagara River Gull Cruise has been designed specifically for gulls, emphasizing the goal of environmental stewardship and social sustainability beyond the human community. 


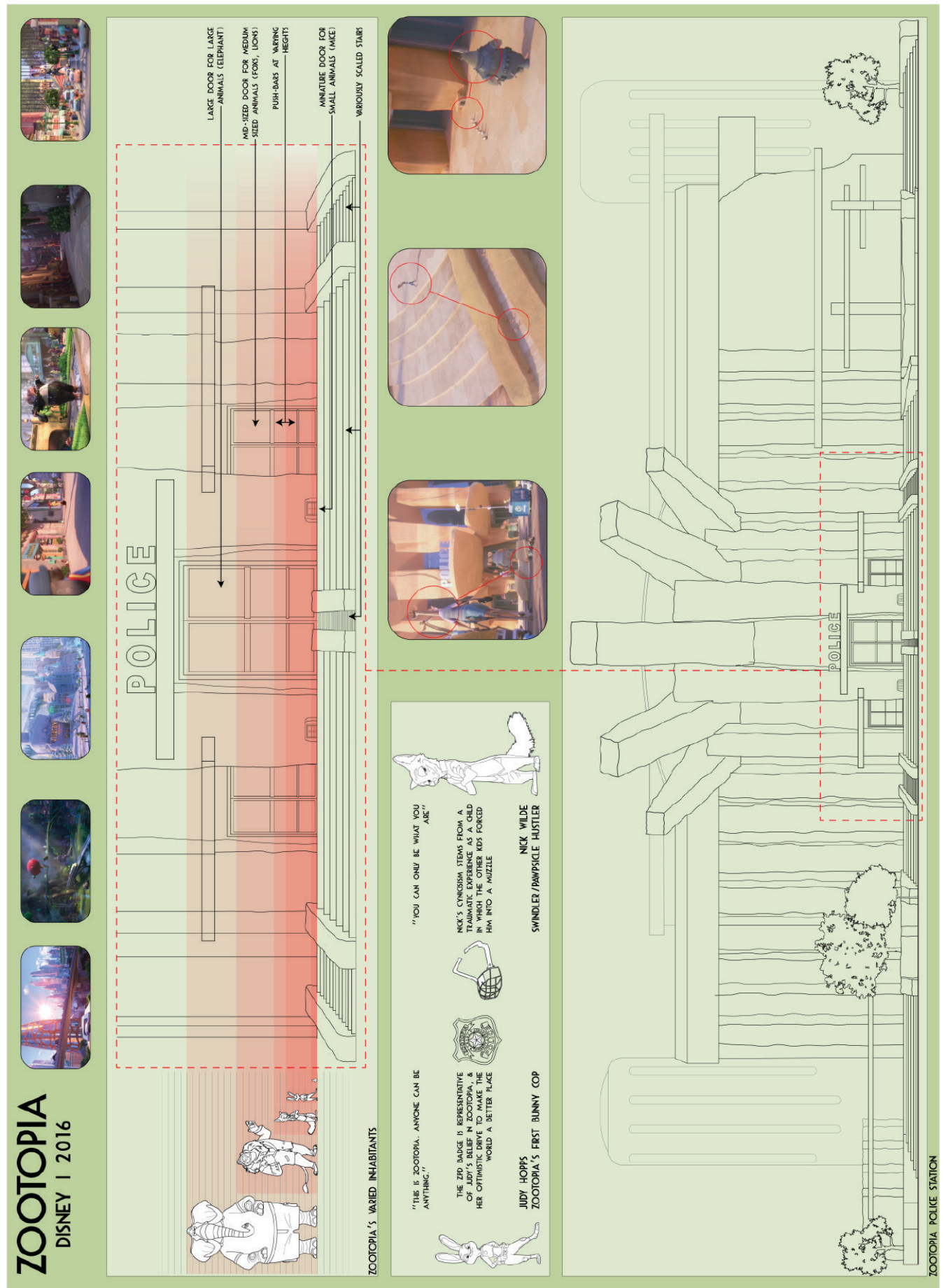


Part Two Endnotes

$1 \quad$ John Wills. Disney Culture. New Brunswick: Rutgers University Press, 2017. p. 105

2 McFadden, Robert M. "Millions Join Battle for a Beloved Planet." The New York Times. April 23, 1990, sec. A.

3 McFadden, Robert M. "Millions Join Battle for a Beloved Planet."

$4 \quad$ Further proof of the environmental movement gaining traction came in Bill Clinton's announcement of Al Gore as his running mate for the US Presidential election.

Kraft, Michael E. "U.S. Environmental Policy and Politics: From the 1960s to the 1990s." Journal of Policy History 12, no. 1 (2000): 17-42. https://doi.org/10.1353/jph.2000.0006.

Carter, April. The Political Theory of Global Citizenship. New York, NY: Taylor \&amp; Francis Books, 2006. p. 03

Price, David A. The Pixar Touch: The Making of a Company. New York: Vintage Books, 2009. p. 316

Price, The Pixar Touch. p.488

In 2014 Jim Morris replaced Ed Catmull as President of Pixar, and Andrew Millstein became President of Walt Disney Animation, though they would continue to report to Catmull until 2019.

In 2018, John Lasseter was let go from his role as Chief Creative Officer of Disney and Pixar Animation Studios following allegations of sexual misconduct in the workplace. He was replaced by Jennifer Lee (Writer/Director Frozen [2013] \& Frozen II [2019]), and Pete Docter (Writer/Director Monsters Inc [2001], Up [2009], Soul [2020]) for Disney and Pixar respectively.

Ollie and his friend Frank are named after legendary Disney animators Ollie Johnston and Frank Thomas, two of Walt Disney's 'Nine Old Men,' the name Walt gave to his team of principal animators.

"Niagara River Corridor." IBA Site Listing. Accessed May 23, 2021. https://www.ibacanada.ca/site. jsp?sitelD=ON002.

"Niagara River Corridor." IBA Site Listing. Accessed May 23, 2021. https://www.ibacanada.ca/site. jsp?sitelD=ON002.

Freytas-Tamura, Kimiko de. "Hakuna Matata? Can Disney Actually Trademark That?" The New York Times. The New York Times, December 20, 2018. https://www.nytimes.com/2018/12/20/world/africa/hakuna-matata-disneytrademark.html.

Mputhia, Cathy. "Trademarking 'Hakuna Matata' a Wake up Call." Business Daily, November 25, 2018. https://www. businessdailyafrica.com/lifestyle/pfinance/Trademarking-hakuna-matata-a-wake-up-call/4258410-4867976wyiem7z/index.html.

Giddings, Seth. "The Circle of Life." Third Text 13, no. 49 (1999): 83-92. https://doi.org/10.1080/09528829908576825. Morton, John. "Simba's Revolution: Revisiting History and Class in The Lion King." Social Identities 2, no. 2 (1996):

311-17. https://doi.org/10.1080/13504639652358.

The Lion King (Walt Disney Animation Studios, 1994)

The Lion King (Walt Disney Animation Studios, 1994)

Böck Ingrid. Six Canonical Projects by Rem Koolhaas: Essays on the History of Ideas. Berlin: Jovis, 2014. p. 64

Beaudine, Gregory, Oyemolade Osibodu, and Aliya Beavers. "Disney's Metaphorical Exploration of Racism and Stereotypes: A Review of Zootopia." Comparative Education Review 61, no. 1 (2017): 227-34. https://doi. org/10.1086/690061.

Kois, Dan. "Zootopia Is a Delightful Kids' Movie That Is Also Totally About Racial Profiling." Slate Magazine. Slate, March 2, 2016. https://slate.com/culture/2016/03/disney-s-zootopia-has-a-message-for-kids-about-racial-profiling. html.

Zootopia (Walt Disney Animation Studios, 2016) 
This flm takes an idealist's perspective of the police and the police station. In contemporary North America this view has become increasingly contested, especially in light of the Black Lives Matter protests of 2020, following the murders of several Black Americans at the hands of police. Today, there is a question of the efficacy of police forces and the power they weild in society. The following links shed more light on these evolving issues.

Bazelon, Emily. "Police Reform Is Necessary. But How Do We Do It?" The New York Times. The New York Times, June 13, 2020. https://www.nytimes.com/interactive/2020/06/13/magazine/police-reform.html.

Black Lives Matter, April 28, 2021. https://blacklivesmatter.com/.

"Black Lives Matter: Police Brutality in the Era of COVID-19." Lerner Center for Public Health Promotion, January 29, 2021. https://lernercenter.syr.edu/2020/06/16/ib-31.

Dunham, Roger G., and Nick Petersen. "Making Black Lives Matter." Criminology \&amp; Public Policy 16, no. 1 (2017): 341-48. https://doi.org/10.1111/1745-9133.12284.

Gittens, Dwayne. "Dying While Dying: COVID-19 \&amp; Police Brutality in Black America." Liberty Project. Liberty Project, June 2, 2020. https://www.libertyproject.com/black-lives-matter-covid-2646147395.html.

Karla Adam, Rick Noack. "Defund the Police? Other Countries Have Narrowed Their Role and Boosted Other Services." The Washington Post. WP Company, June 14, 2020. https://www.washingtonpost.com/world/europe/ police-protests-countries-reforms/2020/06/13/596eab16-abf2-11ea-a43b-be9f6494a87d.story.html. 
PART THREE

TO INFINITY \& BEYOND

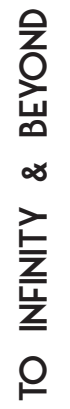




\subsection{SOME CONCLUSIONS}

Character driven animated film, exemplified by the work of Disney and Pixar Studios, offers a novel lens through which to consider the role of architecture in fostering environmental stewardship and social sustainability in our communities. The specific method of storytelling that centers on character emotion and experience creates opportunities to see the world through unique perspectives that are not so readily available through other, more common sources of architectural inspiration. Where visionary architecture proposes often impossible designs for real-world issues, these films create impossible worlds and scenarios grounded in just enough reality to render them impactful. This plausible impossibility is the door through which architects may enter into a meaningful analysis of how space is used to support major narrative themes like environmental stewardship and 
social sustainability in order to translate that analysis into real-world practice.

Rather than concrete or tangible practical lessons, my analysis of these four films resulted a number of important questions and challenges related to the philosophy, ideology, and practice of architecture. I interpret The Lion King as a call to recontextualize our collective human relationship to the natural world, and to consider ourselves as part of a greater environmental community. The film's use of Pride Rock to exaggerate the consequences of a failure to be stewards highlights the complex interconnections between environmental stewardship and social sustainability in such a way that they cannot be separated from each other, but addressed cooperatively. WALL.E emphasizes the need for immediate action to mediate the effects of human degradation on the planet. That means putting into practice all three measures - protection, restoration, and sustainability - in our daily activities, but more significantly in our role as architects. We have the agency to refuse work on a site that will displace an entire ecosystem or threaten any number of species. We have the capacity to conceive of better, more sustainable systems in the buildings we design, and to specify the use of materials with a lower environmental impact. And we have the opportunity to intervene on the sites of our projects with systems and technologies that can serve to remediate and 
restore the natural context rather than cause further harm.

Furthermore, we have the responsibility to do all we can

with the tools we are given. As Liam Young says, mitigating the effects of the climate crisis is no longer a technological problem, but an ideological one.

$W A L L \cdot E$, and significantly, UP, put forth the challenge to rethink the role architecture has in shaping an individual and what user-based design really means. The buildings we design are more than just shelters, they are the places in which people spend the majority of their lives, whether it's a home, an office, a store, or a gym. In these two films the idea is exaggerated, with Carl and Ellie physically building their space to suit their personalities, and WALL.E collecting enough human knick-knacks to earn himself an episode on Hoarders. However, as I have suggested, this exaggeration draws attention to a real issue in contemporary design, namely homogeneity. I have argued that WALL.E, Carl, and Ellie are encouraged to pursue their own self-actualization in part because they have been able to create for themselves a space in which they feel recognized, empowered, and fulfilled. Why then, can we not endeavour to provide the same kind of spaces for our clients? There is not a blanket solution to be applied here, yet the challenge is for us to be ever pursuant of that ideal.

In Zootopia I see a striking call for more truly socially sustainable space which actively supports or even drives the 
social ideals of a society rather than passively or retroactively applying band-aid solutions. Zootopia illustrates the notion that accessibility is about more than an elevator or a ramp tacked on at the end of a design. The accessibility of the city of Zootopia is foundational to its very existence: animals of varying shapes, sizes, and abilities need to get around with equal ease. How is this exaggerated condition any different than our human cities? Architecture should be democratic, equal, indiscriminate, and unprejudiced towards each and every user. As designers of public space, architects have a duty to provide every user the opportunity to have an equal experience as every other.

Although there is overlap between the narrative structure of these films and those which are employed by visionary architects like Archigram and Liam Young, these insights were only attainable through an analysis specifically of character-driven animated film. The unique way that these stories are built around character - without the explicit agenda typically attached to visionary or narrative architecture - inherently precludes the animators and storywriters from adhering to any kind of pre-established formula for design. Instead, spaces in these films are designed in response to the needs of the plot and the emotions of the characters, as well as in servitude of establishing an overarching theme. This freedom by design from any common architectural experiment is what makes 
animated film so exciting to explore; within them are embedded works of architecture often developed without architects, and always without the same constraints and criteria that weigh down real-world practice. Animated film's autonomy from architecture however, also complicates any serious attempt to suggest animation as inspiration, especially in terms of environmental stewardship and social sustainability.

As I discovered during the course of my research, the complicated history of Walt Disney and his company as well as certain individuals within the Pixar organization becomes an impediment when entering into a discussion of environmental stewardship and social sustainability. The countless critiques lobbied against Disney and Pixar films from Snow White to Raya and the Last Dragon can destabilize such an endeavour. All four films I analyzed have been the subject of critical reviews and insightful critiques. The Lion King has been reexamined as profiting on and exhibiting cultural appropriation.' WALL·E'S cautionary commentary on mass-consumerism has been pointed out to be extremely hypocritical coming from an organization like The Walt Disney Company which arguably invented modern consumerism. ${ }^{2} U p$ is guilty of employing imperialist and colonialist narratives with its characterization and portrayal of South America. ${ }^{3}$ And Zootopia has been critiqued for displaying the same implicit racial biases its plot seeks 
to condemn. ${ }^{4}$ All such critiques provoke important and meaningful discussion surrounding the making of these films, the messages they broadcast, and their impacts on viewers, especially the primarily young audience.

Despite being a professed fan of Disney and Pixar films going into this thesis, I was not blind to their imperfections and common instances of harmful representation. However, as I took a more focused look at these four films in particular, I was forced to reconcile more deeply my affinity for the Disney and Pixar films. This ongoing reconciliation produced some challenges in the writing of this thesis as I sought to highlight fruitful narratives within specific stories without ignoring the complicated legacy of the Disney brand. The intentions of my thesis placed me decidedly outside the realm of critique, as I believe there are others better equipped than I to grapple with such issues. This does not, however, place me in opposition of those critiques either. Just as we can reevaluate historical figures and recontextualize their faults alongside their virtues, I believe these films, as works of mass-art, can be critiqued for their failures and harms without dismissing their merits. With my analysis of these four films, I sought to avoid areas where there was overwhelming criticism. This was not always possible, as in The Lion King, thus I was compelled to address those issues within my analysis. If I have elsewhere highlighted a moment or an image which 
offends or is harmful to any persons, it was not done so out of deliberate indifference, but more likely ignorance or oversight. That being said, I hope I have not erred so.

Concurrent to my interpretation and analysis of The Lion King, WALL•E, Up, and Zootopia, I generated a series of vignettes exploring the philosophy of Disney/Pixar storytelling that I deciphered within the films, through the creation of my own original story. Gull Story is an experiment in applying my research and analysis to a real-world issue to better understand how character driven animation might be looked to for creative perspectives of architectural dilemmas. As a native to the Niagara Region, the issue of the Niagara River's degradation and its associated implications on gull migration was an issue I was interested in addressing. Thus Ollie was born, named after one of Walt Disney's 'Nine Old Men', Ollie Johnston. As I analyzed each film, I sought to translate the perceived lessons through the story of Ollie as he makes journey south, finding the boat, making friends, and building a home. I eventually compiled these vignettes into a very loose storyboard, chronicling Ollie's experience aboard the Niagara River Gull Cruise. As human beings, Gull Story poses the questions: How can we reconsider our relationship to the rest of the natural world? What role can we play in fostering an environmentally and socially sustainable community with nature? As architects it asks: How can we design spaces in which individuals feel 
empowered? How can we give users agency within the built environment? How can we design inclusive spaces that offer unique but equitable experiences for unique users? Although I am certainly no Walt or Lasseter, I thoroughly enjoyed experimenting with Gull Story and calling to attention a local issue of environmental stewardship.

The intention of this thesis is to make a viable argument for character-driven animated film to be interpreted and analyzed as architectural inspiration and (loose) precedent. Given the novelty of this suggestion, I opted to emphasize a certain 'pop' element as to begin the conversation on common, familiar ground. Hence the discussion of the history popular social-consciousness rather than that of the scientific field, as well as the example of Archigram as visionary architecture. Significantly this is also the primary reason for the focus on the films of Walt Disney Animation Studios and Pixar Animation Studios. As the

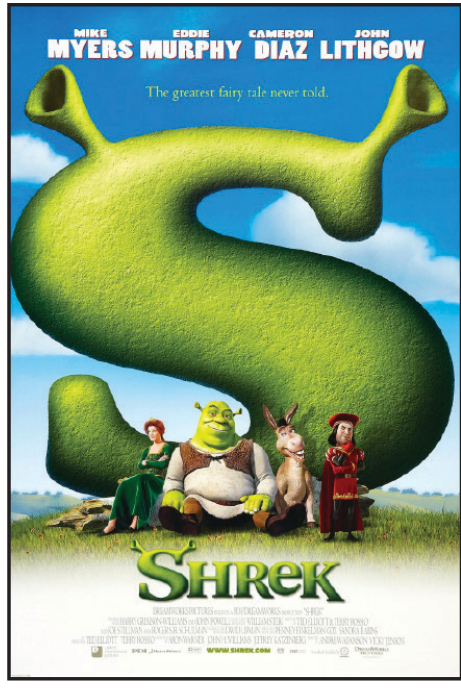

Fig. 68

'Shrek,' 2001 two most ubiquitous animation studios in the history of the medium Disney and Pixar have become synonymous with family-friendly animated film. The familiarity and prevalence of Disney/Pixar films make them ideal for an introduction to the kind of analysis I have undertook in this thesis. However, these are just two of the hundreds of animation studios creating character driven films world wide, each with a unique brand of storytelling worth investigating. There is the American studios Dreamworks Animation (Shrek, 2001) and 


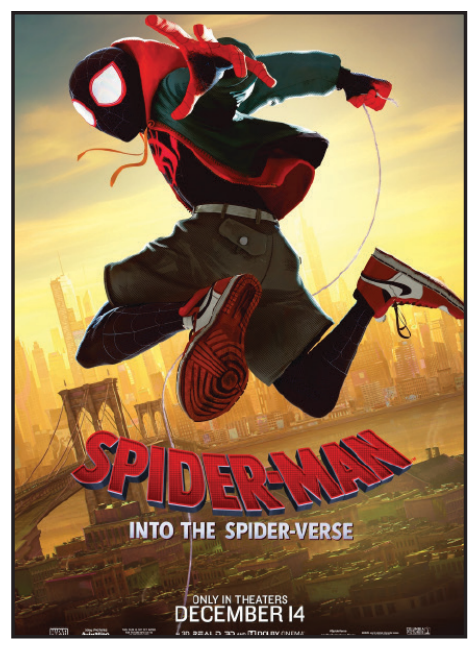

Fig. 69

'Spider-Man: Into the Spiderverse,' 2018

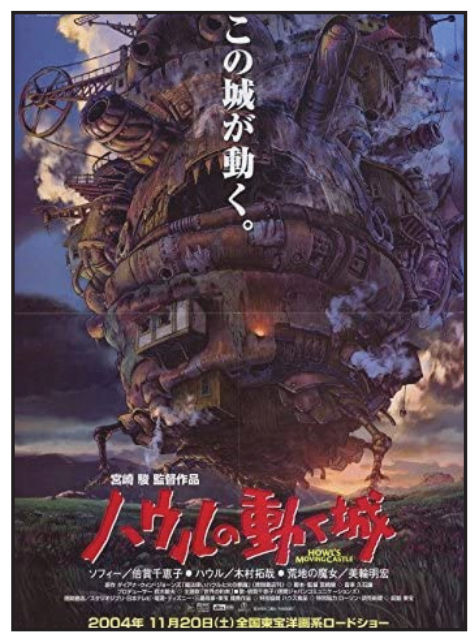

Fig. 70

'Howl's Moving Castle,' 2004

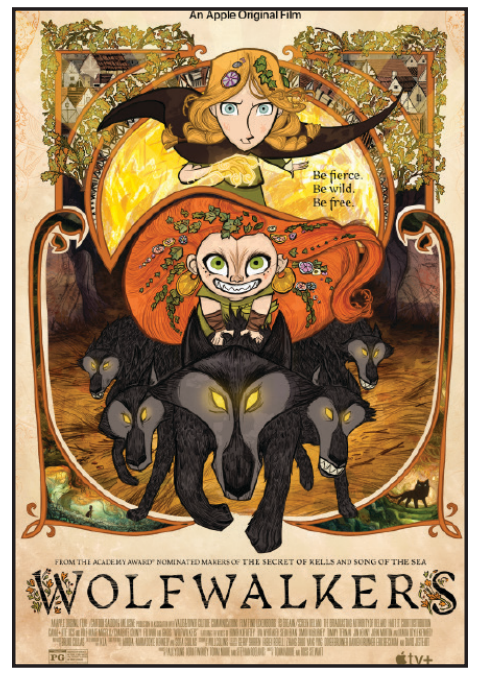

Fig. 71

'Wolfwalkers,' 2020
Sony Animation (Spider-Man: Into the Spiderverse, 2018). In

Japan there is Studio Ghibli (Howl's Moving Castle, 2004) and Ireland has Cartoon Saloon (Wolfwalkers, 2020). My hope is that my first foray into the films of Disney and Pixar will inspire others to consider the films of these and other studios as more than mere children's stories, and to find in them opportunities for architectural insights as I have begun to with this thesis. 
Endnotes

1 See Part Two, Endnote 11.

2 McNaughtan, Hugh. "Distinctive Consumption and Popular Anti-Consumerism: The Case of Wall-E." Continuum 26, no. 5 (2012): 753-66. https://doi.org/10.1080/10304312.2012.664116.

3 Figueredo, Patricia Bronislawski, Maria Ester Wollstein Moritz, Maria Lúcia Milléo Martins, and Viviane Maria Heberle. "'The Adventure Is out There!': Encounters between North and South in Disney-Pixar's Up." Essay. In Echoes: Further Reflections on Language and Literature, edited by Magali Sperling Beck, 141-50. Florianópolis: Universidade Federal de Santa Catarina, 2016.

Meinel, Dietmar. "Empire Is out There!?: The Spirit of Imperialism in the Pixar Animated Film 'Up."' NECSUS. European Journal of Media Studies 3, no. 1 (2014): 69-87. https://doi.org/10.5117/necsus2014.1.mein. Elman, Julie Passanante. "Slothful Movements: Disability, Acceleration, and Capacity Feminism in Disney's Zootopia (2016)." Feminist Media Studies, 2020, 1-18. https://doi.org/10.1080/14680777.2020.1855223.

Flory, Dan. "Audience, Implicit Racial Bias, and Cinematic Twists in Zootopia." The Journal of Aesthetics and Art Criticism 77, no. 4 (2019): 435-46. https://doi.org/10.1111/jaac.12672. 
APPENDIX B

GULL STORY 


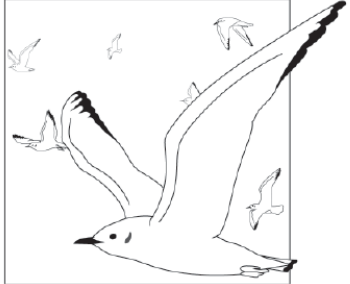

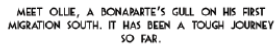

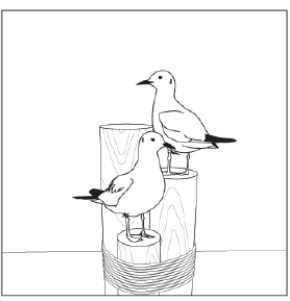

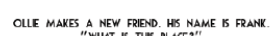

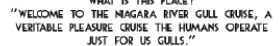

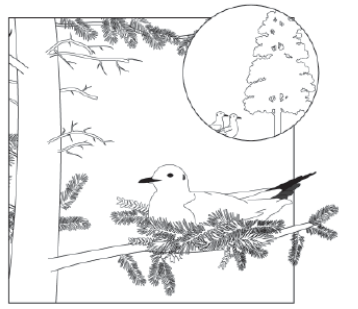

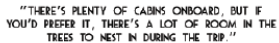
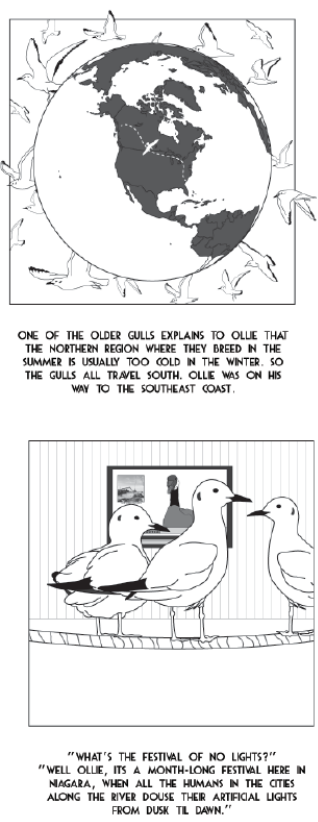
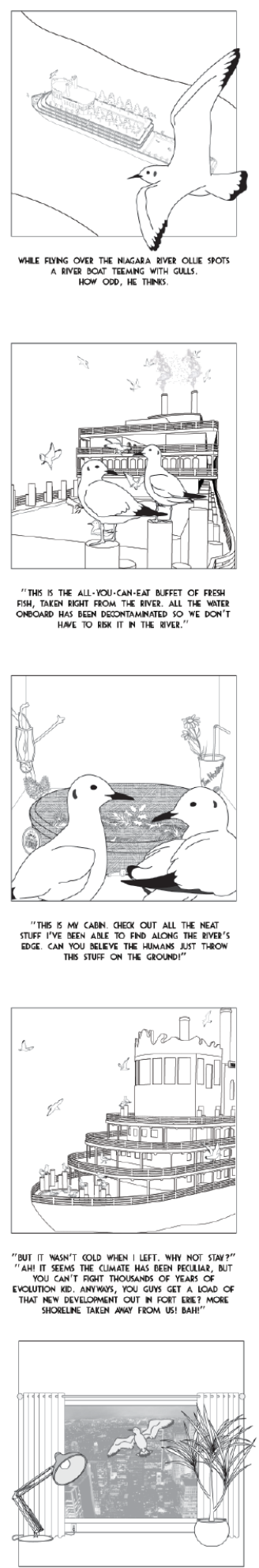

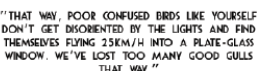

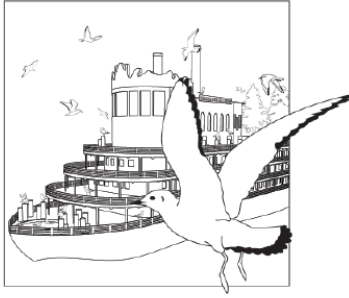

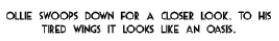
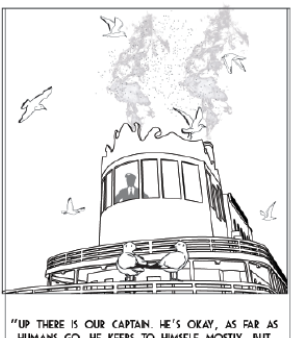

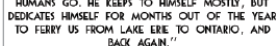
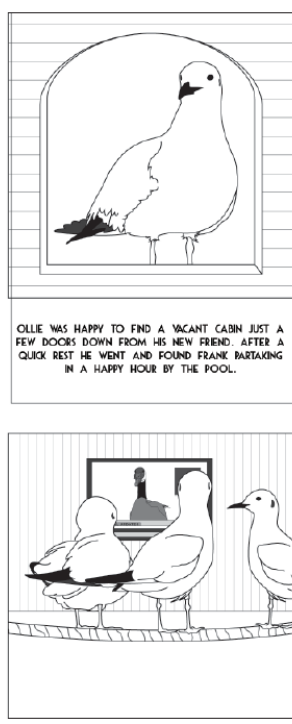

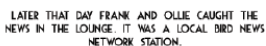
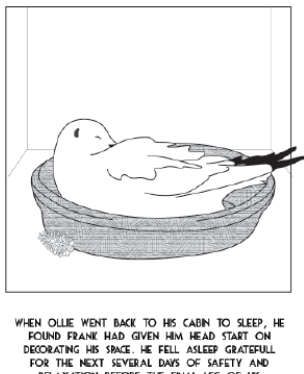
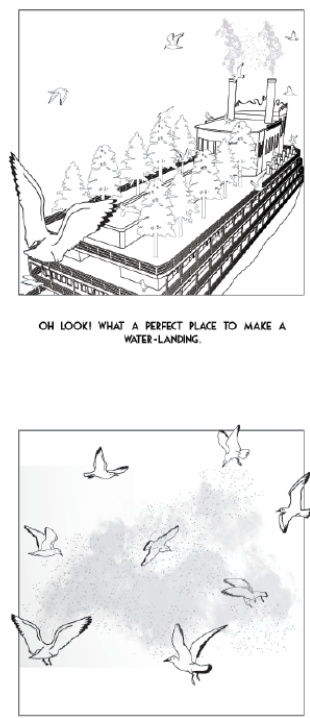

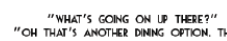

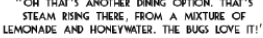
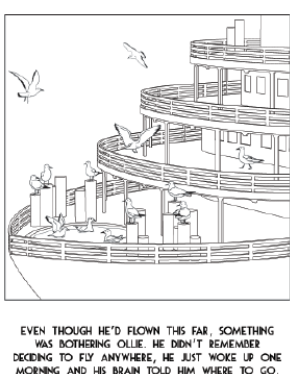

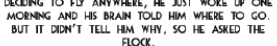
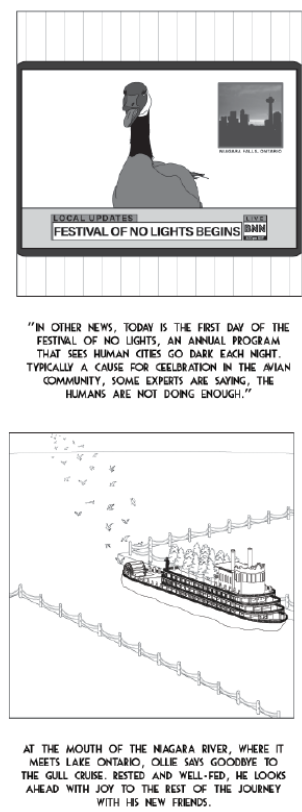
APPENDIX B

\section{ADDITIONAL INFORMATION ON DISNEY \& PIXAR FILMS}


DISNEY AND PIXAR FEATURE FILM CATALOGUE.
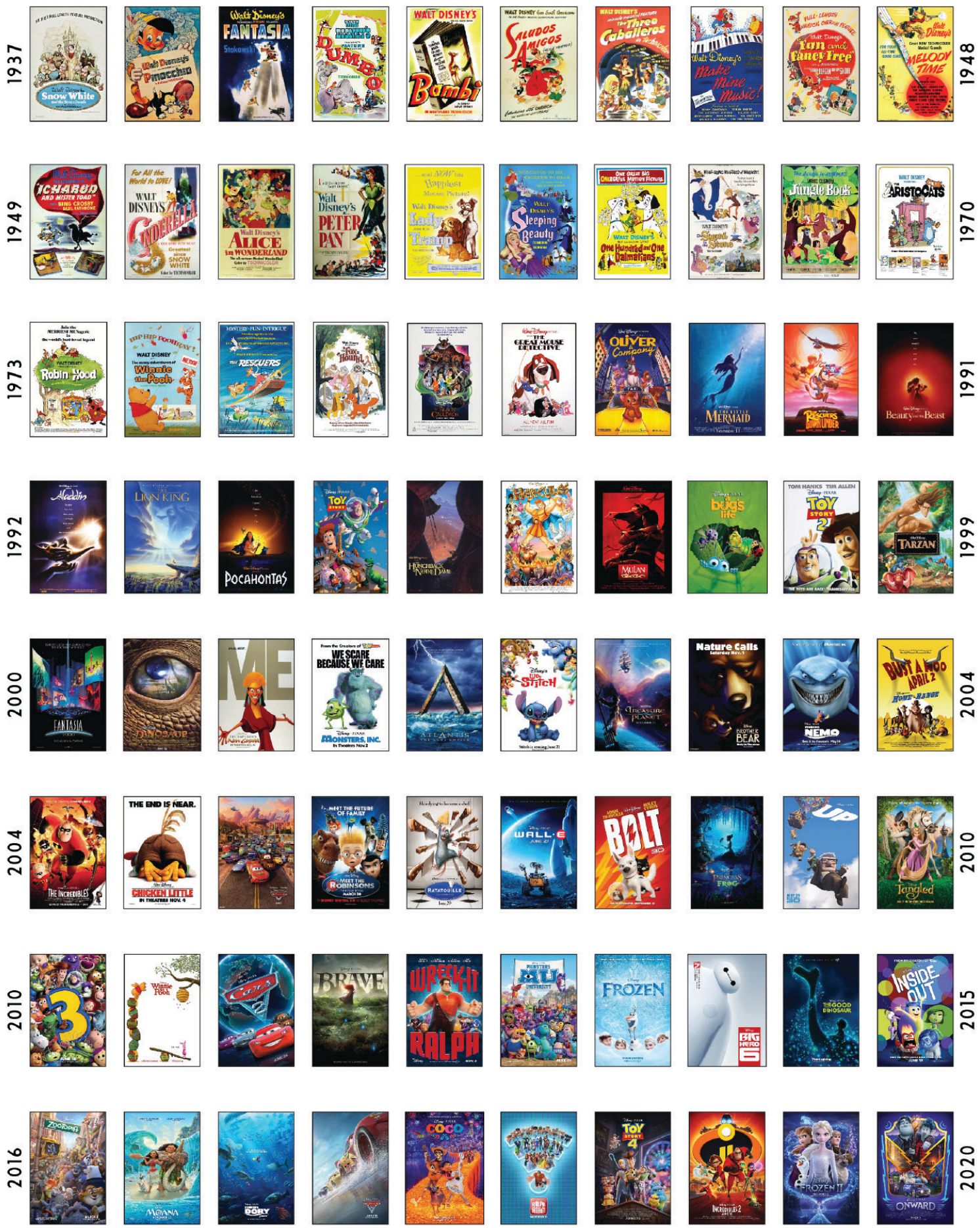

1937 - 2019: 58 Films from Walt Disney Animation Studios 


\section{PRELIMINARY CONCEPT ANALYSIS}
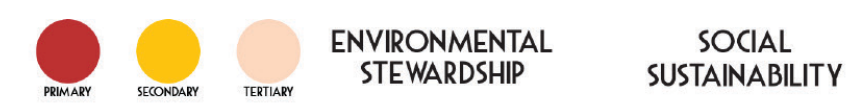

SELF STEWARDSHIP

ACTUALIZATION

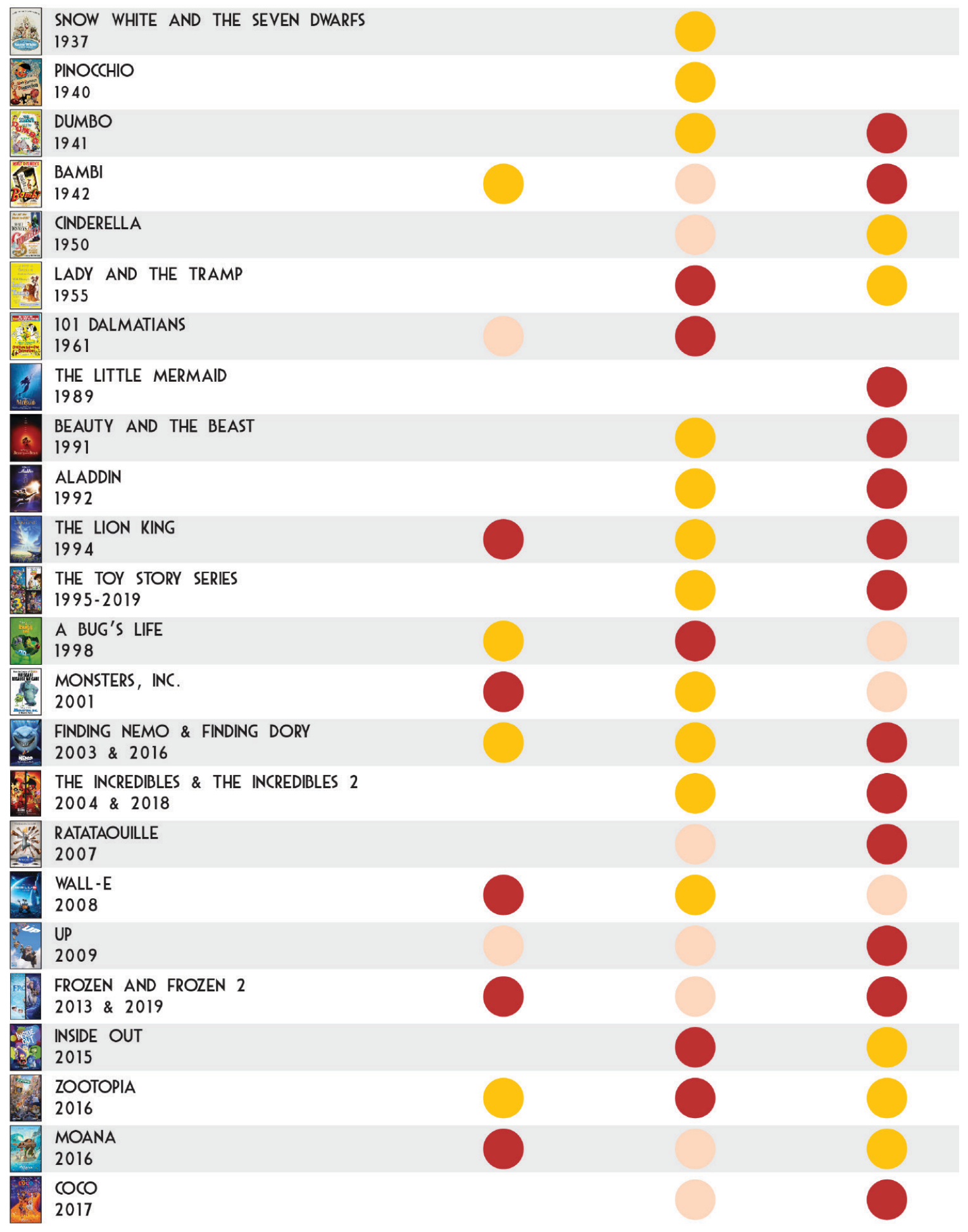

Each concept (Environmental Stewardship, Social Sustainability, and

Self-Actualization) has been identified as being a Primary, Secondary, Tertiary, or inconsequential theme in the narrative. 
FILM SYNOPSIS

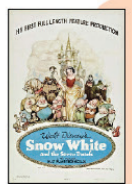

SNOW WHITE AND THE SEVEN DWARFS

1937

RT SCORE: 98

FOREVER ENCHANTING AND INSPIRING, SNOW WHITE

AND THE SEVEN DWARES EMBODIES THE WALT DISNEY SIGNATURE COLLECTION'S LEGACY OF ANIMATION. IN THIS EPIC STORY OF LOVE AND FRIENDSHIP, THE KIND AND BEAUTIFUL PRINCESS SNOW WHITE WINS THE HEARTS OF THE SEVEN DWARES AND TRIUMPHS OVER THE EVIL PLANS OF A WICKED QUEEN. DISCOVER THE MOVIE CALLED "THE GREATEST ANIMATED FLLM

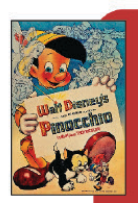

PINOCCHIO
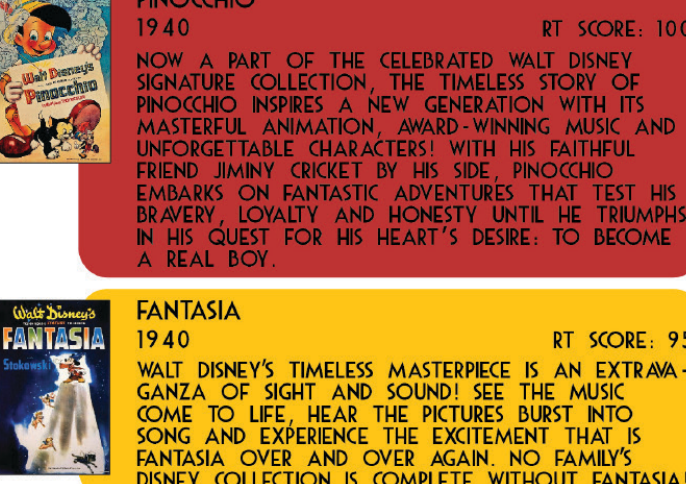

FANTASIA

1940

RT SCORE: 95

WALT DISNEY'S TIMELESS MASTERPIECE IS AN EXTRAVAGANZA OF SIGHT AND SOUND! SEE THE MUSIC COME TO LIFE, HEAR THE PICTURES BURST INTO SONG AND EXPERIENCE THE EXCITEMENT THAT IS
FANTASIA OVER AND OVER AGAIN. NO FAMIIL'S DISNEY COLLECTION IS COMPLETE WITHOUT FANTASIA!

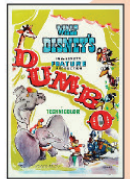

DUMBO

1941

RT SCORE: 98

EXPERIENCE THE DARING ADVENTURES OF THE

WORLD'S ONLY FLYING ELEPHANT. THE INSPIRATIONAL TALE OF DUMBO, THE COURAGEOUS BABY ELEPHANT
WHO USES HIS SENSATIONAL EARS TO SOAR TO WHO USES HIS SENSATIONAL EARS TO SOAR TO FAME WITH THE HELP OF HIS CLEVER BEST FRIEND
TIMOTHY Q. MOUSE, WILL THRILL AND DELIGHT TIMOTHY Q. MOUSE, WILL THRILL AND DELICHT AUDIENCES OF ALL AGES. AND NOW THE AWARD-WINNING MUSIC AND EMPOWERING MESSAGES ABOUT FRIENDSHIP AND BELIEF IN YOURSELF REACH NEW HEIGHTS IN THIS MUST-HAVE PRESENTATION OF WALT DISNEY'S ANIMATED CLASSIC DUMBO!
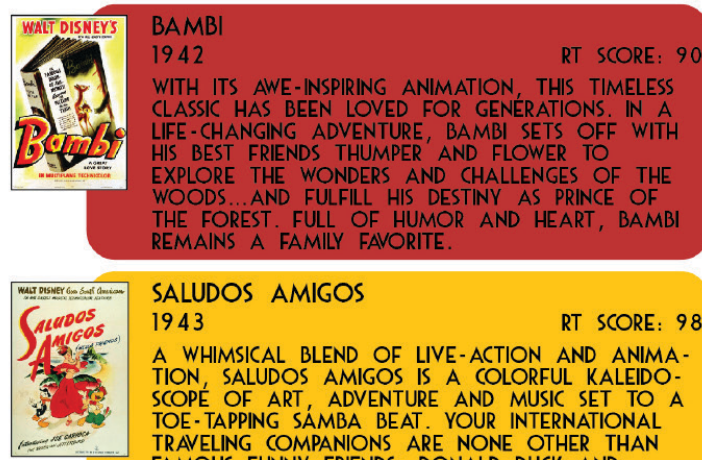

SALUDOS AMIGOS

1943

RT SCORE: 98

A WHIMSICAL BLEND OF LIVE-ACTION AND ANIMATION, SALUDOS AMIGOS IS A COLORFUL KALEIDO-

TOE TRA TANG COMPANONS ARE NONE OTHER THAN

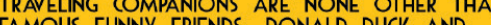
AAMOUS THEY KEE THINGS LVEDY AS DAND GOOFY. THEY KEEP THNGS LIVELY AS DONALD LLAMA AND" GAUCHO" GOOFY TRES ON THE COWBOY WAY OF LIFE...SOUTH AMERICAN-STYLE. FROM HIGH ANDES PEAKS TO ARGENINAS PAMPAS TO THE SIGHTS AND A HILARIOUS VISUAL FEAST THAT WILL ENTERTAIN AND DELIGHT THE WHOLE FAMILY

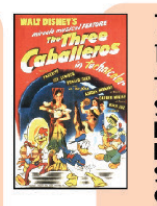

THE THREE CABALLEROS

1945

RT SCORE: 98

THE EVER POPULAR AND EXCITABLE DONALD DUCK STARS IN ONE OF HIS GREATEST ADVENTURES - A DAZZLING BLEND OF LIVE ACTION AND CLASSIC DISNEY ANIMATION BURSTING WITH SIGHTS AND SOUNDS! WHEN DONALD RECEIVES A MAGICAL COLLECTION OF GIFTS FROM HIS FRIENDS, THEY BECOME HIS PASSPORT TO A FANTASTIC MUSICAL JOURNEY WITH JOE CARIOCA AND PANCHITO. WITH THESE EXPERTS TO GUIDE HIM, DONALD HOPS, SKIPS AND JUMPS HIS WAY THROUGH AN ADVENTURE, WITH EACH STOP FULL OF SURPRISES AND SENSATIONAL SONGS! DISNEY'S SEVENTH FULL-LENGTH ANIMATED FILM, THE THREE CABALLEROS IS A STUNNING CELEBRATION OF VII UAL FINE-FEAT'HERED FUN FOR THE WHOLE FAMILY!

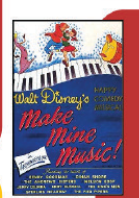

\section{MAKE
1946}

A SERIES OF MUSICAL VIGNETTES ARE PRESENTED IN THIS ANIMATED PRODUCTION. THE TEN SHORTS IN THE COYS" ARE AS FOLUE BAYOW" "ALE THE CATS AOIN

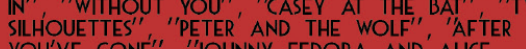
BLUEBONNET", AND "THE WHALE WHO WANTED TO FUN AND FANCY FREE

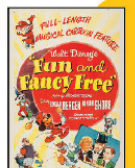

1947

RT SCORE: 67

FUN AND FANCY FREE IS A DELIGHTFUL GEM THAT NOT ONLY SPARKLES WITH CHARM, BUT IS UNBELIEV ABLY RICH IN HISTORY-MAKING DISNEY MOMENTS. IT WAS THE LAST ANIMATED FEATURE STARRING WALT DISNEY ALS THE ONLY FLLM FEATURING ALL FOUR OF WALT DISNEY'S MOST FAMOUS CHARACTERS - MICKEY MOUSE, DONALD DUCK, GOOFY, AND JIMINY CRICKET.
FOLLOWING DISEY'S CLASSSIC TRADITION OF GREAT FOLLOWING DISNEY'S CLASSIC TRADITION OF GREAT
STORYTELING UNFORGETTABIE CHARACTERS, MUSIC, STORYTELLING, UNFORGETABLE CHARACTERS, MUSIC, AND ADVENTURE, FUN AND FANCY FREE IS THE THE JOYFUL TELLING OF "BONGO" AND MMCKE
BEANSTALK" TWO TIMELESS TALES MAGICALLY BROUGGT TÓ LIFE BY THE BELOVED JIMINY CRICKET AND THE MASTERFUL COMBINATION OF ANIMATION AND LIVE ACTION.

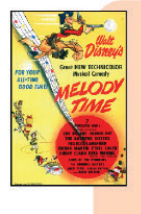

MELODY TIME

1948

RT SCORE: 80

"ONCE UPON A WINTERTIME": A PICTURE TOLD WITH MUSIC AND A SONG BY FRANCES LANGFORD ABOUT A BOY AND GIR'S SLEIGHING AND SKATING OUTING IN THE 1800 's. RABBITS JOIN THE BOY AND GIRL ON THE ICE BUT THEIR, PLAY ALMOST ENDS IN TRAGEDY. "BUMBLE BOOGIE": FREDDY MARTIN AND HIS ORCHESTRA WITH JACK FINA AT THE PIANO. FANTASY OF A BEE'S NIGHTMARE. "JOHNNY APPLESEED" OLD SETTLER, JOHNNY APPLESEED AND JOHNNY'S ANGEL, AS JOHNNY JOINS THE PIONEER TREK WEST, PLANTING APPLE ORCHARDS. LITTLE TOOT. A LITTLE TUGBOAT GETS INTO MISCHIEF AND IS BANISHED, BUT WINS A REPRIEVE BY SAVING A HUGE OCEAN LINER IN A STORM. "TREES": CARTOON INTERPRETATION BASED ON THE POEM "TREES." A CHORAL GROUP SINGS LYRICS. "BLAME IT ON THE SAMBA'": STREET SCENE IN BRAZIL WITH THE DINNING SISTERS SINGING. JOSE CARIOCA AND THE ARACUAN BIRD TEACH DONALD DUCK THE SAMBA. LIVE ACTION WITH ETHEL SMITH AT THE ORGAN. "PECOS BILL": "BLUE SHADOWS ON THE TRAIL" SUNG BY ROY ROGERS AND THE SONS OF THE PIONEERS LEADS INTO ROGERS NARRATING THE STORY OF PECOS BILL BROUGHT UP BY WOLVES AND BECOMING A LEGENDARY COWBOY. LIVE ACTION ENDING: ROY ROGERS ARY COWBOY. LIVE ACTION ENDING: ROY ROGERS
SONS OF THE PIONEERS, LUANA PATTEN AND BOBBY DRISCOLL AROUND A CAMPPIRE. 


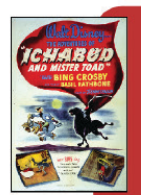

THE ADVENTURES OF ICHABOD AND MR. TOAD

1949

TWO UNFORGETTABLE CHILDREN'S STORIES, "THE WIND IN THE WILLOW" AND "THE LEGEND OF SLEEPY

HOLLOW, COME TOGETHER IN ONE FABULOUS
ADVENTURE AND IN ITS ORIGINAL THEATRICAL

ADVENTURE ...AND IN ITS ORIGINAL THEATRICAL
FORMAT. FIRST, HANG ON FOR A WILD MOTORCAR RIDE WITH J. THADDEUS TOAD AS HE DRIVES HIS FRIENDS MOLE, RAT AND ANGUS MACBADGER INTO A WORRIED FRENZY. THEN MEET THE SPINDLY
ICHABOD CRANE WHO DREAMS OF SWEEPING ICHABOD CRANE, WHO DREAMS OF SWEEPING BEAUTIFUL KATRINA VAN TASSEL OFF HER FEET DESPITE OPPOSITION FROM TOWN BULLY BROM BONES, WHO ALSO HAS HIS OF THE HEADLESS HORSEMAN, RESULTING IN A HEART-THUMPING CLIMAX. WONDERFULLY NARRATED BY BASIL RATHBONE AND BING CROSBY, THE ADVEN -
TURES OF ICHABOD AND MR TOAD BRIMS WITH HIGH-SPIRITED ADVENTURE, BRILLIANT ANIMATION AND CAPTIVATING MUSIC

CINDERELLA

1950

RT SCORE: 97

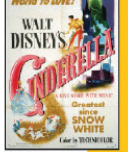

PART OF THE WALT DISNEY SIGNATURE COLLEC

TION AND THE PRESTIGIOUS NATIONAL FILM REGIS

TRY DISNEY'S ANIMATED CLASSIC CINDERELLA IS BELÓVED BY GENERATIONS OF FANS FOR ITS TIMELESS STORY, UNFORGETTABLE CHARACTERS AND ICONIC ARTISTRY. SHARE THE MAGIC AS KIND AND HARDWORKING CINDERELLA IS REWARDED WITH AN ENCHANTED EVENING AT THE ROYAL BAI ENCHANTED EVENING AT THE ROYAL BALL. IT JUS TAKES THE HELP OF HER LOYAL ANIMAL FRIENDS JAQ AND GUS A WAVE "OF HER FAIRY GODMOT CELEBRATE THE LEGACY OF DISNEY'S CLASSIC ANIM TION IN CINDERELLA, WHERE DREAMS REALLY DO COME TRUE!

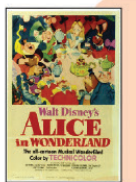

ALICE IN WONDERLAND

195

RT SCORE : 8

JOIN ALICE AS SHE FALLS INTO THE MADCAP WORLD OF WONDERLAND AND MEETS EXTRAORDINARY CHARACTERS SUCH AS TWEEDLEDEE AND TWEEDLEDUM, THE MAD HATTER, THE QUEEN OF
HEARTS, AND' THE FRANTICALLY LATE WHITE RABBIT.

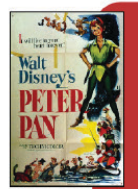

\section{PETER PAN}

1953

RT SCORE:

BID YOUR CARES GOODBYE AS WENDY AND HER

BROTHERS EMBARK ON FANTASTIC ADVENTURES WITH

WITH FAITH, TRUST AND TINKER BELL'S PIXIE DUST

PETER TEACHES THEM HOW TO FLY AND LEADS
THEM TO THE "SECOND STAR TO THE RIGHT" AND BEYOND ... TO NEVER IAND!

\section{LADY AND THE TRAMP}

1955

RT SCORE: 93

FALI IN LOVE WITH WALT DISNEY'S BELOVED CLASSIC, LADY AND THE TRAMP! EXPERIENCE THE THRILLINC ADVENTURES OF LADY, A LOVINGLY PAMPERED COCKER SPANIEL, AND 'TRAMP, A FREEWHEELING MUTT WITH A HEART OF GOLD. THIS HEARTWARMING TALE NOW CHARMS A NEW GENERATION OF FAMILIES AND FANS WITH ITS EXQUISITE ANIMATION, UNFORGETTABIE SONGS AND ONE OF IOVE STORIES OF AL AN THE IS THE NIGHT TO SHADE A SPECIA BLL NE.TH WITH YOUR FAMIY AND INTRODUCE THEM TO THIS TIMELESS CLASSIC.
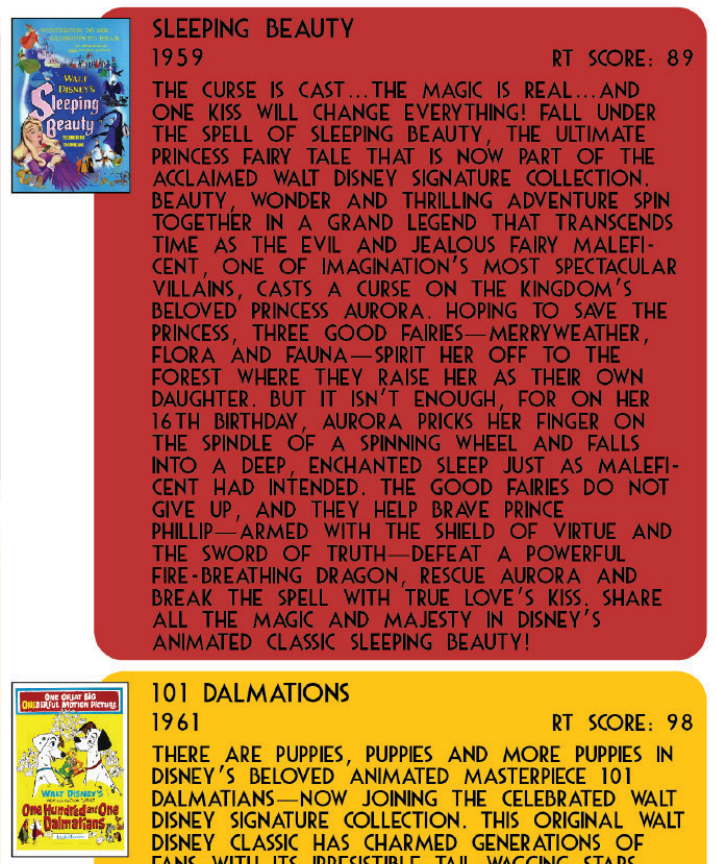

01 DALMATIONS

1961

RT SCORE: 98

THERE ARE PUPPIES, PUPPIES AND MORE PUPPIES IN DISNEY'S BELOVED ANIMATED MASTERPIECE 101 DALMATIANS - NOW JOINING THE CELEBRATED WALT DISNEY SIGNATURE COLLECTION. THIS ORIGINAL WALT DISNEY CLASSIC HAS CHARMED GENERATIONS OF FANS WITH ITS IRRESISTIBLE TAIL-WAGGING STARS MEMORABLE STORY AND PERFECT BLEND OF HUMOR AND ACTION-PACKED ADVENTURE. CRUELLA DE VIL THE MOST FABULOUSLY OUTRAGEOUS VILLAINESS OF ALL TIME, SETS THE FUR-RAISING ADVENTURE IN MOTION WHEN SHE DOGNAPS ALL ADVENTURE IN MOTON WHEN SHE DOGNAPS ALL OF THE ADORABLE DALMATIAN PUPPIES IN LON'DON-INCLUDING IS FROM PONGO AND PERDITA'S FAMILY I THROUGH THE POWER OF THE "TWEIIA'S BARK HEROES OF ALL SPOTS AND STRIPES, AND TOGETH ER THEY LAUNCH A DRAMATKC QUEST TO RESCUE THE PUPPIES FROM CRUELLA'S GREEDY CLUTCHES. UNLEASH ALL THE EXCITEMENT AND SUSPENSE OF DISNEY'S YOUR FAMILY WILL ENJOY' AGAIN AND AGAIN!

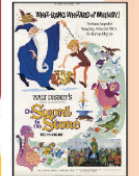

THE SWORD IN THE STONE

1963

RT SCORE: 66

HUMOR, SPECTACLE AND MAGIC RULE IN WALT DISNEY'S LEGENDARY CLASSIC TALE THE SWORD IN THE STONE! EMBARK ON AN ADVENTURE-FILLED QUEST FOR AN UNLIKELY HERO! ACCORDING TO LEGEND, ONLY SOMEONE WITH HONOR, DECENCY AND INNER STRENGTH CAN CLAIM THE THRONE OF ENGLAND - BY PULLING OUT THE ENCHANTED SWORD THAT LIES LOCKED IN A MASSIVE STONE. MANY BRAVE KNIGHTS HAVE TRIED, SO IT SEEMS IMPOSSIBLE THAT A YOUNG APPRENTICE KNOWN AS WART COULD SUCCEED. BUT WITH THE GUIDANCE OF THE WIZARD MERLIN, HELP FROM SOME HILARIOUS FRIENDS AND TRUE STRENGTH OF CHARACTER, WART JUST MIGHT BECOME ENGLAND'S GREATEST KING. 


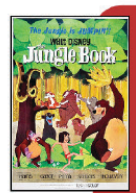

THE

EXPERIENCE THE SONG-FILLED CELEBRATION O

FRIENDSHIP, FUN AND ADVENTURE THAT WAS THE

LAST FILM TO RECEIVE WALT DISNEY'S PERSONAL

IOUCH. EMBARK ON A THRILLING, ADVENTURE-FILLED
OUURNEY WITH THE BOY MOWGLI AS HE MAKES HIS WAY TO THE MAN-VILLAGE WITH BAGHEERA THE WISE PANTHER. ALONG THE WAY HE MEETS JAZZY KING LOUIE, THE HYPNOTIC SNAKE KAA AND THE LOVABLE, HAPPY-GO-LUCKY BEAR BALOO, WHO TEACHES' MOWGLI "THE BARE NECESSITIES"' OF LIFE
AND THE TRUE MEANING OF FRIENDSHIP.

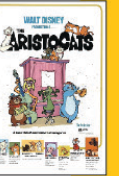

THE ARISTOCATS

1970

RT SCORE: 64

IN THE HEART OF PARIS, A KIND AND ECCENTRIC

MILLIONAIRESS WILLS HER ENTIRE ESTATE TO DUCHESS,

HER HIGH-SOCIETY CAT, AND HER THREE LITTLE
KITTENS. LAUGHS AND ADVENTURE ENSUE AS THE GREEDY, BUMBLING BUTLER PULLS OFF THE ULTIMATE CATNAP' CAPER. NOW IT'S UP TO THE ROUGH-AND-TUMBLE ALLEY CAT, THOMAS O'MALLEY, AND HIS BAND OF SWINGIN' JAZZ CATS TO SAVE THE DAY.

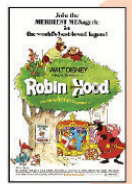

OBIN HOOD

1973

RT SCORE: 54

A LONG TIME AGO, IN A FARAWAY LAND, LEGEND TELLS AN EXTRAORDINARY TALE OF COURAGE AND FRIENDSHIP.... GET READY FOR SWASHBUCKLING

ADVENTURE, UNFORGETTABLE CHARACTERS, MEMORAADVENTURE, UNFORGETTABLE CHARACTERS, MEMORA BLE MUSIC, AND LOTS OF LAUGHS IN DISNEY'S ROBIN TRUSTED COMPANION LITTLE JOHN AND HIS DEVOTED TRUSTED COMPANION LITTLE JOHN AND HIS FAMOUSLY FUNNY AND DARING DEED AFTER ANOTHFAMOUSY FUNNY AND DARING DEED AFTER ANOTH HAPPINESS TO THE RESIDENTS OF SHERWOOD FOREST.

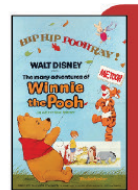

\section{THE}

\section{7}

CELEBRATE THE MAGICAL AND HEARTWARMING
STORIES THAT DELIGHTED FAMILIES FOR GENERATIC

XPERIENCE THE MAGICAL TALES THAT STARTED THE

POOH TRADITION - AN EXTRAORDINARY MASTERPI

STORIES ARE FILLED WITH TIMELESS POOH ADVEN

TURES - THE FIRST MEETING BETWEEN TIGGER AND

POOH, POOH GETTING STUCK IN RABBIT'S HOUSE

FROM EATING IOO MUCH HONEY, AND THE LOV-

ABLE CHARACTERS' FLURRY OF ACTIVITY ON A

HILARIOUS WINDY DAY. ACCOMPANIED BY THE ENGAGING SONGS THAT ENDEARED WINNIE THE POOH TO FANS OF ALL AGES, SUCH AS "LITTLE BLACK RAIN CLOUD" AND "RUMBLY IN MY TUMBLY," THE CLA MOMENIS CONTINUE TO ENCHANT CHILDREN AND

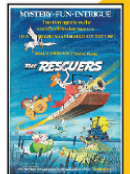

THE RESCUERS

1977

RT SCORE: 81

JOIN THE SHY BUT BRAVE MOUSE BERNARD AND HIS GLAMOROUS PARTNER MISS BIANCA -- TWO TIN HEROES ON A GREAT BIG MISSION TO SAVE A YOUNG GIRL NAMED PENNY WHO HAS SENT AN URGENT CALL FOR HELP! TAKING OFF ON THE WINGS OF THEIR TRUSTED ALBATROSS FRIEND ORVILLE, BERNARD AND BIANCA SOAR TO THE MARSHY SWAMP OF DEVII'S BAYOU. THERE THEY FIND THEMSEIVES ON THE RIVERBOAT HIDEOUT OF THE HILARIOUSIY EVIL MADAME MEDUSA, WHO NEEDS PENNY TO RETRIEVE THE WORLD'S LARGEST DIAMOND! THE RESCUERS IS HIGH-FLYING FUN YOU'LL WANT TO SHARE WITH YOUR LOVED ONES!

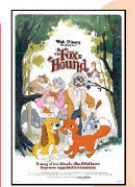

THE FOX AND THE HOUND

1981

RT SCORE: 70

WHEN A FEISTY LITTLE FOX NAMED TOD MEETS COPPER, AN ADORABLE HOUND PUPPY, THE TWO GROW UP TOGETHER AND VOW TO BE BEST BUDDIES FOREVER. BUT WHEN COPPER IS EXPECTED TO TAKE ON HIS NATURAL ROLE AS A HUNTING DOG, HE AND TOD FACE THE ULTIMATE TEST OF THEIR' UNLIKELY FRIENDSHIP.
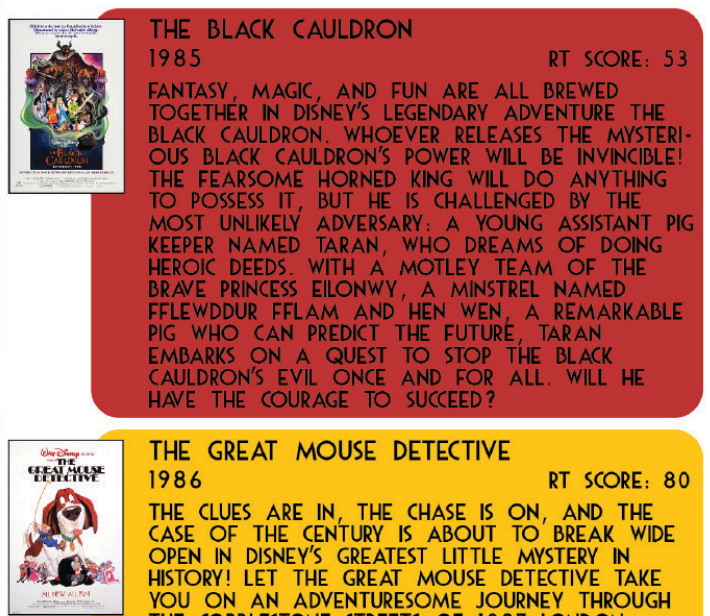

THE GREAT MOUSE DETECTIVE

1986

RT SCORE: 80

THE CLUES ARE IN, THE CHASE IS ON, AND THE

CASE OF THE CENTURY IS ABOUT TO' BREAK WIDE OPEN IN DISNEY'S GREATEST LITTLE MYSTERY IN HISTORY! LET THE GREAT MOUSE DETECTIVE TAKE YOU ON AN ADVENTURESOME JOURNEY THROUGH THE COBBLESTONE STREETS OF 1897 LONDON, WHERE SOME SUSPICIOUS "MOUSECHIEF" IS THE ADVENTURE START TO THS THRILLNG MUSICAL ADVENTURE. OLIVIA, THE BRAVE DAUGHTER OF A BELIE STREET FOD HEP WITH HEP FATHER'S DISAP. BAKER STREET FOR HELP WITH HER FATHER'S DISAP PEARANCE. BASILS JOLLY ASSISTANT, DR. DAWSON AND LOYAL DOG TOBY LEND A HAND ... AND NOSE ... AS THEY SNIFF OUT CLUES THROUGH THEIR CHARMING MINIATURE WORLD. THE FINAL CHASE LEADS TO PROFESSOR RATIGAN (VINCENT PRICE), A HARD-HEARTED CRIMINAL WHOM BASIL. MUST OUTWIT TO SAVE ALL OF MOUSEDOM!

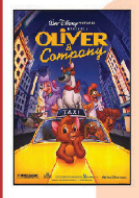

\section{OLIVER AND COMPANY}

1988

RT SCORE: 50

EXPERIENCE A MAGICAL ADVENTURE, FILLED WITH FRIENDSHIP, FUN AND "PAWS-ITIVELY" COOL MUSIC IN OLIVER AND COMPANY! OLIVER, A FEISTY YOUNG CAT, EXPLORES NEW YORK IN THIS THRILLING ANIMATED CLASSIC CLEVERLY BASED ON CHARLES DICKENS' TIMELESS STORY, OLIVER TWIST - FEATURING UNFORGETTABLE SONGS PERFORMED BY MUSICAL GREATS BILLY JOEL, HUEY LEWIS AND BETTE MIDLER! JOINED BY A PACK OF HILARIOUS CHARACTERS DOGS DODGER, TITO AND THEIR PALS - OLIVER KNOWS HE'S FOUND A LIFELONG FRIEND AND A REAL HOME. 


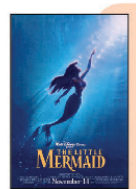

THE LITTLE MERMAID

1989

RT SCORE: 93

ARIEL, THE FUN-LOVING AND MISCHIEVOUS MERMAID, IS ENCHANTED WITH ALL THINGS HUMAN. DISREGARD ING HER FATHER'S ORDER TO STAY AWAY FROM THE WORLD ABOVE THE SEA, SHE SWIMS TO THE SURFACE AND, IN A RAGING STORM, RESCUES THE PRINCE OF HER DREAMS. DETERMINED TO BE HUMAN, SHE STRIKES A BARGAIN WITH THE DEVIOUS SEA WITCH URSULA AND TRADES HER FINS AND BEAUTIFUL VOICE FOR LEGS. WITH HER BEST FRIEND, THE ADORABLE AND CHATTY FLOUNDER, AND HER RELUCTANT CHAPERONE SEBASTIAN, THE HILARIOUS, REGGAE-SINGING CARIBBEAN CRAB, AT HER SIDE, ARIEL MUST WIN THE PRINCE'S LOVE AND SAVE HER FATHER'S KINGDOM - ALL IN A HEART-POUNDING RACE AGAINST TIME.

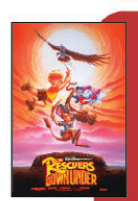

THE RESCUERS DOWN UNDER

1990

HOLD ON TIGHT FOR THRILING FAST-PACED ADVENTURE IN THE HEART OF AUSTRÁLIA IN DISNEY'S

ANIMATED CLASSIC THE RESCUERS DOWN UNEER! DEEP

BACK, A YOUNG BOY NAMED CODY FORGES AN

INCRÉDIBLE FRIENDSHIP WITH A GREAT GOLDEN EAGLE BUT WHEN A RUTHLESS POACHER SETS OUT TO CAPTURE THE EAGLE, CODY STEPS IN TO PROTECT HIM. KNOWING HE CAN'T DO IT ALONE, A CALL FOR HELP GOES OUT THAT'S ANSWERED BY THE FIVING IN ON THE WINGS OF THEID HII ADIOUS ALBATROSS FRIEND WILBUR, THESE TOP MOUSE AGENTS ARE READY TO TACKLE THEIR BIGGEST MOST DANGEROUS MISSION YET! SAY "G'DAY" 'TO A CLASSIC DISNEY ADVENTURE FULL OF HEARTWARMING DOWN-UNDER DELIGHT YOUR FAMILY WILL LOVE

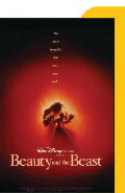

BEAUTY AND THE BEAST

1991

RT SCORE: 94

JOIN BRAVE, INDEPENDENT BELLE ON THE ADVENTURE OF A LIFETIME AS SHE SETS OUT TO RESCUE HER FATHER - AND DISCOVERS THE ENCHANTED CASTLE OF A MYSTERIOUS BEAST. ENJOY THIS TIMELESS TALE OVERFLOWING WITH UNFORGETTABLE CHARACTERS AND MUSIC YOU'LL NEVER FORGET.

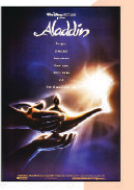

ALADDIN

1992

RT SCORE: 95

WHAT WOULD YOU DO IF A POWERFUL GENIE GRANTED YOU THREE WISHES? RELIVE THE THRILLING POSSIBILITIES IN DISNEY'S ANIMATED CLASSIC ALAD. DIN-NOW PART OF THE ESTEEMED WALT DISNEY SIGNATURE COLLECTION. JOIN THE CHARMING STREET RAT ALADDIN, THE DETERMINED PRINCESS JASMINE AND THE HILARIOUS GENIE ON A WONDROUS JOURNEY FILLED WITH ACTION, LAUGHTER ICONIC ANIMATION AND ACADEMY AWARD ${ }^{\circledR}$ - WINNING MUSIC (BEST ORIGINAL SONG AND BEST ORIGINAL SCORE 1992). SOAR AWAY TO "A WHOLE NEW WORLD" IN DISNEY'S ANIMATED MASTERPIECE.

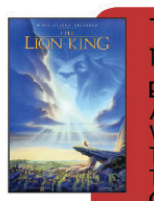

\section{THE LION KINC}

1994

RT SCORE: 93

MBARK ON AN EXTRAORDINARY COMING-OF-AGE

WAIT TO BE KING, SEARCHES, FOR HIS DESTINY IN

THE GREAT "CIRCLE OF LIFE." YOU WILL BE

THRILLED BY THE BREATHTAKING ANIMATION, UNFOR-

GE TABLE ACADEMY AWARD WINNING MUST (1994:

BEST ORIGINAL SCORE; BEST SONG "(AN YOU FEEL
THE LOVE TONIGHT"), AND TIMELESS STORY.

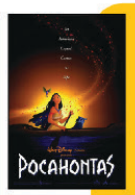

POCAHONTAS

1995

RT SCORE: 55

DISNEY HEROINE POCAHONTAS SPARKLES WITH ALL THE "COLORS OF THE WIND" IN THIS CAPTIVATING CLASSIC INSPIRED BY A REAL-LIFE AMERICAN LEGEND. FUN AND EXCITEMENT ARE "JUST AROUND THE RIVERBEND AS THE FREE-SPIRITED POCAHONTAS AND HER WOODLAND PALS MEEKO AND FLIT, DISCOVER THE FIRST ENGLISH SETTLERS ON THE SHORES OF THEIR VILLAGE. WITH THE GUIDANCE AND WISDOM OF HER BELOVED GRANDMOTHER WILLOW AND THE FRIENDSHIP OF THE COURAGEOUS CAPTAIN JOHN SMITH, POCAHONTAS MUST FIND A WAY TO BRIDGE THE DIVIDE BETWEEN THE TWO VASTLY DIFFERENT CULTURES. WITH RICH ANIMATION AND ACADEMY AWARD ${ }^{\otimes}$ - WINNING MUSIC, DISNEY'S POCAHONTAS IS A FUN-FILLED TALE OF ADVENTURE, FRIENDSHIP AND COURAGE THAT YOUR FAMILY WILL CHERISH FOREVER.

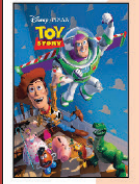

STORY

1995 RT SCORE: 100

EVER WONDER WHAT TOYS DO WHEN PEOPLE AREN'T AROUND? TOY STORY ANSWERS THAT QUESTION WITH A FANTASTIC FUN-FILLED JOURNEY, VIEWED MOSTLY THROUGH THE EYES OF TWO RIVÁL TOYS - WOODY THE LANKY, LIKABLE COWBOY AND BUZZ LIGHTYEAR, THE FEARLESS SPACE RANGER. LED BY WOODY, ANDY's TOYS LIVE HAPPILY IN HIS YEAR ONTO THE SCEN AFPAD OF LOZL LIGH YEAR ONTO THE SCENE. AFRADY OF LOSZ L HIS BUAZ.

BUT WHEN CIRCUMSTANCES SEPARATE BUZZ AND WOODY FROM THEIR OWNER, THE COMICALLY-MIS. WOODY FROM THEIR OWNER, THE COMICALLY-MISMATCHED DUO EVENTUALY LEARN TO PUT ASIDE
THEIR DIFFERENCES, AND THEY FIND THEMSELVES ON A HILARIOUS ADVENTURE-FILLED MISSION WHERE THE ONIY WAY THEY CAN SURVIVE IS TO FORM AN UNEASY ALLIANCE.

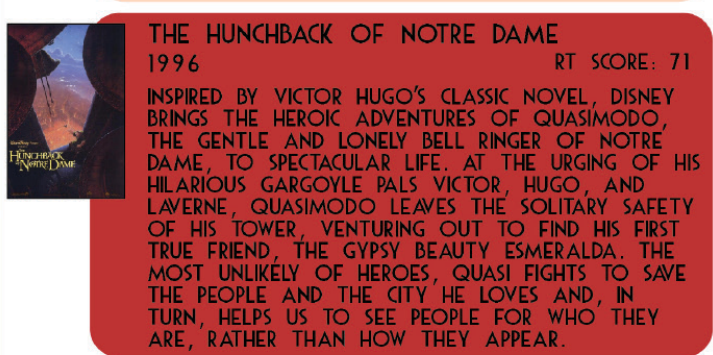

HERCULES

1997 RT SCORE: 84

AN OUTRAGEOUS ODYSSEY OF FUN, FANTASY, AND ADVENTURE UNFOLDS IN THE HILARIOUS HIT FILM HERCULES. TAKEN FROM THE GODS AS A NEWBORN, ADOPTED ON EARTH, HERCULES BECOMES AN AWKWADD TTENAGE PILLAR OF STRENGTH. TRYING TO FIT IN, HE DISCOVERS HIS DAD IS ZEUS AND HOME IS MOUNT, OLYMPUS -IF HE CAN MOVE FROM BABYHOOD PAL PEGASUS THE FIYING STAUION AND PHIL ‥ A FEISTY PERSONAL TRAINER ... FOR THE MISSION BUT IT'S NO EASY TASK AS HE MUST MATCH WITS WITH GRECAN BEAUTY MEG AND A COMICA HOTHEAD NAMED HADES WITH THE HEDP OF PAIN AND PANIC HADES PLANS TO PUIE THE UNIVEPSE WITH ONIÝ HADPUIES STANDING IN HIS WAY! WITH A BOLD ANIMATION STYLE, COLOSSAL VOICE CAST AND SPECTACULAR MUSIC, HERCULES IS UNMÁTCHED IN STRENGTH $\cdots$ DELIVERING SOMETHING FOR EVERYONE. 


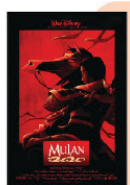

MULAN

1998

RT SCORE: 86

CLEVER MULAN PROVES HER WORTH OUTSIDE OF HER TRADITION-BOUND SOCIETY WHEN, DISGUISED AS MALE SOLDIER "PING, SHE BRAVELY TAKES HER FATHER'S PLACE IN CHINA'S IMPERIAL ARMY. HELPED BY HER OUTRAGEOUSLY FUNNY GUARDIAN DRAGON MUSHU AND A LUCKY CRICKET NAMED CRI-KEE, MULAN STRIVES TO EARN THE RESPECT OF HER FELLOW WARRIORS AND THEIR COURAGEOUS CAPTAIN SHANG. MULAN'S ADVENTURES LEAD TO A CLIMACTIC BATTLE ATOP THE IMPERIAL PALACE, WHERE HER FAMILY'S HONOR AND THE FATE OF THE EMPEROR AND ALL OF CHINA RESTS IN HER HANDS.
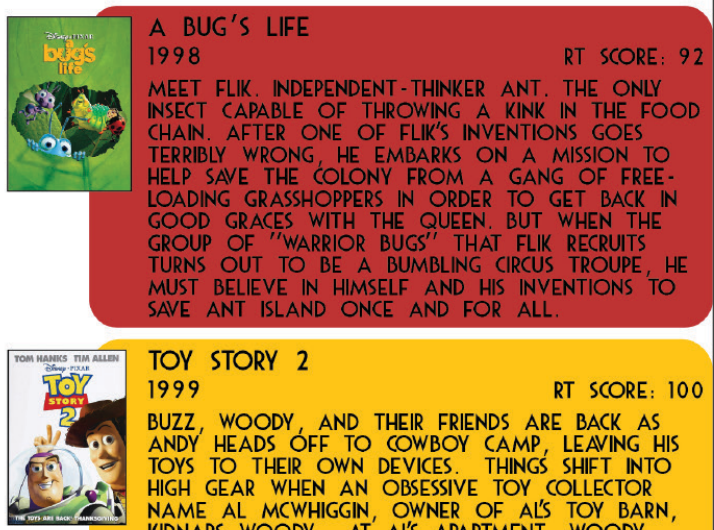

TOY STORY 2

1999

RT SCORE: 100

BUZZ, WOODY, AND THEIR FRIENDS ARE BACK AS

ANDY HEADS OFF TO COWBOY CAMP, LEAVING HIS

TOYS TO THEIR OWN DEVICES. THINGS SHIFT INTO

HIGH GEAR WHEN AN OBSESSIVE TOY COLLECTOR

NAME AL MCWHIGGIN, OWNER OF AL'S TOY BARN, DISCOVERS THAT HE IS A HIGHLY VALUED COLLECTIBLE FROM A "1950 S TV SHOW CALLED WOODY'S ROUNDUP, HE MEETS THE OTHER PRIZED TOYS FROM THE SHOW: JESSIE THE COWGIRL, BULLSEYE THE HORSE, AND STINKY PETE THE PROSPECTOR ANDY'S TOYS MOUNT A DARING RESCUE MISSION, BUZZ LIGHTYEAR MEETS HIS MATCH, AND WOODY HAS TO DECIDE WHERE HE AND HIS' HEART TRULY BELONG.

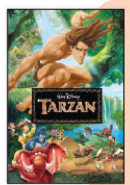

TARZAN

1999

RT SCORE: 89

DISNEY'S MAGNIFICENT ANIMATED ADAPTATION OF EDGAR RICE BURROUGHS'S STORY OF THE APE MAN BEGINS DEEP WITHIN THE JUNGLE WHEN BABY TARZAN IS ADOPTED BY A FAMILY OF GORILLAS. EVEN THOUGH HE IS SHUNNED AS A "HAIRLESS WONDER" BY THEIR LEADER, TARZAN IS ACCEPTED BY THE GORILLAS AND RAISED AS ONE OF THEIR OWN. TOGETHER WITH HIS WISECRACKING APE BUDDY TERK AND NEUROTIC ELEPHANT PAL TANTOR, TARZAN LEARNS HOW TO "SURF" AND SWING THROUGH THE TREES AND SURVIVE IN THE ANIMAL KINGDOM. HIS "TWO WORLDS" COLLIDE WITH THE ARRIVAL OF HUMANS, FORCING TARZAN TO CHOOSE BETWEEN A "CIVILIZED" LIFE WITH THE BEAUTIFUL JANE AND THE LIFE HE KNOWS AND LOVES WITH HIS GORILLA FAMILY.

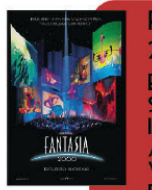

ANTASIA 2000

2000

RT SCORE:

XPERIENCE AN EXTRAVAGANZA OF SIGHT AND

SOUND IN FANTASIA 2000 , THE TRIUMPHANT CLASSIC
NSPIRED BY WALT DISNEY'S VISION OF FANTASIA AS

A CONTINUING WORK -IN-PROGRESS FULIY IMMER

BLEND OF MUSIC AND ANIMATED IMAGERY. SEE THE

BLEND OF MUSIC AND ANIMATED IMAGERY. SEE
MUSIC COME TO LIFE, HEAR THE PICTURES BURST INTO SONG AND SHARE THE EXCITEMENT THAT FANTASIA 2000 WITH YOUR FAMILY AGAIN AND
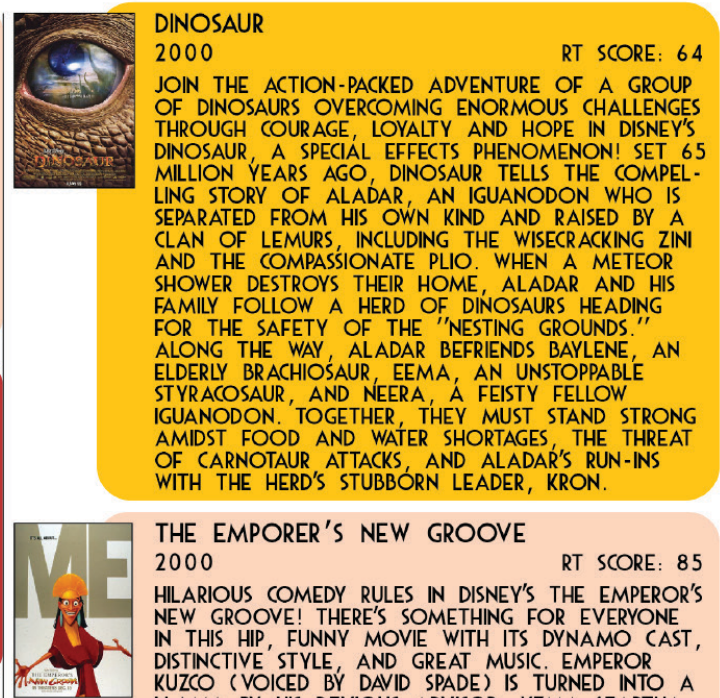

THE EMPORER'S NEW GROOVE

2000

RT SCORE: 85

HILARIOUS COMEDY RULES IN DISNEY'S THE EMPEROR'S NEW GROOVE! THERE'S SOMETHING FOR EVERYONE IN THIS HIP, FUNNY MOVIE WITH ITS DYNAMO CAST, DISTINCTIVE' STYLE, AND GREAT MUSIC. EMPEROR KUZCO (VOICED BY DAVID SPADE) IS TURNED INTO A LLAMA BY HIS DEVIOUS ADVISOR, YZMA (EARTHA KITT), AND HER HUNKY HENCHMÁN, KRONK (PATRICK WARBURTON). NOW THE RULER WHO ONCE HAD IT ALL MUST FORM AN UNLIKELY ALLIANCE WITH A PLEASANT PEASANT NAMED PACHA (JOHN GOODPLEASANT PEASANT NAMED PACHA (JOHN GOOD DIFFERENCES AS THEY EMBARK ON A HILARIOUS, "GROOVY" ADVENTURE. DISCOVERING THE GOOD' IN EVERYONE HAS NEVER BEEN THIS MUCH FUN!
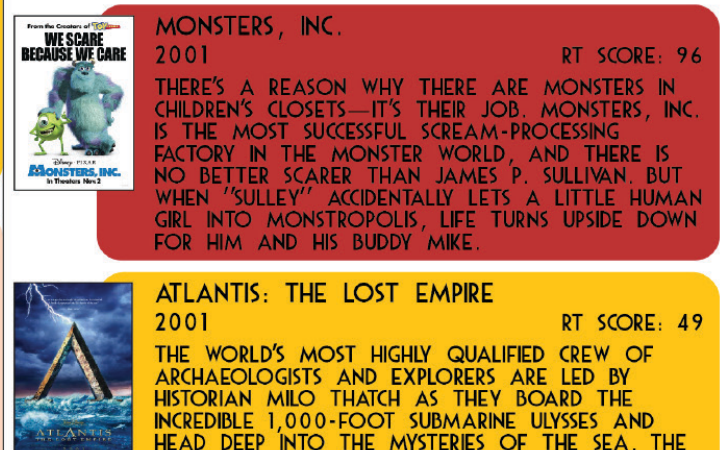

ATLANTIS: THE LOST EMPIRE

2001

RT SCORE: 49

THE WORLD'S MOST HIGHLY QUALIFIED CREW OF ARCHAEOLOGISTS AND EXPLORERS ARE LED BY HISTORIAN MILO THATCH AS THEY BOARD THE INCREDIBLE 1,000-FOOT SUBMARINE ULYSSES AND HEAD DEEP INTO THE MYSTERIES OF THE SEA. THE UNDERWATER EXPEDITION TAKES AN UNEXPECTED TURN WHEN THE TEAM'S MISSION MUST SWITCH FROM EXPLORING ATLANTIS TO PROTECTING IT. FILLED WITH STUNNING VISUAL EFFECTS, THIS CAPTIVATING STORY IS LOADED WITH LAUGHS AND MESSAGES OF FRIENDSHIP AND TEAMWORK.

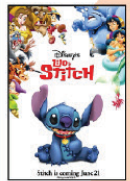

LILO AND STITCH

2002

RT SCORE: 86

LILO'S AN INDEPENDENT LITTLE GIRL: STITCH IS A

MISCHIEVOUS CREATURE FROM OUTER SPACE, AND

WHEN THEIR WORLDS COLLIDE, IT'S LOVE - AND

CHAOS! - AT FIRST SIGHT PACKED WITH ACTION HUMOR AND HEART, THIS WINNING TALE CELEBR'ATES THE BONDS OF FAMIILY ('OHANA) AND FRIENDSHIP! 


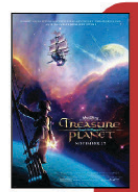
TREA
2002 BUCKLE UP FOR THRILLS AND EXCITEMENT AS A CLASSIC STORY OF FRIENDSHIP, COURAGE, AND
SEIF-DISCOVERY GETS AN INCREDIBLE FUTURISTIC TWIST FOD AN AEII-NEW GENERATION A SECRET TWIST FOR AN ALL-NEW GENERATION. A SECRET
MAP INSPIRES A THRILLING TREASURE HUNT ACROS MAP INSPIRES A S YRILING JIM HAWKINS AND A HILARIOUS COSMIC CREW HEADED BY THE DARING CAPTAIN AMELIA SET OFF IN SEARCH OF THEIR DESTINY. ABOARD A GLITTERING SPACE GALLEON, JIM MEETS THE SHP'S CYBORG COOK, JOHN SILVER, WHO TEACHES HIM THE VALUE OF FRIENDSHIP AND THE POWER OF DREAMS. JIM SOON TEAMS UP WITH HIS CRAZY NEW ROBOT PAL, B.E.N., AND THE SHAPE-SHIFTING MORPH TO DISCOVER A TREASURE
GREATER THAN HE EVER IMAGINED.

BROTHER BEAR

2003

RT SCORE: 37

DISNEY PROUDLY PRESENTS BROTHER BEAR, AN EPIC ANIMATED ADVENTURE FULL OF COMEDY AND HEART WITH FIVE GREAT SONGS FROM ACADEMY AWARD WINNER PHIL COLLINS (BEST ORIGINAL SONG). WHEN AN IMPULSIVE BOY NAMED KENAI IS MAGICALLY TRANSFORMED INTO A BEAR, HE MUST LITERALLY WALK IN ANOTHER'S FOOTSTEPS UNTIL HE LEARNS SOME VALUABLE LIFE LESSONS. HIS COURAGEOUS AND OFTEN ZANY JOURNEY INTRODUCES HIM TO A FOREST FULL OF WILDLIFE, INCLUDING THE LOVABLE BEAR CUB KODA, HILARIOÚS MOOSE RUTT AND TUKE, WOOLLY MAMMOTHS, RAMBUNCTIOUS RAMS, AND MORE!

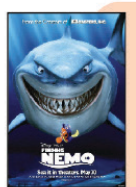

\section{FINDING NEMO}

2003

RT SCORE: 99

IN THE COLORFUL AND WARM TROPICAL WATERS OF THE GREAT BARRIER REEF, A CLOWN FISH NAMED MARLIN LIVES SAFE AND SECLUDED IN HIS ANEMONE MOME WI HS NLY SON, NEMO. FEARFUL OF THE OCEAN AND ITS UNPREDICTABLE RISKS, HE STRUGGLES TO PROTECT HIS SON. NEMO, LIKE ALL YOUNG FSH, IS EAGER TO EXPLORE TEE MYSTERIOU REEF. WHEN NEMO IS UNEXPECTEDLY TAKEN FAR FROM HOME AND THRUST INTO A TACKY DENTIST'S OFFICE FISH TANK, MARLIN FINDS HIMSELF THE
UNLIKELY HERO ON AN EPIC JOURNEY TO RESCUE HIS SON.

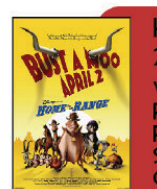

HOME ON THE RANGE

2004

WHEN A GREEDY OUTLAW SCHEMES TO TAKE

POSSESSION OF THE "PATCH OF HEAVEN" DAIRY

FARM, THREE DETERMINED COWS, A KARATE-KICKING

OF CRITTERS JOIN FORCES TO SAVE THEIR HOME. THE STAKES ARE SKY HIGH AS THIS UNLIKELY ANIMAL A MYSTERIOUS BAND OF BAD GUYS.

THE INCREDIBLES

2004

RT SCORE: 97

IT TAKES A WILL OF STEEL TO HIDE YOUR SUPERHERO TALENTS FROM A WORLD THAT STILL NEEDS YOU, YET NO LONGER APPRECIATES WHAT YOU CAN DO. 'BATTLING A BULGING BELLYY AND A BORING JOB, MR. INCREDIBLE LONGS FOR THE GLORY DAYS OF UPHOLDING LAW AND ORDER WHILE HIS SUPERHUMAN FAMIIY TRIES TO FIT IN WITH THEIR "NORMAL" LIFE. RELIEF FROM QUIET SUBURBIA FINALLY COMES YEARS IATER WHEN THE FAMILY UNCOVERS A DIABOLICAL PLAN AND MUST BRING TOGETHER THEIR RESPECTIVE STRENGTHS TO SAVE THE DAY.

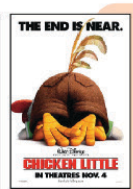

CHICKEN LITTLE

2005

RT SCORE: 37

WHEN THE SKY REALLY IS FALLING AND SANITY HAS FLOWN THE COOP, WHO WILL RISE TO SAVE THE DAY? TOGETHER WITH HIS HYSTERICAL BAND OF MISFIT FRIENDS, CHICKEN LITTLE MUST HATCH A PLAN TO SAVE THE PLANET FROM ALIEN INVASION AND PROVE THAT THE WORLD'S BIGGEST HERO IS A
LITTLE CHICKEN.
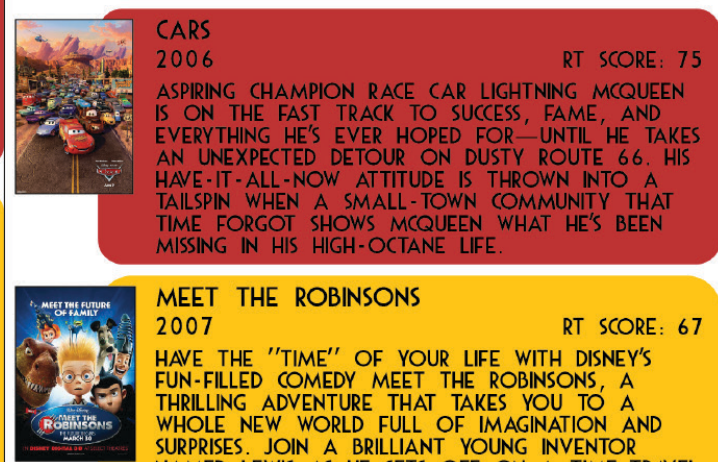

MEET THE ROBINSONS

2007

RT SCORE: 67

HAVE THE "TIME" OF YOUR LIFE WITH DISNEY'S

FUN-FILED COMEDY MEET THE ROBINSONS, A

THRILLING ADVENTURE THAT TAKES YOU TO A WHOLE NEW WORLD FULL OF IMAGINATION AND SURPRISES. JOIN A BRILLIANT YOUNG INVENTO NAMED LEWIS AS HE SETS OFF ON A TIME-TRAVELNNG JOURNEY TO FIND THE FAMILY HE NEVER KNEW NPO FANTASTCAL WORLD OF 2033 'S HP-HOPPN' FROGS AND DOGS THAT WEAR GLASSES ARE AS TWIST I AW TALKING DINOSAURS. IN AN AMAZING TWTS FUTURE RESIS IN HIS HANDS, BUT HE CANT SAVE IT ALONE $O$ HE'LL NEED EVERY B WOF HELP HE CAN GE FAMILY, WHO HELP HIM LEARN TO KEEP MOVING FORWARD AND NEV HIM STOP BELIEVNG IN MIMSELF. BLAST OFF WTH MEET PHE ROBNSONS .. IT'S AN EXCITING TRIP YOUR WHOLE FAMILY WILL ENJOY!

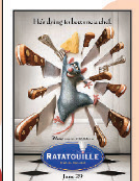

RATATOUILLE

RT SCORE: 96

A RAT NAMED REMY DREAMS OF BECOMING A GREAT CHEF DESPITE HIS FAMILY'S WISHES, AND THE OBVIOUS PROBLEM OF BEING A RAT IN A DECIDEDLY RODENT-PHOBIC PROFESSION. WHEN FATE PLACES REMY IN THE SEWERS OF PARIS, HE FINDS HIMSELF IDEALLY SITUATED BENEATH A RESTAURANT MADE FAMOUS BY HIS CULINARY HERO AUGUSTE GUSTEAU. REMY'S PASSION FOR COOKING SOON SETS INTO MOTION A HILARIOUS AND EXCITING RAT RACE THAT TURNS THE WORLD OF PARIS UPSIDE DOWN.

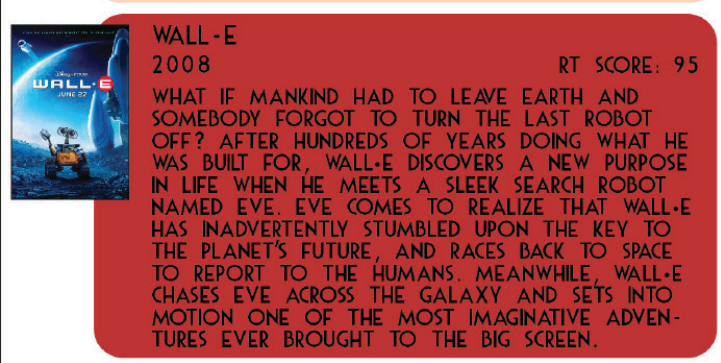




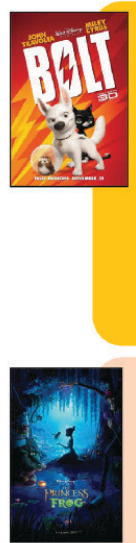

$\mathrm{BOLT}$

2008

RT SCORE: 89

GET READY FOR THE MOST PAWS-ITIVELY AWESOME ADVENTURE EVER! BOLT IS THE STAR OF THE BIGGEST SHOW IN HOLLYWOOD. THE PROBLEM IS, HE THINKS IT'S REAL, AND AFTER HE'S ACCIDENTALLY SHIPPED TO NEW YORK CITY, HE'S DETERMINED TO UNLEASH HIS MIND-BLOWING "SUPER POWERS" TO DEFEAT EVIL AND FIND A WAY HOME! EXPERIENCE ALL THE HIGH-FLYING, DEATH-DEFYING STUNTS BOLT AND HIS HILARIOUS SIDEKICKS PERFORM AS THEY SET OFF ON THEIR INCREDIBLE JOURNEY - AN ACTION-PACKED QUEST IN WHICH BOLT DISCOVERS YOU DON'T NEED SUPER POWERS TO BE A HERO.

THE PRINCESS AND THE FROG

2009

RT SCORE: 85

WALT DISNEY ANIMATION STUDIOS PRESENTS THE

MUSICAL THE PRINCESS AND THE FROG, AN ANIMATED COMEDY SET IN THE GREAT CITY OF NEW ORLEANS. THIS IS A MODERN TWIST ON A CLASSIC TALE FEATURING A BEAUTIFUL GIRL NAMED TIANA (ANIKA NONI ROSE), A FROG PRINCE WHO DESPERATELY WANTS TO BE HUMAN AGAIN, AND A FATEFUL KISS THAT LEADS THEM BOTH ON A HILARIOUS ADVENTURE THROUGH THE MYSTICAL BAYOUS OF LOUISIANA. THE PRINCESS AND THE FROG MARKS THE RETURN TO HAND-DRAWN ANIMATION FROM THE REVERED TEAM OF JOHN MUSKER AND RON CLEMENTS WITH MUSIC BY OSCAR ${ }^{\circledR}$. WINNING COMPOSER RANDY NEWMAN.

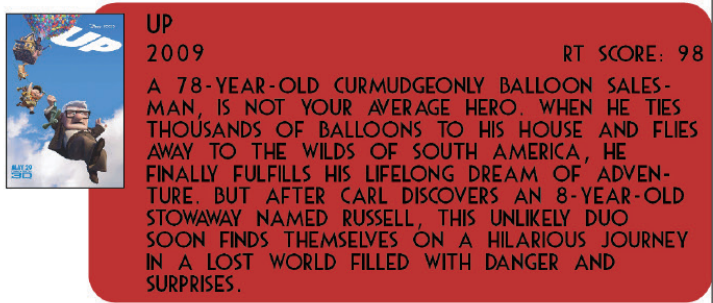

TANGLED

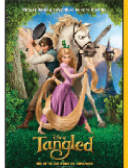

2010

RT SCORE: 89

WHEN THE KINGDOM'S MOST WANTED-AND MOS CHARMING-BANDIT, FLYNN RIDER (ZACHARY LEVI), HIDES OUT IN A MYSTERIOUS TOWER, HE'S TAKEN HOSTAGE BY RAPUNZEL (MANDY MOORE), A BEAUTIFUL AND FEISTY TOWER-BOUND TEÉN WITH 70 FEET OF MAGICAL, GOLDEN HAIR. FLYNN'S CURIOUS CAPTOR, WHO'S LOOKING FOR HER TICKET OUT OF THE TOWER WHERE SHE'S BEEN LOCKED AWAY FOR YEARS, STRIKES A DEAL WITH THE HANDSOME THIEF, AND THE UNLIKELY DUO SETS OFF ON AN ACTION-PACKED ESCAPADE, COMPLETE WITH A SUPER - COP HORSE (MAXIMUS), AN OVER-PROTECTIVE CHAMELEON (PASCAL), AND A GRUFF GANG OF PUB THUGS.

TOY STORY 3

2010

RT SCORE: 98

THE CREATORS OF THE BELOVED TOY STORY FILMS RE-OPEN THE TOY BOX AND BRING MOVIEGOERS BACK TO THE DELIGHTFUL WORLD OF OUR FAVORITE GANG OF TOY CHARACTERS IN TOY STORY 3. AS ANDY PREPARES TO DEPART FOR COLLEGE, BUZZ,
WOODY AND THE REST OF HIS LOYAL TOYS ARE WOOUY, AND THE REST OF HIS LOYAL TOYS

TOY STORY 3 IS A COMICAL ADVENTURE THAT LANDS THE TOYS IN A ROOM FULL OF UNTAMED TOTS WHO CAN'T WAIT TO GET THEIR STICKY LITTLE AS THE TOYS TRY TO STAY TOGETHER, ENSURING AS THE TOYS TRY TO STAY TOGETHER, ENSURING
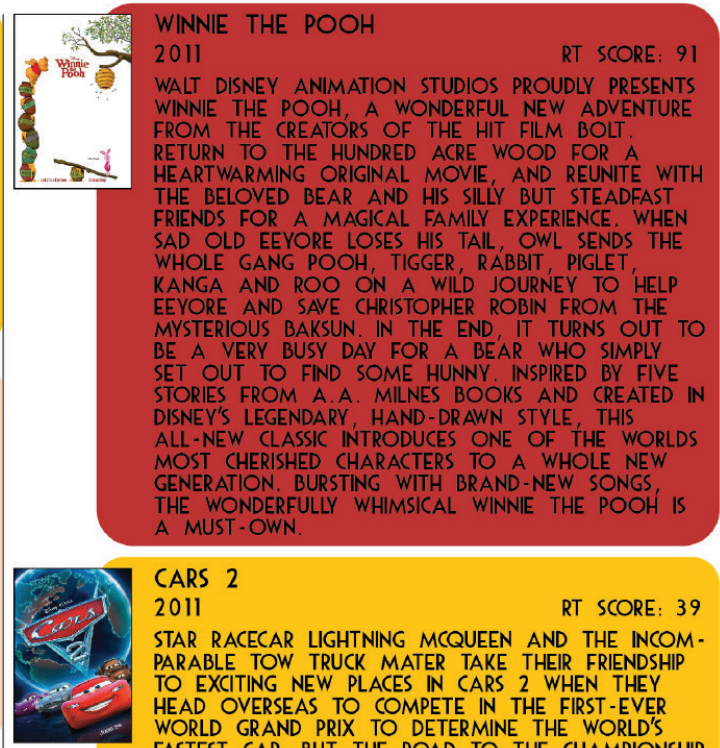

CARS 2

2011

RT SCORE: 39

STAR RACECAR LIGHTNING MCQUEEN AND THE INCOMPARABLE TOW TRUCK MATER TAKE THEIR FRIENDSHIP TO EXCITING NEW PLACES IN CARS 2 WHEN THEY HEAD OVERSEAS TO COMPETE IN THE FIRST-EVER WORLD GRAND PRIX TO DETERMINE THE WORLD'S FASTEST CAR. BUT THE ROAD TO THE CHAMPIONSHIP IS FILLED WITH PLENTY OF POTHOLES, DETOURS, AND HILARIOUS SURPRISES WHEN MATER GETS CAUGHT UP IN AN INTRIGUING ADVENTURE OF HIS OWN: INTERNATIONAL ESPIONAGE.

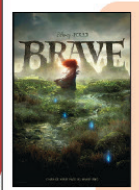

BRAVE

2012

RT SCORE: 78

SINCE ANCIENT TIMES, STORIES OF EPIC BATTLES AND MYSTICAL LEGENDS HAVE BEEN PASSED THROUGH THE GENERATIONS ACROSS THE RUGGED AND MYSIERIOUS HIGLLANDS OF SCOTLAND. A NEW TALE JOINS THE LORE WHEN THE COURAGEOUS MERIDA CONFRONTS
TRADITION AND CHALLENGES DESTINY TO CHANGE TRADITION
HER FATE.
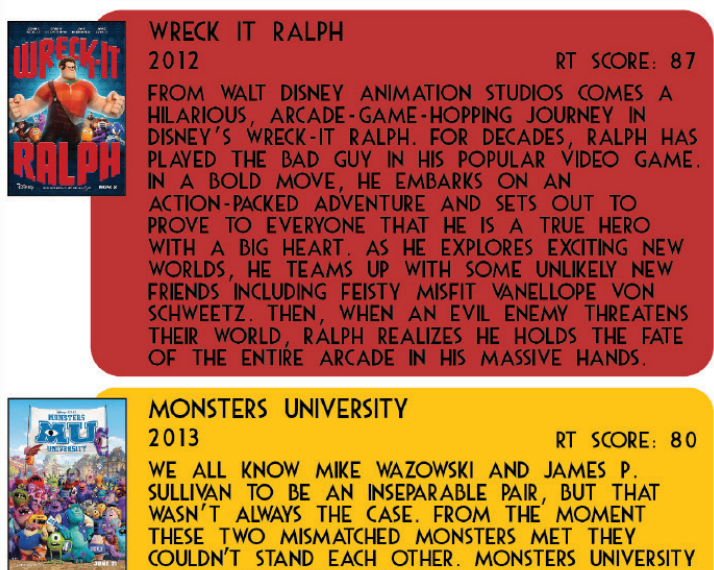

MONSTERS UNIVERSITY

2013

RT SCORE: 80

WE ALL KNOW MIKE WAZOWSKI AND JAMES $P$. SULLIVAN TO BE AN INSEPARABLE PAIR, BUT THAT SULIVA TO BE AN INSEPARABLE PAIR, BUT THAT
WASN'T ALWAYS THE CASE. FROM THE' MOMENT THESE TWO MISMATCHED MONSTERS METT THEY
COULDN'T STAND EACH OTHER. MONSTERS UNIVERSITY UNLOCKS THE DOOR TO HOW MIKE AND SULLEY OVERCAME THEIR DIFFERENCES AND BECAME THE BEST OF FRIENDS. 


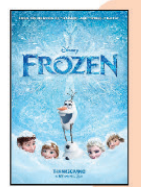

FROZEN

2013

RT SCORE: 90

IN FROZEN, FEARLESS OPTIMIST ANNA TEAMS UP WITH RUGGED MOUNTAIN MAN KRISTOFF AND HIS OYAL REINDEER SVEN IN AN EPIC JOURNEY ENCOUNTERING EVEREST-LIKE CONDITIONS, MiYSTICAL TROLLS AND A HILARIOUS SNOWMAN NÁMED OLAF IN A RACE TO FIND ANNA'S SISTER ELSA, WHOSE KCY POWERS HAVE TRAPPED THE KINGDOM ÓF AREN DELLE IN ETERNAL WINTER.
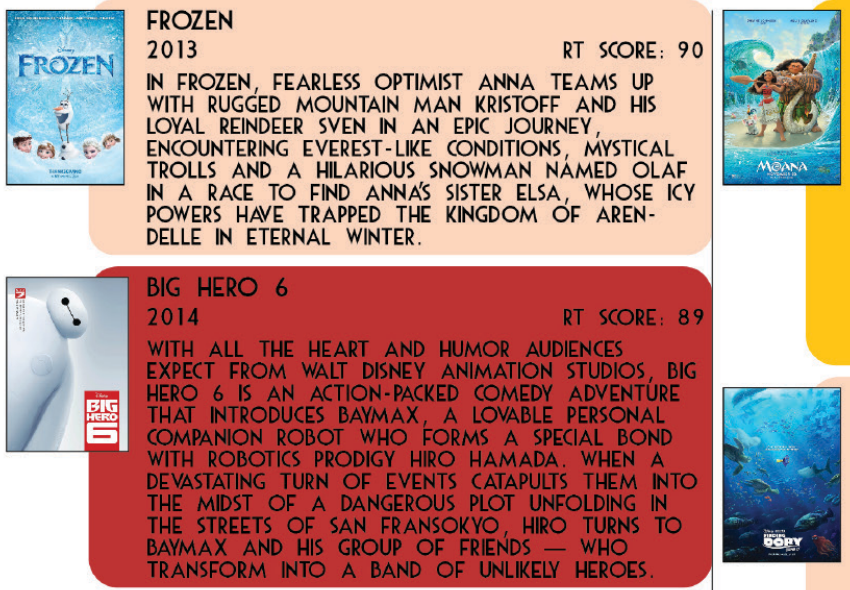

MOANA

2016

RT SCORE: 95

FROM WALT DISNEY ANIMATION STUDIOS COMES MOANA, AN EPIC ADVENTURE ABOUT A SPIRITED TEEN WHO SETS SAIL ON A DARING MISSION TO PROVE HERSELF, A MASTER WAYFINDER AND FULFILL HER ANCESTORS' UNFINISHED QUEST. DURING HER JOURNEY, MOANA (AULI'I CRAVALHO) MEETS THE MIGHTY DEMIGOD MAUI (DWAYNE JOHNSON), AND TOGETHER THEY CROSS THE OCEAN ON A FUN-FILLED, ACTION-PACKED VOYAGE, ENCOUNTERING ENORMOUS' SEA CREATURES, BREATHTAKING UNDERWORLDS AND IMPOSSIBLE ODDS. ALONG THE WAY MOANA DISCOVERS THE ONE THING SHE'S ALWAYS SOUGHT: HER OWN IDENTITY.

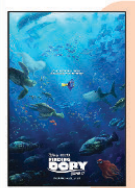

\section{FINDING DORY}

2016 RT SCORE: 94

FORGETFUL BLUE TANG DORY IS LIVING HAPPILY IN THE REEF WITH MARLIN AND NEMO. WHEN DORY SUDDENLY REMEMBERS THAT SHE HAS A FAMILY OUT THERE WHO MAY BE LOOKING FOR HER, THE TRIO TAKES OFF ON A LIFE-CHANGING ADVENTURE ACROSS THE OCEAN TO CALIFORNIA'S PRESTIGIOUS MARINE LIFE INSTITUTE A REHABILITATION CENTER AND AQUARIUM IN AN EFFORT TO FIND HEP MOM AND DAD DORY ENLSTS THE HELP OF THREE OF THE MLI'S MOST INTRIGUING RESIDENTS: HANK, A
CANTANKEROUS "SEPTOPUS" WHO FREQUENTLY GIVES EMPLOYEES THE SLIP; BAILEY, A BELUGA WHALE WHO IS CONVINCED HIS BIOLOGICAL SONAR SKILLS ARE ON THE FRITZ; AND DESTINY, A NEARSIGHTED WHALE SHARK. DEFTLY NAVIGATING' THE COMPLEX INNER WORKINGS OF THE MLI, DORY AND HER FRIENDS DISCOVER THE MAGIC WITHIN THEIR FLAWS, FRIENDSHIPS AND FAMILY. YOU ON AN EPIC JOURNEY INTO THE WORLD OF MANOSAURS WHERE AN APATOSAURUS NAMEL ARLIKELY HUMAN FRIEND. WHILE TRAVELING THROUGH A HARSH AND MYSTERIOUS LANDSCAPE, ARLO IEARNS THE POWER OF CONFRONTING HIS FEARS AND DISCOVERS WHAT HE IS TRULY CAPABLE OF

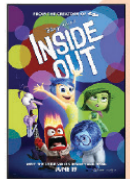

\section{INSIDE OUT}

RT SCORE: 98

GROWING UP CAN BE A BUMPY ROAD, AND IT'S NO EXCEPTION FOR RILEY, WHO IS UPROO'TED FROM

HER MIDWEST LIFE WHEN HER FATHER STARTS A NEW JOB IN SAN FRANCISCO. LIIE ALL OF US, RILEY IS GUIDED BY HER EMOTIONS - JOY, FEAR, ANGER, DISGUST AND SADNESS. THE EMOTIOONS LIVIV IN HEADQUARTERS, THE CONTROL CENTER INSIDE RILEY'S MIND, WHERE THEY HELP ADVISE HER THROUGH EVERYDAY LIFE. AS RILEY AND HER EMOTIONS STRUGGLE TO ADJUST TO A NEW LIFE IN SAN FRANCISCO, TURMOIL ENSUES IN HEADQUARTERS. ALTHOUGH JOY, RLLEY'S MAIN AND MOST IMPORTANT EMOTION, TRIES TO KEEP THINGS POSITIVE,
THE EMOTIONS' CONFLICT ON HOW BEST TO NAVIGATE A NEW CITY, HOUSE AND SCHOOL.

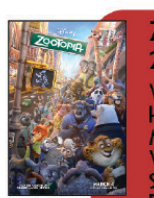

\section{ZOOTOPIA}

2016

RT SCORE:

DALT DISNEY ANIMATION STUDIOS PRESENTS A

MODERN MAMMAL METROPOLIS OF ZOOTOPIA

WITH HABITAT NEIGHBORHOODS LIKE RITZY SAHARA

QUAARE AND FRIGID TUNDRATOWN, IT'S A MELTING

POI WHERE ANIMALS FROM EVERY ENVIRONMENT

YOU ARE, FROM THE BIGGEST ELEPHANT TO THE

SMALLEST' SHREW, YOU CAN BE ANYTHING. BUT

WHEN OPTIMISTIC OFFICER JUDY HOPPS ARRIVES, SHE

DISCOVERS THAT BEING THE FIRST BUNNY ON A

POLICE FORCE OF BIG, TOUGH ANIMALS ISN'T SO

EASY DETERMINED TO' PROVE HERSELF, SHE JUMPS

IT MEANS PARTNERING WITH FAST - TALKING

CAM-ARTIST FOX NICK WILDE TO SOLVE THE

MYSTERY 

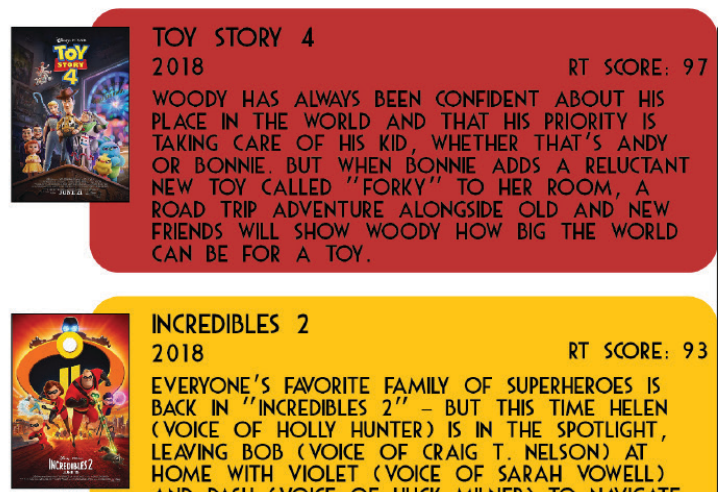

INCREDIBLES 2

2018

RT SCORE: 93

EVERYONE'S FAVORITE FAMILY OF SUPERHEROES IS BACK IN "INCREDIBLES 2" 2 - BUT THIS TIME HELEN (VOICE OF HOLLY HUNTER) IS IN THE SPOTLIGHT, LEAVING BOB (VOICE OF CRAIG T. NELSON) AT HOME WITH VIOLET (VOICE OF SARAH VOWELL) AND DASH (VOICE OF HUCK MILNER) TO NAVIGATE THE DAY-TO-DAY HEROICS OF "NORMAL" LLFE. IT'S A TOUGH TRANSITION FOR EVERYONE, MADE TOUGHER BY THE FACT THAT THE FAMIILY IS STILL UNAWARE OF BABY JACK-JACK'S EMERGING SUPERPOWERS. WHEN A NEW VILLAIN HATCHES A BRILLIANT AND DANGEROUS PLOT, THE FAMILY AND FROZONE (VOICE OF SAMUEL L.' JACKSON) MUST FIND A WAY TO WORK TOGETHER AGAIN - WHICH IS EASIER SAID THAN DONE, EVEN WHEN THEY'RE ALL INCREDIBLE.

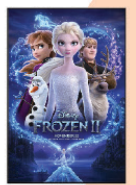

FROZEN ॥

2019

WHY WAS ELSA BOPN WITH MAGICAL POWES? 77 WHAT TRUTHS ABOUT THE PAST AWAIT EISA AS SHE VENTURES INTO THE UNKNOWN TO THE ENCHANTED FORESTS AND DARK SEAS BEYOND ARENDELE? THE ANSWERS ARE CALLING HER BUT ALSO THREATENING HER KINGDOM. TOGETHER WITH ANNA, KRISTOFF, OLAF AND SVEN, SHE'LL FACE A DANGEROUS BUT' REMARKABLE JOÚRNEY. IN FROZEN, ELSA FEARED HER POWERS WERE TOO MUCH FÓR THE WORLD. IN FROZEN 2, SHE MUST HOPE THEY ARE ENOUGH.

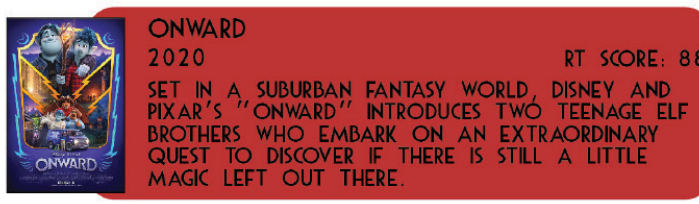




\section{BIBLIOGRAPHY}

A Bug's Life. Film. Canada: Pixar Animation Studios \&amp; Walt Disney Pictures, 1998.

Archigram. "Amazing Archigram 4: Zoom Issue," May 1964.

Bachelard, Gaston. The Poetics of Space. Penguin Books, 2014.

Barrier, Michael. The Animated Man: The Life of Walt Disney. Berkeley, CA: University of California Press, 2008.

Bazelon, Emily. "Police Reform Is Necessary. But How Do We Do It?" The New York Times. The New York Times, June 13, 2020. https://www.nytimes.com/interactive/2020/06/13/magazine/police-reform.html.

Beaudine, Gregory, Oyemolade Osibodu, and Aliya Beavers. "Disney's Metaphorical Exploration of Racism and Stereotypes: A Review of Zootopia." Comparative Education Review 61, no. 1 (2017): 227-34. https:// doi.org/10.1086/690061.

Bennett, Nathan. "Environmental Stewardship: A Conceptual Review and Analytical Framework." Environmental Management, no. 61 (April 2018): 597-614. https://doi.org/https://doi.org/10.1007/s00267-017-0993-2.

Berland, David I. "Disney and Freud: Walt Meets the Id." The Journal of Popular Culture XV, no. 4 (1982): 93-104. https://doi.org/10.1111/j.0022-3840.1982.1504-93.x.

Black Lives Matter, April 28, 2021. https://blacklivesmatter.com/.

"Black Lives Matter: Police Brutality in the Era of COVID-19." Lerner Center for Public Health Promotion, January 29, 2021. https://lernercenter.syr.edu/2020/06/16/ib-31.

Böck Ingrid. Six Canonical Projects by Rem Koolhaas: Essays on the History of Ideas. Berlin: Jovis, 2014.

Carson, Rachel. Silent Spring. Boston: Houghton Mifflin, 1962.

Carter, April. The Political Theory of Global Citizenship. New York, NY: Taylor \&amp; Francis Books, 2006.

Catmull, Ed, and Amy Wallace. Creativity, Inc.: Overcoming the Unseen Forces That Stand in the Way of True Inspiration. Toronto: Vintage Canada, 2014.

Christian, Jessi. "The New Hierarchy of Needs - Maslow's Lost Apex." Medium. Coachilla HQ May 13, 2020. https://medium.com/coachilla-hq/the-new-hierarchy-of-needs-maslows-lost-apex-5e51031ce3fb.

Cook, Peter. "Amazing Archigram: A Supplement." Perspecta 11 (1967): 131-54. https://doi.org/10.2307/1566943.

Crystal, Gary. "Civil Rights in the Uk." Civil Rights in the UK. Accessed May 22, 2021. http://www. civilrightsmovement.co.uk/civil-rights-uk.html\#:囚:text=Racial\%20discrimination\%20in\%20Britain\%20 during,first\%20to\%20lose $\% 20$ their\%20jobs.

Development., World Commission on environement and. Our Common Future. Delhi: Oxford, Univ. Press, 1987.

Disneydetail. "September 8." DisneyDetail, September 8, 2012. https://disneydetail.me/2012/09/08/ september-8/.

Dunham, Roger G., and Nick Petersen. "Making Black Lives Matter." Criminology \&amp; Public Policy 16, no. 1 (2017): 341-48. https://doi.org/10.1111/1745-9133.12284.

Elman, Julie Passanante. "Slothful Movements: Disability, Acceleration, and Capacity Feminism in Disney's 
Zootopia (2016)." Feminist Media Studies, 2020, 1-18. https://doi.org/10.1080/14680777.2020.1855223.

"EPCOT Center Concept Art and Models." RetroWDW, March 21, 2018. https://www.retrowdw.com/pictorialsouvenir/wdw-concept-art-models/epcot-center/.

Fairs, Marcus. "Liam Young's 'Planet City' Could Tackle Climate Change by Housing 10 Billion People in a Single Metropolis." Dezeen, January 6, 2021. https://www.dezeen.com/2021/01/06/liam-young-planet-cityclimate-change-10-billion-people-metropolis/.

Figueredo, Patricia Bronislawski, Maria Ester Wollstein Moritz, Maria Lúcia Milléo Martins, and Viviane Maria Heberle. "'The Adventure Is out There!': Encounters between North and South in Disney-Pixar's Up." Essay. In Echoes: Further Reflections on Language and Literature, edited by Magali Sperling Beck, 141-50. Florianópolis: Universidade Federal de Santa Catarina, 2016.

Doucet, Isabelle. "Learning in the 'Real' World: Encounters with Radical Architectures (1960s-1970s)." Journal of Educational Administration and History 49, no. 1 (2016): 7-21. https://doi.org/10.1080/00220620.2017.12 52735.

Dundes, Lauren. Preface. In The Psychosocial Implications of Disney Movies, ix. MDPI (Multidisciplinary Digital Publishing Institute), 2019.

Finding Nemo. Film. Canada: Pixar Animation Studios \&amp; Walt Disney Pictures, 2003.

Flory, Dan. "Audience, Implicit Racial Bias, and Cinematic Twists in Zootopia." The Journal of Aesthetics and Art Criticism 77, no. 4 (2019): 435-46. https://doi.org/10.1111/jaac.12672.

Foster, Norman. "'Architecture Is an Expression of Values."' The European, October 15, 2014, https:// www.theeuropean.de/en/norman-foster/9114-the-role-of-architecture-in-todays-society?utmmedium=website\&amp;utm-source=archdaily.com.

Fourier, Charles, and Gareth Stedman Jones. Introduction. In The Theory of the Four Movements, 15. Cambridge: Cambridge Univ. Press, 1996.

Freytas-Tamura, Kimiko de. "Hakuna Matata? Can Disney Actually Trademark That?" The New York Times. The New York Times, December 20, 2018. https://www.nytimes.com/2018/12/20/world/africa/hakunamatata-disney-trademark.html.

George. "TREASURES OF THE WALT DISNEY ARCHIVES OPENS AT THE MUSEUM OF SCIENCE AND INDUSTRY, CHICAGO." ImagiNERDing, October 23, 2013. http://www.imaginerding.com/2013/10/23/ treasures-of-the-walt-disney-archives-opens-at-the-museum-of-science-and-industry-chicago/.

Giddings, Seth. "The Circle of Life." Third Text 13, no, 49 (1999): 83-92. https://doi. org/10.1080/09528829908576825.

Gittens, Dwayne. "Dying While Dying: COVID-19 \&amp; Police Brutality in Black America." Liberty Project. Liberty Project, June 2, 2020, https://www.libertyproject.com/black-lives-matter-covid-2646147395. html.

Goldberger, Paul. Why Architecture Matters. New Haven, CT: Yale University Press, 2011.

Griswold, Eliza. "How 'Silent Spring' Ignited the Environmental Movement." The New York Times. September 23, 2012. https://www.nytimes.com/2012/09/23/magazine/how-silent-spring-ignited-the-environmentalmovement.html. 
"Howl's Moving Castle Movie Poster (11 x 17)." Amazon.ca. Accessed May 25, 2021. https://www.amazon.ca/ Howls-Moving-Castle-Movie-Poster/dp/B003T179XI.

Hoyle, Matt. "John Lasseter: the Man Behind Pixar's Brave." The Times. The Times, August 6, 2012. https://www. thetimes.co.uk/article/john-lasseter-the-man-behind-pixars-brave-gv8sbqdlj3c.

Karla Adam, Rick Noack. "Defund the Police? Other Countries Have Narrowed Their Role and Boosted Other Services." The Washington Post. WP Company, June 14, 2020. https://www.washingtonpost.com/ world/europe/police-protests-countries-reforms/2020/06/13/596eab16-abf2-11ea-a43b-be9f6494a87d story.html.

Kennicott, Philip. "Designing to Survive." The Washington Post, July 13, 2020. https://www.washingtonpost.com/ magazine/2020/07/13/pandemic-has-shown-us-what-future-architecture-could-be/?arc404=true.

Koglek, nuno. "\&gt; Introduction to Frank Lloyd Wright and Broadacre City." UTOPICUS, January 1, 1970. http:// utopicus2013.blogspot.com/2013/06/introduction-to-frank-lloyd-wright-and.html.

Kois, Dan. "Zootopia Is a Delightful Kids' Movie That Is Also Totally About Racial Profiling." Slate Magazine. Slate, March 2, 2016. https://slate.com/culture/2016/03/disney-s-zootopia-has-a-message-for-kids-aboutracial-profiling.html.

Koltko-Rivera, Mark E. "Rediscovering the Later Version of Maslow's Hierarchy of Needs: Self-Transcendence and Opportunities for Theory, Research, and Unification." Review of General Psychology 10, no. 4 (2006): 302-17. https://doi.org/10.1037/1089-2680.10.4.302.

Kraft, Michael E. "U.S. Environmental Policy and Politics: From the 1960s to the 1990s." Journal of Policy History 12, no. 1 (2000): 17-42. https://doi.org/10.1353/jph.2000.0006.

Kuhn, Betsy. "So Bold Sixties." Essay. In Gay Power!: the Stonewall Riots and the Gay Rights Movement, 1969, 48-63. Minneapolis, MN: Twenty-First Century Books, 2011.

"Liam Young - Tomorrow's Thoughts Today." WIA - What is architecture? Accessed May 23, 2021. https://olafgrawert.squarespace.com/liam-young-los-angeles-2018.

"Liam Young Planet City." NGV. National Gallery of Victoria. Accessed May 23, 2021. https://www.ngvvic.gov.au/ liam-young-planet-city/.

Lion King, The Film. Canada: Walt Disney Animation Studios, 1994.

MacDonald, Fiona. "Liam Young: The Man Designing Our Futures." BBC, December 18, 2019.

MacLeish, Archibald. "Riders on Earth Together, Brothers in Eternal Cold." The New York Times. December 25, 1968, sec. Cover. https://www.nytimes.com/1968/12/25/archives/a-reflection-riders-on-earthtogether-brothers-in-eternal-cold.html.

Maslow, Abraham. Self-Actualization and Beyond. Winchester, MA: New England Board of Higher Education, 1965.

Mayne, Thom. "The Pritzker Architecture Prize Acceptance Speech." May 31, 2005.

McFadden, Robert M. "Millions Join Battle for a Beloved Planet." The New York Times. April 23, 1990, sec. A.

McKenzie, Stephen. Social Sustainability: Towards Some Definitions. 27. Vol. 27. Hawke Research Institute Working Paper. Magill: University of South Australia, 2004. 
McLeod, Saul. "Maslow's Hierarchy of Needs." Simply Psychology, May 21, 2018.

McNaughtan, Hugh. "Distinctive Consumption and Popular Anti-Consumerism: The Case of Wall-E." Continuum 26, no. 5 (2012): 753-66. https://doi.org/10.1080/10304312.2012.664116.

Meinel, Dietmar. "Empire Is out There!?: The Spirit of Imperialism in the Pixar Animated Film 'Up.' NECSUS. European Journal of Media Studies 3, no. 1 (2014): 69-87. https://doi.org/10.5117/necsus2014.1.mein.

Miller, Michelle. "AD Classics: Cenotaph for Newton / Etienne-Louis Boullée." ArchDaily, September 10, 2014. https://www.archdaily.com/544946/ad-classics-cenotaph-for-newton-etienne-louis-boullee.

Moran, Joe. "Earthrise: the Story behind Our Planet's Most Famous Photo." The Guardian, December 22, 2018. https://www.theguardian.com/artanddesign/2018/dec/22/behold-blue-plant-photograph-earthrise.

Morelli, John. "Environmental Sustainability: A Definition for Environmental Professionals." Journal of Environmental Sustainability 1, no. 1 (2011): 1-10. https://doi.org/10.14448/jes.01.0002.

Morton, John. "Simba's Revolution: Revisiting History and Class in The Lion King." Social Identities 2, no. 2 (1996): 311-17. https://doi.org/10.1080/13504639652358.

Mputhia, Cathy. "Trademarking 'Hakuna Matata' a Wake up Call." Business Daily, November 25, 2018. https:// www.businessdailyafrica.com/lifestyle/pfinance/Trademarking-hakuna-matata-a-wake-upcall/4258410-4867976-wyiem7z/index.html.

Muschamp, Herbert. "Ideals Made of Paper and the Impact of the Unbuilt." The New York Times, March 11, 2001, sec. Art/Architecture.

Neuman, Robert. "'Now Mickey Mouse Enters Art's Temple': Walt Disney at the Intersection of Art and Entertainment." Visual Resources 14, no. 3 (1999): 249-61. https://doi.org/10.1080/01973762.1999.96584 55.

"Niagara River Corridor." IBA Site Listing. Accessed May 23, 2021. https://wwwibacanada.ca/site. jsp?sitelD=ON002.

Olóriz, Clara, and Koldo Lus Arana. "Amazing Archigram!" Mas Context, no. 20 (2013): 48-61. https://www. mascontext.com/issues/20-narrative-winter-13/amazing-archigram/.

Ououssof, Nicolai. "Towers' Symbolic Image." Los Angeles Times. September 13, 2001.

Price, David A. The Pixar Touch: The Making of a Company. New York: Vintage Books, 2009.

"Rem Koolhaas: MoMA." The Museum of Modern Art. Accessed May 25, 2021. https://www.moma.org/ artists/6956.

Robinson, Tom, Mark Callister, Dawn Magoffin, and Jennifer Moore. "The Portrayal of Older Characters in Disney Animated Films." Journal of Aging Studies 21, no. 3 (March 18, 2018): 203-13. https://doi.org/10.1016/j. jaging.2006.10.001.

Sadler, Simon. Archigram: Architecture without Architecture. Cambridge, MA: MIT Press, 2005.

Sandlin, Jennifer, and Nathan Snaza. "It's Called a Hustle, Sweetheart': Black Lives Matter, the Police State, and the Politics of Colonizing Anger InZootopia." The Journal of Popular Culture 51, no. 5 (2018): 1190-1213. https://doi.org/10.1111/jpcu.12714. 
Schickel, Richard. The Disney Version. New York: Simon and Schuster, 1968.

Shariatmadari, David. "How 1967 Changed Gay Life in Britain." The Guardian, July 23, 2017. https://www. theguardian.com/world/2017/jul/23/how-1967-changed-gay-life-in-britain-i-think-for-my-generationwere-still-a-little-bit-uneasy.

"Shrek." IMDb. IMDb.com, May 18, 2001. https://www.imdb.com/title/tt00126029/.

Small, Melvin. Antiwarriors: the Vietnam War and the Battle for America's Hearts and Minds. Wilmington, DE: Scholarly Resources, 2004.

Smith, Conrad. "The Early History of Animation: Saturday Morning TV Discovers 1915." Journal of the University Film Association 29, no. 3 (1977): 23-30. https://www.jstor.org/stable/20687377.

Smith, Harold L., and Elizabeth Meehan. "British Feminism from the 1960s to the 1980s." Essay. In British Feminism in the Twentieth Century, 189-204. Meherst: University Of Massachusetts Press, 1990.

"Spider-Man: Into the Spider-Verse." IMDb. IMDb.com, December 14, 2018. https://www.imdb.com/title/ tt4633694/.

Sprigge, T. L. "Has Speculative Metaphysics a Future?" The Monist 81, no. 4 (October 1998): 513-33. https://doi. org/10.5840/monist199881428.

"The Amazing Archigram 4!" Archigram: Cushicle and Suitaloon. Accessed May 25, 2021. http:// architecturewithoutarchitecture.blogspot.com/2012/12/the-amazing-archigram-4-zoom-issue-1964. html.

"The Lion King." IMDb. IMDb.com, June 23, 1994. https://www.imdb.com/title/tt0110357/.

"The Plausible Impossible." Episode. Walt Disney's Disneyland 3, no. 8. Burbank, California: ABC, October 31, 1956.

Thomas, Bob. Walt Disney: an American Original. Glendale, CA: Disney Editions, 2012.

Toy Story. Film. Canada: Pixar Animation Studios \& Walt Disney Pictures, 1995.

"Ub Iwerks." Disney Wiki. Accessed May 25, 2021. https://disney.fandom.com/wiki/Ub_Iwerks.

"Up." IMDb. IMDb.com, May 29, 2009. https://www.imdb.com/title/tt1049413/?ref_=fn_al_tt_1.

VanDerWerff, Emily. "Zootopia Wants to Teach Kids about Prejudice. Is It Accidentally Sending the Wrong Message?" Vox, May 7, 2016. https://www.vox.com/2016/3/7/11173620/zootopia-review-racism.

Wall-e. Film. Canada: Pixar Animation Studios \& Walt Disney Pictures, 2008.

"WALL-E." IMDb. IMDb.com, June 26, 2008. https://www.imdb.com/title/tt0910970/?ref_=fn_al_tt_1.

Ward, Annalee. Mouse Morality: the Rhetoric of Disney Animated Film. Austin, TX: University of Texas Press, 2003.

Wasko, Janet. Understanding Disney: The Manufacture of Fantasy. Cambridge: Polity Press, 2020.

Watt, Paul, and Anna Minton. "London's Housing Crisis and Its Activisms." City: analysis of urban trends, culture, theory, policy, action 20, no. 2 (2016): 204-21. https://doi.org/10.1080/13604813.2016.1151707. 
Welchman, Jennifer. "A Defence of Environmental Stewardship." Environmental Values 21, no. 3 (2012): $297-316$. https://doi.org/10.3197/096327112x13400390125975.

Wells, Paul. Understanding Animation. London: Routledge, 2016.

Winters, Edward. "A Dance to the Music of Architecture." The Journal of Aesthetics and Art Criticism 69, no. 1 (2011): 61-67. https://doi.org/10.1111/j.1540-6245.2010.01447.x.

"Wolfwalkers." IMDb. IMDb.com, October 30, 2020. https://www.imdb.com/title/tt5198068/.

Wright, Frank Lloyd. "Broadacre City: A New Community Plan." Architectural Record 77, no. 4 (April 1935): 345-49.

Venter, Henry J. "Maslow's Self-Transcendence: How It Can Enrich Organization Culture and Leadership." International Journal of Business, Humanities and Technology 2, no. 7 (December 2012): 64-71.

"Visionary Architecture." New York, NY: MOMA, 1960. The Museum of Modern Art.

Zootopia. Film. Canada: Walt Disney Animation Studios, 2016.

"Zootopia." IMDb. IMDb.com, February 11, 2016. https://www.imdb.com/title/tt2948356/?ref_=fn_al_tt_1. 


\section{ILLUSTRATIONS SOURCES}

Fig. 01 Original composition Adapted from "Architect at his drawing board." wood engraving (Teknisk Ukeblad. May 25, 1893)

Fig. 02 Personal photo from author's colleciton

Fig. 03 Original composition

Fig. 04 Zontar. "Winsor McCay Political Cartoons 1." Zontar of Venus, January 1, 1970. http://zontarmag.blogspot.com/2012/01/winsor-mccay-political-cartoons-1.html.

Fig. 05 Vitagraph Company Of America, and Afi/Blackton. Humorous Phases of Funny Faces. produceds by Blackton, James Stuart, Uction United States: Vitagraph, 1906. Video. https://www.loc.gov/item/00694006/.

Fig. 06 George. "TREASURES OF THE WALT DISNEY ARCHIVES OPENS AT THE MUSEUM OF SCIENCE AND INDUSTRY, CHICAGO." ImagiNERDing, October 23, 2013. http://www.imaginerding.com/2013/10/23/treasures-of-the-waltdisney-archives-opens-at-the-museum-of-science-and-industry-chicago/.

Fig. 07 "Ub Iwerks." Disney Wiki. Accessed May 25, 2021. https://disney.fandom.com/ wiki/Ub.lwerks.

Fig. 08 "Walt's First Fairy Tales." D23, March 27, 2018. https://d23.com/walt-files-firstfairy-tales/.

Fig. 09 "Alice Comedies." D23. Accessed April 1, 2021. https://d23.com/a-to-z/alicecomedies/.

Fig. 10 "Oswald Historian Lauds Debut of Lost Short Hungry Hoboes." D23, March 26, 2018. https://d23.com/oswald-historian-lauds-debut-of-lost-short-hungryhoboes/.

Fig. 11 "Steamboat Willie (Film)." D23. Accessed April 1, 2021. https://d23.com/a-to-z/ steamboat-willie-film/.

Fig. 12 Hellerman, Jason. "How Disney's Iconic Multiplane Camera Changed Animation." No Film School. No Film School, February 28, 2020. https://nofilmschool.com/ disney-multiplane-camera.

Fig. 13 "Snow White and the Seven Dwarfs." IMDb. IMDb.com, February 4, 1938. https://www.imdb.com/title/tt0029583/?ref.=tt.mv.close.

Fig. 14 Taylor, Alan. "Opening Day at Disneyland: Photos From 1955." The Atlantic. Atlantic Media Company, July 24, 2019. https://www.theatlantic.com/ photo/2019/07/opening-day-disneyland-photos-1955/594655/. 
Fig. 15 Catmull, Ed, and Amy Wallace. Creativity, Inc.: Overcoming the Unseen Forces That Stand in the Way of True Inspiration. Toronto: Vintage Canada, 2014.

Fig. 16 DisneyDetail. "September 8." DisneyDetail, September 8, 2012. https:// disneydetail.me/2012/09/08/september-8/.

Fig. 17 Person. "John Lasseter: the Man Behind Pixar's Brave." The Times. The Times, August 6, 2012. https://www.thetimes.co.uk/article/john-lasseter-the-manbehind-pixars-brave-gv8sbqdlj3c.

Fig. 18 Carlson, Wayne E. Computer Graphics and Computer Animation: a Retrospective Overview. The Ohio State University, 2017.

Fig. 19-20 Pixar Animation Studios. Accessed march 31, 2021. https://www.pixar.com/ andre-wally-b

Fig. 21 "Pixar Animation Studios." Logopedia. Accessed April 1, 2021. https://logos. fandom.com/wiki/Pixar.Animation.Studios/Other?file=Vlcsnap-2013-11-0307h01m46s97.png.

Fig. 22-23 Pixar Animation Studios. Accessed March 31, 2021. https://www.pixar.com/luxojr

Fig. 24 Wall-e. Film. Canada: Pixar Animation Studios \& Walt Disney Pictures, 2008.

Fig. 25 Pixar Animation Studios. Accessed march 31, 2021. https://www.pixar.com/tintoy

Fig. 26 The Little Mermaid. Burbank, CA.: Walt Disney Pictures, 1989.

Fig. 27 'Jamieson, Doug. "THE HOUSE OF MOUSE PROJECT - 'The Rescuers Down Under.' The Jam Report, June 1, 2020. https://thejamreport.com/2020/05/05/ the-house-of-mouse-project-the-rescuers-down-under/.

Fig. 28 "Toy Story." Pixar Wiki. Accessed April 1, 2021. https://pixar.fandom.com/wiki/ Toy.Story?file=817D1E58-FA61-4701-A1E8-0D2E6354D47A.jpeg.

Fig. 29-30 "The Plausible Impossible." Episode. Walt Disney's Disneyland 3, no. 8. Burbank, California: ABC, October 31, 1956.

Fig. 31-33 "Rem Koolhaas: MoMA." The Museum of Modern Art. Accessed May 25, 2021. https://www.moma.org/artists/6956.

Fig. 34-35 Miller, Michelle. "AD Classics: Cenotaph for Newton / Etienne-Louis Boullée." ArchDaily. ArchDaily, November 5, 2018. https://www.archdaily.com/544946/adclassics-cenotaph-for-newton-etienne-louis-boullee.

Fig. $36 \quad$ Wright, Frank Lloyd. "Broadacre City: A new community plan." Architectural Record 77, no. 4 (1935): 243-254. 
Fig. 37 "EPCOT Center Concept Art and Models." RetroWDW, March 21, 2018. https:// www.retrowdw.com/pictorial-souvenir/wdw-concept-art-models/epcot-center/.

Fig. 38 Smith, Yvette. "Apollo 8: Earthrise." NASA. NASA, April 13, 2015. https://www. nasa.gov/image-feature/apollo-8-earthrise.

Fig. 39 Smith, Yvette. "Apollo 17: Blue Marble." NASA. NASA, April 13, 2015. https://www. nasa.gov/image-feature/apollo-17-blue-marble.

Fig. 40 Christian, Jessi. "The New Hierarchy of Needs - Maslow's Lost Apex." Medium. Coachilla HQ, May 13, 2020. https://medium.com/coachilla-hq/the-newhierarchy-of-needs-maslows-lost-apex-5e51031ce3fb.

Fig. 41-43 "The Amazing Archigram 4!" Archigram: Cushicle and Suitaloon. Accessed May 25, 2021. http://architecturewithoutarchitecture.blogspot.com/2012/12/theamazing-archigram-4-zoom-issue-1964.html.

Fig. 44 Cook, Peter. "Plug-in City: Maximum Pressure Area, project (Section)" 1964

Fig. 45-47 Fairs, Marcus. "Liam Young's 'Planet City' Could Tackle Climate Change by Housing 10 Billion People in a Single Metropolis." Dezeen, January 6, 2021. https://www.dezeen.com/2021/01/06/liam-young-planet-city-climate-change10-billion-people-metropolis/.

Fig. 48-49 Original compositions

Fig. 50 "The Lion King." IMDb. IMDb.com, June 23, 1994. https://www.imdb.com/title/ tt0110357/.

Fig. 51-54 Original compositionss

Fig. 55 "WALL-E." IMDb. IMDb.com, June 26, 2008. https://www.imdb.com/title/ tt0910970/?ref-=fn_al_tt_1.

Fig. 56-60 Original compositions

Fig. 61 "Up." IMDb. IMDb.com, May 29, 2009. https://www.imdb.com/title/ tt1049413/?ref_=fn_al_tt_1.

Fig. 62 Original compositions

Fig. 63 "Zootopia." IMDb. IMDb.com, February 11, 2016. https://www.imdb.com/title/ tt2948356/?ref_=fn_al_tt_1.

Fig. 64-67 Original compositions

Fig. 68 "Shrek." IMDb. IMDb.com, May 18, 2001. https://www.imdb.com/title/ tt00126029/. 
Fig. 69 "Spider-Man: Into the Spider-Verse." IMDb. IMDb.com, December 14, 2018. https://www.imdb.com/title/tt4633694/.

Fig. 70 "Howl's Moving Castle Movie Poster (11 x 17)." Amazon.ca. Accessed May 25, 2021. https://www.amazon.ca/Howls-Moving-Castle-Movie-Poster/dp/ B003T179XI.

Fig. 71 "Wolfwalkers." IMDb. IMDb.com, October 30, 2020. https://www.imdb.com/title/ tt5198068/.

Fig. 72 Original composition adapted from Fernandez, Toni. "Donald Duck Inspired by Norman Rockwell's-Self Portrait" 


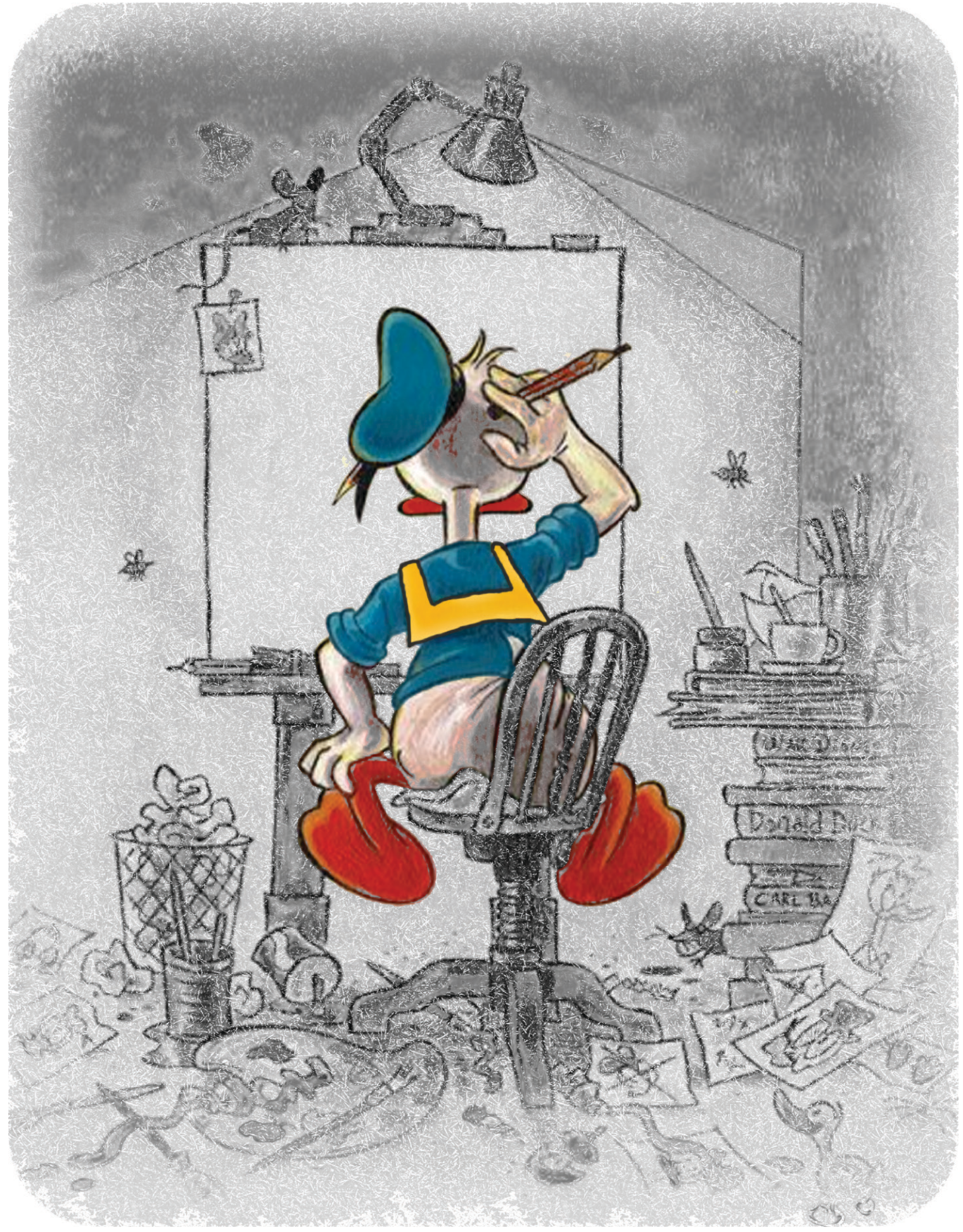

Fig. 72

Donald at the Drawing Board 